MttR 381

MARLENE TRIGO

\title{
DIMENSIONAMENTO DO PESSOAL DOS SERVIÇOS DE NUTRIÇÁO E DIETÉTICA DE HOSPITAIS GERAIS NO MUNICÍPIO DE SẢO PAULO
}

\author{
Dissertação apresentada à \\ Faculdade de Saúde Pública \\ da Universidade de São Paulo, \\ Departamento de Nutrição, \\ para obtenção do título de \\ Mestre em Saúde Pública. \\ Orientador: \\ Prof. Dr. Maria José Roncada
}

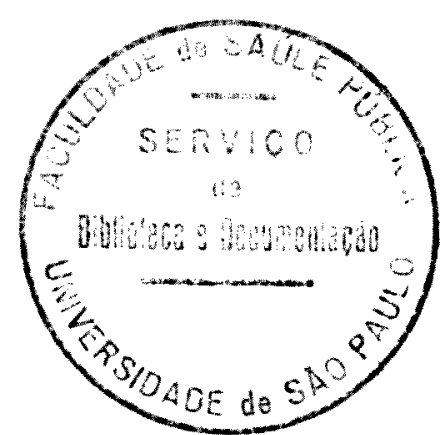

São Paulo

1985 


\section{DEDICATŌRIA}

A minha mãe 


\section{AGRADECIMENTOS}

Agradecemos a inestimāvel colaboração prestada por todos, que direta ou indiretamente contribuíram para a realização deste trabalho.

Especialmente expressamos nossos agradecimentos aos professores:

Prof. Dr. Maria José Roncada

Prof. Dr. Sophia Cornbluth Szarfarc

Prof. Dr. Donald Wilson 
RESUMO

Visando preencher lacuna sobre informações referen tes ao pessoal necessário aos Serviços de Nutrição e Dietética (SND) de hospitais nacionais, propusemo-nos a realizar este trabalho, onde estudamos o dimensionamento de pessoal em SND de 49 hospitais gerais de grande porte e de capacidace extra (hospi tais com mais de 150 leitos), localizados no Município de são Pau lo. Para isso, valemo-nos de indicadores especificos que utilizam a produtividade do serviço como um dos elementos fundamentais para determinar o número de funcionários necessários ao SND. Os resultados do Indicador de Pessoal Total (I.P.T.) foram estudados por meio de um índice de adequação, cujos valores foram classificados em quatro níveis: "deficiente" ( $\leqslant 508)$;"bajxo"(51 a 898); "ade quado"(90 a 1108) e"excessivo"( >1108). Estabelecemos comparações entre os SND dos hospitais estudados, segundo o nível de adequação, o número de leitos e a finalidade da entidade mantenedora, ve rificando também a influência de alguns fatores intervenientes. Dentre as conclusões finais, destacamos que cêrca da quinta parte (10) dos hospitais estudados apresentaram número de funcionários do SND no nível "adequado"; 5 hospitais $(10,28)$ no nível "deficiente"; 26 hospitais $(53,18)$ no nivel"baixo" e 8 hospitais $(16,38)$ no nivel"excessivo". 


\section{SUMMARY}

In order to fill a gap regarding information on personnel necessary for Nutrition and Dietetics Services of Brazilian hospitals, the present study was carried out. In this study dimensioning of personnel involved on Nutrition and Dietetics Services of forty nine general hospitals of large and extra-large capacity (over 150 beds), located in the city of são Paulo, Brazil, was carried out. Specific indicators, that include service productivity as one of the fundamental elements to determine the number of necessary employees were used. The results of the Total Personnel Indicator were studied using an adequacy index. The values of the adequacy index were classified as follows: deficient $(\leq 508)$; low (51\% to 898$)$; adequate $(90 \%$ to $110 \%)$ and excessive (> 110\%). The Nutrition and Dietetics Services of the studied hospitals were compared considering adequacy level, number of beds and the finality of the maintaining institution, taking into account the influence of some intervening factors. We were able to conclude that one fifth of the hospitals studied employed an adequate number of employees; five hospitals were on the deficient; twenty six hospitals were on level low and eight hospitals on excessive levels. 
RESUMO

SUMMARY

1. INTRODUCAOO $\ldots \ldots \ldots \ldots \ldots \ldots \ldots \ldots \ldots \ldots \ldots \ldots \ldots \ldots \ldots \ldots \ldots \ldots$

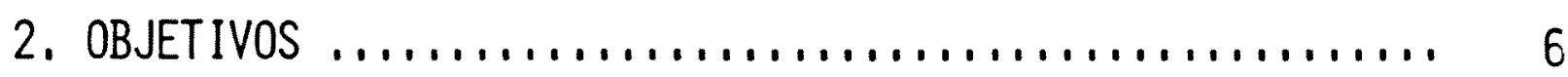

3. MATERIAL E MËTODOS $\ldots \ldots \ldots \ldots \ldots \ldots \ldots \ldots \ldots \ldots \ldots \ldots$

3.1. Universo de Estudo $\ldots \ldots \ldots \ldots \ldots \ldots \ldots \ldots \ldots \ldots \ldots \ldots$

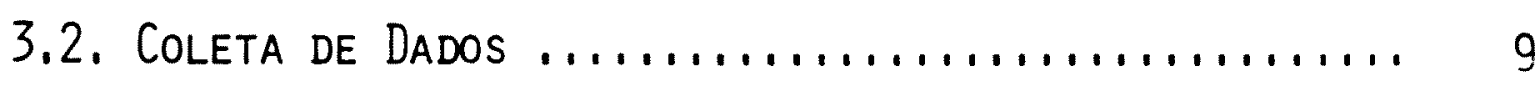

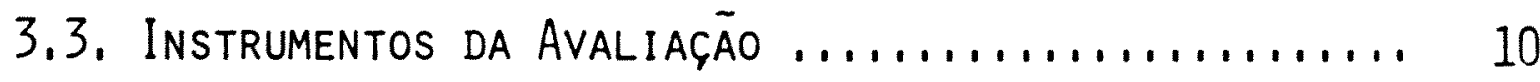

3.4. İndice de Adequação do Pessoal Do SND............ 11

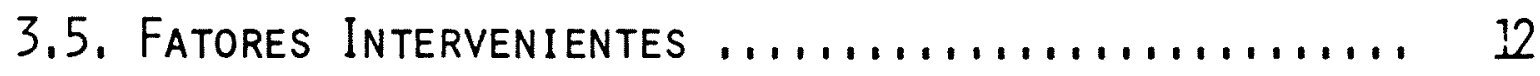

4. ALGUMAS CARACTERISTIICAS DOS HOSPITAIS ESTUDADOS ....... 19

4.1. Número de leitos e Finalidade da Entiddade

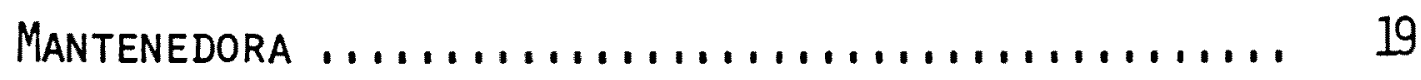

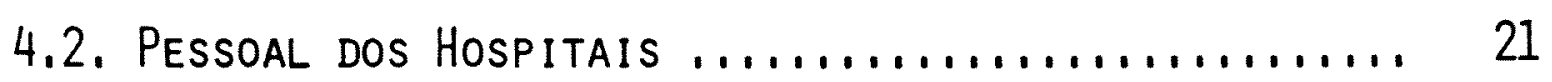

4.3. Pessoal dos Servicos de Nutrição e Dietética ...... 23

5. RESULTADOS E COMENTÁRIOS $\ldots \ldots \ldots \ldots \ldots \ldots \ldots \ldots \ldots \ldots \ldots \ldots \ldots \ldots \ldots \ldots \ldots$

5.1. Instrumentos de Avalią̧Āo $\ldots \ldots \ldots \ldots \ldots \ldots \ldots \ldots \ldots \ldots \ldots$

5.1.1. INDICADOR DE PESSOAL FIXO $\ldots \ldots \ldots \ldots \ldots \ldots \ldots, 28$

5.1 2. Indicador DE PERÍOdOS DE dESCANSO ........ 36

5.1.3. INDICADOR DE PESSOAL SUBSTITUTO ......... 38

5.1.4. INDICADOR DE ABSENTEISMO DIARIO ......... 40

5.1.5. INDICADOR DO PESSOAL TOTAL ............ 42

5.2. Indice de Adequação do Pessoal do SND ........... 44

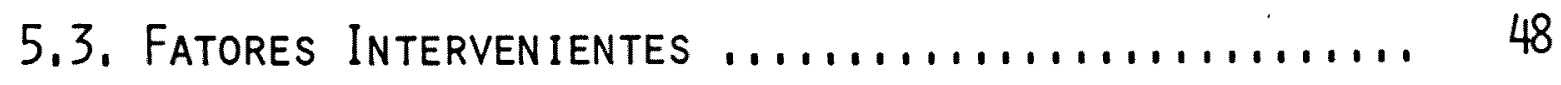

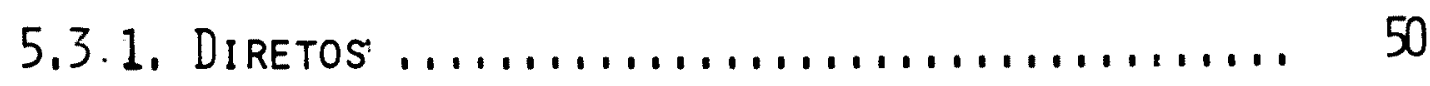

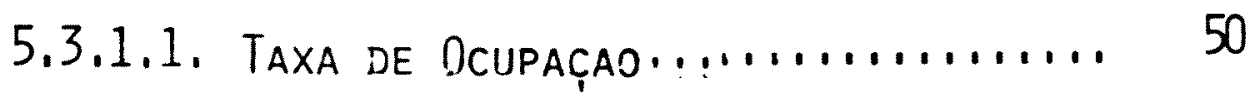

5.3 .1 .2 . Categoria do Paciente Internado.... 53 
5.3.1.3. TIPOS DE CARDÁPIO $\ldots \ldots \ldots \ldots \ldots \ldots, 55$ 5.3.1.4. Sistema de Distribuiçäo das REFEI̧̧ŌES E higienizaçĀo dos UTENSÍlios... 58

5.3.2. Indiretos $\ldots \ldots \ldots \ldots \ldots \ldots \ldots \ldots \ldots \ldots \ldots \ldots, 60$

$5,3.2 .1$. Planta física $\ldots \ldots \ldots \ldots \ldots \ldots, \ldots 0$

5.3.2.2. Equi pamentos $\ldots \ldots \ldots \ldots \ldots \ldots \ldots \ldots, 66$

$5.3 .2,3$, QUALIDADE DO PESSOAL $\ldots \ldots \ldots \ldots \ldots, 72$

6. CONCLUSÕES $\ldots \ldots \ldots \ldots \ldots \ldots \ldots \ldots \ldots \ldots \ldots \ldots \ldots \ldots \ldots \ldots \ldots \ldots \ldots$

7. REFERẼNCIAS BIBLIOGRÄFICAS $\ldots \ldots \ldots \ldots \ldots \ldots \ldots \ldots \ldots, 83$

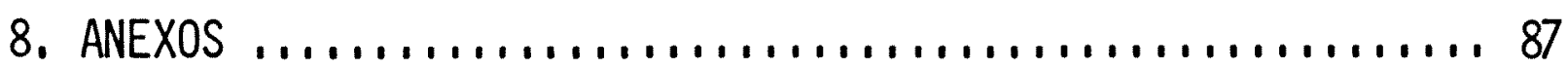




\section{INTRODUÇÃO}

Os hospitais são instituições complexas dos servi ços de saúde. O investimento de capital inicial é elevado e os custos ano a ano vão alcançando proporções cada vez maio res. ${ }^{26}$ Grande parte desses gastos são destinados ao pessoal , quer na forma de salários,quer na de obrigações trabalhistas. Procurando proporcionar aos pacientes atendimento de boa qualidade, os hospitais preocupam-se em dispor seus recursos hu manos com maior eficiência e economia. ${ }^{41}$ No entanto, com o crescente aumento desses custos e decrescente disponibilidade de funcionários qualificados e eficientes, os administrado res têm enfrentado a necessidade de diminuir os custos com a produção, a fim de equilibrar seus orçamentos. 41 Dentro desse contexto, o Serviço de Nutrição e Dietética (SND) assume grande importância, jā que é responsāvel por parcela con siderável dos gastos do orçamento hospitalar. $5,8,9,27$

E desnecessário enfatizar a importância de um Servi ço de Nutrição e Dietētica numa instituição, pois è inegāvel a contribuição à saūde de uma dieta equilibrada, com apresentação adequada e boa qualidade e organoléptica. Quando esse Serviço está implantado numa instituição hospitalar avulta sua importância de vez que a dieta é um dos fatores primor dials na recuperação da saúde dos pacientes.

Vários autores têm se preocupado em definir os objẹ tivos dos Serviços de Nutrição e Dietética. Assim, para West, o objetivo do SND é elaborar e servir os melhores alimentos possiveis dentro de seus recursos financeiros. 50

Segundo os "participantes dos Grupos de Trabalho das diversas áreas, reunidos para pađronizar os processos de ava liação de SNDs ${ }^{17}$, é: elaborar e fornecer dieta que seja a 
um só tempo balanceada (aqui definida como aquela que é suficiente, completa, harmônica e adequada às características e hábitos alimentares dos usuários), segura do ponto de vista de higiene e que se ajuste aos limites financeiros da instituição.

Já Cavalcanti define como: "contribuir para a melhoria das condições de saüde dos grupos populacionais a que se destinam, através de uma alimentação correta". 10

Como vemos, todos esses objetivos guardam semelhan ça de propósitos: oferecer a melhor qualidade da dieta, ao me nor custo possível. O responsāvel por esses serviços deve verificar periodicamente se esses objetivos estão sendo alcança dos e em que grau o estão. 10, 17, 50 Isso é conseguido através de uma atividade usualmente desenvolvida na administração cientifica: a avaliação.

A avaliação, como um meio para determinar se os oḅ jetivos foram alcançados, deve ser uma atividade contínua e parte integrante das funções da administração.

No passado era difícil mensurar a produtividade em uma organização que produzia um serviço e não um produto, mas, com a aplicação de técnicas de engenharia industrial no campo hospitalar, tornou-se possivel a avaliação do tempo do trá balho. Em sistemas alimentares, a taxa de produtividade definida como sendo o tempo gasto por refeição servida 24,44 , tornou-se, assim, passîvel de quantificação.

Para mensurar a medida do trabalho foram adotados vários métodos: amostra do trabalho ("work sampling"), simpli ficação do trabalho ("work simplification") e tempo gasto por refeição servida. Os dois primeiros métodos utilizam a técnica do tempo e movimento muito empregada na área de engenharia 
industrial, alēm da anālise do trabalho ("job analysis"). Esses trabalhos, realizados nos Estados Unidos, visavam uma me lhor utilização da mão de obra, com uma redistribuição dos recursos materiais e humanos. $19,37,39,40,51,52,53$ Já os trabalhos sobre a produtividade em SND (tempo gasto por refeição servida) utilizavam o número total de refeições e o nūmero de homens/hora, visando uma padronização na determinação do pes soal necessário a um SND. 4,13,18,46 Foi nessa época (década de 60) que se determinou um tempo padrão de 15 minutos por refeição servida ${ }^{13}$, que perdura até hoje.

Os resultados dessas pesquisas demonstraram que programas de medidas do trabalho causam sempre um impacto posi tivo dentro da organização. 12,14,21 outros trabalhos, com me todologia semelhante, serviram para a determinação do número de funcionários para os Serviços de Nutrição e Dietética. ${ }^{6,38,43}$ Alguns autores mencionaram mesmo, uma redução do custo da produtividade com a diminuição do nümero de funcionários. 12,21 Com o advento do computador e com técnicas operacio nais de pesquisas,os Serviços de Nutrição e Dietética aperfeiçoaram os métodos empregados pela engenharia industrial, crian do medidas padrão de tempo do trabalho e volume de produção. Adotando novos métodos (Master Standart Data Quality Food Pro duction Code) e propondo parâmetros, a produtividade desses serviços pode ser comparada àquela da indústria de manufaturados. $7,20,48,49,54$ o objetivo é sempre o mesmo: o aumento da produtividade com uma melhor distribuição dos recursos para uma efetiva diminuição do custo do trabalho.

Essas medidas de trabalho, juntamente com outras medidas de pessoal e desempenho da organização, constituem um sistema de administração para avaliar e controlar o uso dos 
recursos.

Quanto mais complexo for um Serviço de Nutrição e Dietētica, mais difícil é a obtenção de meios de avaliação sa tisfatórios, necessitando de um eficiente sistema para obter, resumir e analisar as informações necessárias para esse fim. ${ }^{36}$

Nos Serviços de Nutrição e Dietética são inúmeros os instrumentos de registro que podem ser usados para a avaliação; ${ }^{1}$ no entanto, raramente são utilizados para tal,e, quando isso é feito, o é de maneira intermitente e não unifor me. Geralmente, nota-se falta de interesse em avaliar o serví ço, talvez devido aos próprios objetivos, pouco quantificáveis, e, portanto, dificeis de operacionalizar.

Diante de tal problemātica, vārios Grupos Técnicos, coordenados pelo Departamento de Nutrição da Faculdade de Saū de Pública da Universidade de são Paulo, reunidos em 1976 em Mesa Redonda ${ }^{16}$ propuseram modelos de avaliação em Serviços de Nutrição e Alimentação.

Um dos principais objetivos seria chamar a atenção dos profissionais responsáveis por esses serviços, para a importância da avaliação como um meio de verificar se os objetí vos estavam sendo atingidos. Estavam sendo dados, entre nós, os primeiros passos em direção à formulação de normas e padrões em Serviços de Nutrição, reunindo nutricionistas de diversas áreas, procurando, através de metodologia científica, uma melhor racionalização da mão-de-obra e, como consequência, maior eficiência do Serviço. Estes modelos utilizavam uma série de instrumentos de registro, como fichas, mapas de contro le e estatísticas de serviço para operacionalização de indica dores que permitiam avaliar os Serviços de forma racional e objetiva. 
Retomando o trabalho anterior, os Grupos Técnicos reuniram-se novamente em 1982, sob coordenação do mesmo Depar tamento, procurando avaliar os modelos propostos em 1976. Baseados na aplicação daqueles indicadores por algumas institui ções, alguns foram reformulados, assim como outros foram cria dos, atendendo à demanda do momento. Esses indicadores referem-se, na ārea hospitalar, a diversos setores, tais como:pes soal; previsão de gêneros; recebimento, estocagem e saída de material; produção; distribuição e custos.

Nas pesquisas bibliográficas empreendidas sobre tra balhos dessa natureza em nosso meio, encontramos apenas suges tões para $\circ$ uso de alguns indicadores. 1,2 Por esse motivo, visando preencher uma lacuna sobre informações referentes ao pessoal necessário ao SND, propusemo-nos a realizar es te trabalho, onde estudaremos os SND, no que se refere ao dimensionamento de pessoal, utilizando indicadores especificos propostos pelo Grupo Hospitalar daquela Reunião.17 Estamos colaborando para a aplicação dessa metodologia de avaliação que utiliza mētodos científicos, valendo-se da produtividade como um dos elementos fundamentais para dimensionar o pessoal. 


\section{OBJETIVOS}

2.1. Avaliar o dimensionamento de pessoal em SND de hospitais gerais de grande porte e capacidade extra no Municí pio de São Paulo, utilizando indicadores específicos.

2.2. Comparar os SND das instituições hospitalares estudadas quanto ao indice de adequação do Indicador de Pessoal Total (I.P.T.), segundo a finalidade das entidades man tenedoras e o número de leitos.

2.3. Verificar a influência de fatores intervenien tes no Indice de adequação do I.P.T., segundo a finalidade das entidades mantenedoras e o nümero de leitos. 


\subsection{UNIVERSO DE ESTUDO}

No Município de São Paulo estavam registrados na Coordenadoria de Assistência Hospitalar da Secretaria de Saūde do Estado de São Paulo*, 178 hospitais em funcionamento, em 18 de dezembro de 1981. Destes, 119 eram hospitais gerais e 59 hospitais especializados. Entende-se por:

a) Hospital Geral, aquele destinado a atender pacientes de doenças de várias especialidades médicas (Ministērio da Saūde). 31

Segundo a mesma fonte, 31 podemos acrescentar:

b) Hospital Estatal ou Paraestatal:é o que integra o patrimônio da União,Estado, Distrito Federal e Municípios (pes soas jurídicas de direito püblico interno), autarquias, fundaçōes,instituídas pelo Poder püblico,empresas públicas e socie dades de economia mista (pessoas jurídicas de direito privado).

c) Hospital Privado ou Particular: é o hospital que integra o patrimônio de uma pessoa natural ou jurídica de direito privado, não instituído pelo Poder Público.

d) Hospital Beneficente: é o que integra o patrimônio de pessoa jurídica de direito privado, instituído e manti do por contribuições e doações particulares, destinado a pres tação de serviços a seus associados e respectivos dependentes, cujos atos de constituição especifiquem sua clientela, que não remunere os membros da diretoria, que aplique integralmente seus recursos na manutenção e desenvolvimento dos seus objetí

* Secretaria de Saúde de Estado. CAH, Departamento de Técnica Hospitalar, Divisão de Fiscalização, Serviço de Registro e Cadastro. 
vos sociais e cujos bens, no caso de sua extinção, revertam em proveito de outras instituições do mesmo gènero ou ao Po der Público.

e) Hospital Filantrópico: é o que integra patrimônio de pessoa jurídica de direito privado, mantido parcial ou integralmente por meio de doações, cujos membros de seus ór gãos de direção e consultivos não sejam remunerados, que se proponha à prestação de serviços gratuitos à população carente e seus ambulatórios, reservando leitos, de acordo com a legislação em vigor, ao internamento gratuito e organizado e mantido pela comunidade e cujos resultados financeiros revertam exclusivamente ao custeio de despesa de administração e manutenção.

Procurando adequar nosso trabalho à terminologia utilizada no cadastro daquela Coordenadoria de Assistência Hospitalar, classificamos os hospitais segundo a finalidade de entidade mantenedora em: governamentais (hospital estatal ou paraestatal); com finalidade lucrativa (hospital privado ou particular); sem finalidade lucrativa (hospital privado ou particular, filantrópico e beneficente). Para facilidade de exposição designaremos, os hospitais com finalidade lucrá tiva - lucrativos (L), e aqueles sem finalidade lucrativa não lucrativos (NL); assim como, para os governamentais usare mos a sigra - G.

Quanto ao número de leitos, os hospitais classificam-se em: ${ }^{31}$

a) Hospital de pequeno porte - com capacidade até 50 leitos.

b) Hospital de médio porte - de 51 a 150 leitos.

c) Hospital de grande porte - de 151 a 500 leitos.

d) Hospital de capacidade extra - acima de 500 le $\underline{i}$ tos. 
Dos 119 hospitais gerais cadastrados na Coordenado ria, 13 eram de pequeno porte, 48 de médio porte, 50 de grande porte e 8 de capacidade extra.

Optamos por estudar a totalidade dos hospitais de grande porte e capacidade extra.

Os hospitais de grande porte foram subdivididos em três grupos: Grupo I, aqueles de 151 - 249 leitos; Grupo II, de 250 - 349 leitos; e Grupo III, de 350 - 500 leitos. Chama remos os hospitais de capacidade extra, de Grupo IV.

Dos 58 hospitais que atenderam às caracteristicas fixadas, foram estudados $49(84,48)$; 3 hospitais recusaram-se a fornecer informaçōes, 1 estava em fase de implantação, 3 em reforma e 2 eram hospitais militares, que não puderam ser visitados.

Para evitar tendenciosidade dos resultados, procuramos não coletar dados referentes a meses destinados a férias escolares ou feriados prolongados (quando geralmente há redução de pessoal que nem sempre é substituído). Assim, estâ belecemos que os dados a serem colhidos seriam referentes ao mês de março de 1983, ano em que realizamos a parte prática deste trabalho.

\subsection{Coleta de Dados}

Para coleta dos dados utilizamos um formulário (Anexo 1) dividido em três partes: identificação do hospital, identificação do Serviço de Nutrição e Dietética e Instrumentos de Avaliação (os indicadores de dimensionamento).

o formulário foi preenchido pela autora, após ter sido pré-testado. 
A coleta de dados foi realizada tanto no SND (utili zando os registros diários) como na Administração do hospital (utilizando dados referentes ao pessoal e estatisticas do movimento de pacientes). Foram entrevistados os chefes dos servi ços.

\subsection{Instrumentos da Avaliação}

\subsubsection{INDICADORES DE DIMENSIONAMENTO}

- Indicador de Pessoal Fixo (I.P.F.) ${ }^{17}$

I.P.F. $=\frac{\text { Número de refeicões servidas } \times 15 \text { minutos }}{\text { Jomada de Trabalho } \times 60 \text { minutos }}$

onde:

- número de refeições servidas = somatória dos desjejuns, almoços, merendas, jantares e refeições noturnas (média diária total, do mês em questão).

- 15 minutos = tempo médio gasto por refeição servida (produção, distribuição de uma refeição e higienização).

- jornada de trabalho = número de horas diārias normais de trabalho. Este indicador visa avaliar o número de funcionários necessārios para o preparo, distribuição e higienização de um dia de trabalho, sem considerar o pessoal substituto de férias e folgas. Estão excluídos - pessoal do Lactário e da confecção de lanches extras.

- Indicador de Períodos de Descanso (I.P.D.)

I.P.D. $=\frac{\text { dias do ano }- \text { períodos de descanso }}{\text { período de descanso }}$

ande:

- período de desçanso = somatória dos dias de férias e folgas do funcionārio (número que varia em função do regime de trabalho: $48,44^{\circ}$ ou $40 \mathrm{~h}$ de trabalho semanal). 
Este indicador visa avaliar o número máximo de periodos de descanso dos funcionários em férias e folgas que um substituto pode cobrir.

- Indicador de Pessoal Substituto (I.P.S.)

$$
\text { I.P.S. }=\frac{\text { I.P.F. }}{\text { I.P.D. }}
$$

Este indicador permite obter o pessoal substituto ne cessário para cobrir férias e folgas do pessoal fixo.

- Indicador de Absenteismo Diärio (I.A.D.)

$$
\text { I.A.D. }=\frac{\text { média diäria de funcionários ausentes } \times 100}{\text { número de pessoal fixo (I.P.F.) }}
$$

Este indicador visa avaliar a porcentagem de ausência diária do pessoal fixo por licenças e faltas.

- Indicador de Pessoal Total (I.P.T.)

$$
\text { I.P.T. = I.P.F. + I.P.S. + (I.A.D. de I.P.F.) }
$$

Este indicador visa avaliar o número total de funcionários necessários ao Serviço de Nutrição e Dietética (SND) .

3.4. İndice de Adequação do PESSOAL do SND

o Indice de adequação (I.A.) pode ser representado pela fórmula:

$$
\begin{aligned}
& \text { I.A. } \left.=\frac{(E x}{E S} \times 100\right) \% \text {, onde: } \\
& E x=\text { número de funcionários existente no SND } \\
& E s=\text { número de funcionários esperados (I.P.T.) } \\
& \text { Ao criarmos } O \text { indice de adequação pretendemos que }
\end{aligned}
$$


ele fosse usado como uma medida que permitisse ve rificar se o número de funcionários existentes no SND é menor, igual ou maior do que o Indicador de Pessoal Total (I.P.T.). Para analisar nossos dados, consideramos como adequado um va lor de 100\%, com uma margem de \pm 10\%. Portanto, niveis entre 90 e 1108 serão considerados adequados. Os valores aclma - de 1108 serão considerados inadequados, assim como aqueles abaixo de 908, que subdividimos em duas outras categorias: $\leqslant 50 \%$ e de 51 a 898 de adequação. Para facilidade de exposição,achạ mos interessante adotar a seguinte nomenclatura:

$\begin{array}{lrl}\leq \quad \text { de } 508 & \text { deficiente } \\ 51-898 & \text { baixo } \\ 90-1108 & \text { adequado } \\ >\quad 1108 & \text { excessivo }\end{array}$

\subsection{FATORES INTERVEN IENTES}

Fatores Intervenientes são aqueles que podem influ enciar os resultados. Podem ser diretos e indiretos.

a) Fatores diretos:

Os fatores diretos são aqueles que podem interferir diretamente no número total de funcionários existentes no serviço. São eles:

- Taxa de ocupação hospitalar: calculada utilizando-se a seguinte fórmula: 31

Taxa de ocupação $=\underline{\text { ni de pacientes/dia em determinado período } \times 100}$ no de leitos/dia no mesmo período

- Categoria do paciente:

Segundo o Ministério da Saúde, ${ }^{31}$ os pacientes podem pertencer a uma das seguintes categorias: 
- não contribuintes: é aquele que não retribui com qualquer pagamento à assistência médico-hospitalar recebida;

- contribuinte ou pagante: é aquele que retribui com pagamento total ou parcial, direta ou indiretamente, a assistência médico-hospitalar recebida;

- paciente de convênio, de contrato ou segurado: è o paciente contribuinte, que paga indiretamente, de forma total ou parcial, a assistência médico-hospitalar recebida.

- Tipos de Cardápio

Adotamos os critérios apontados por passos, 33 se gundo os quais poderão existir: cardápio popular, médio, libe ral ou de luxo. O cardāpio popular consta de preparações simples, não exigindo muito tempo do pessoal de preparo. o cardá pio médio reune preparações mais elaboradas, necessitando um pessoal mais treinado e maior tempo gasto no seu preparo. Já - cardāpio liberal ou de luxo consta de vārias preparações, pois vai depender da escolha do paciente, muito embora alguns hospitais apresentem algumas sugestões do cardápio do dia. Necessitam, portanto, de pessoal capacitado e bem treinado.

- Sistema de distribuição de refeições e higienizaÇão dos utensilios:

Existem dois sistemas de distribuição das refeições: o centralizado e o descentralizado. No primeiro, as refeições são porcionadas e acondicionadas em pratos térmicos ou recipientes próprios $\theta$ as bandejas identificadas ainda no SND no setor de distribuição. O sistema descentralizado utiliza carros térmicos para a retirada das refeições do SND,. . para 
posterior distribuição nas unidades de internação. 50 Existe ainda a combinação dos dois sistemas anteriores, com a denomí nação de sistema misto de distribuição,que utiliza para as dietas modificadas o sistema centralizado e para a dieta normal o sistema descentralizado. ${ }^{33}$

os sistemas de higienização dos utensílios são também essencialmente dois: o centralizado, onde os utensilios das unidades de internação são reunidos em uma copa central no SND, e o descentralizado, onde são lavados nas copas das unida des de internação. 33

b) Fatores Intervenientes Indiretos:

Estes fatores, que indiretamente podem interferir no número de pessoal existente, dependem principalmente, da quali dade do serviço:qualidade da planta física, equipamentos e pes soal, para cuja avaliação cotejamos os valores existentes com os parâmetros recomendados por órgãos oficiais (na ausência des tes, com os existentes, não oficiais). Chamaremos os valores existentes de REAL e os valores dos parâmetros e recomendaçäes de IDEAL.

- Planta Física:

A área física destinada ao SND foi mensurada pela planta,utilizando-se escalimetro de precisão, na prōpria insti tuição ou naquela arquivada na Coordenadoria de Assistência Hos pitalar.Utilizamos como padrão para área física aquele propos to pelo Ministério da Saúde ${ }^{31}$ para o SND, refeitório,copa da unidade de internação e secretaria. Para a despensa, utilizamos o Código de Edificação de Obras* da Prefeitura Municipal de São Paulo. Os padrões são os seguintes:

* Código de Edificação de Obras. Lei Municipal n\& 8266, de 20/06/1975, do Município de são Paulo. 
SND (inclusive despensa, secretaria (exclusive rafeitório e copa da unidade de internação) : $1 \mathrm{~m}^{2}$ por le1to. ${ }^{31}$

Despensa: ārea mínima $20 \mathrm{~m}^{2}$

Refeitório: $1 \mathrm{~m}^{2}$ por comensal ${ }^{31}$ por turno. ${ }^{11}$

Para o cálculo do comensal por turno, optamos pelo número ideal de comensal; para isso, partimos do número total de funcionários do hospital com jornada de trabalho de 8 horas ou mais; considerando que $60 \%$ deles trabalham no perío do da manhã.33 . Dïvidimos em quatro turnos, nos hospitais dos Grupos I, II, III e em cinco turnos, nos hospi tais do Grupo IV (com duração de $30 \mathrm{mi-}$ nutos cada turno).

Secretaria: $8 \mathrm{~m}^{21^{* *}}$

Copa da unidade de internação: $8 \mathrm{~m}^{2}{ }^{* \star *}$ *

- Equipamentos:

Seguimos as recomendações do Ministério da Saúde ${ }^{30}$ porém, como este se refere a hospitais de até 150 leitos, tivemos que adequá-lo para os hospitais com maior capacidade. Isto foi feito, utilizando recomendações, além das anteriores, constantes no RECLAR 29 e em passos. 33

* No Código de Edificações de Obras não consta a especifí cação do número de leitos do hospital.

** Por não estar discriminada a área deste elemento, valemo-nos do valor recomendado para a sala de encarregada do lactário do hospital até 150 leitos.

*** Para hospitais de até 150 leitos. 
Para o cálculo do número de equipamentos e de sua capacidade, utilizamos, além do número médio de refeições por dia em cada grupo de hospitais, o nümero médio de dietas normals e o número médio de dietas modificadas, considerando um sistema de distribuição de refeições descentralizado.

Após exame do memorial descritivo (quando disponivel), verificamos os equipamentos existentes e considerados apenas aqueles em funcionamento.

As recomendações que usamos neste trabalho são:

Balança de carga $(\mathrm{kg})^{33}$

Balança de mesa $(\mathrm{kg})^{29,30}$

Carro de plataforma $(\mathrm{kg})^{33}$

Câmara Frigorifica $\left(\mathrm{m}^{3}\right)^{29}, 30$

Congelador $\left(\mathrm{m}^{3}\right) *$

Descascador de tubérculos (ud) 30

Picador (maquina universal) (ud) ${ }^{33}$

Medor de carne (ud) 33

Fogão a gás (domest.) (queimad.)

Fogão a gás (industrial) (queimad.) ${ }^{30}$

Forno elétrico industrial (câmara) ${ }^{30}$

Caldeirão vapor/gás (1)

conj.panelas basculantes (1) 30

Bifeteira (ud) $\star \star * 30$

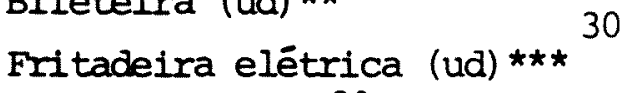

Banho-Maria (ud) ${ }^{30}$

cortador de frios (ud) $)^{30}$

30

Batedeira elétrica incustrial (1)

Liquidificador industrial (1)

Liquidificador doméstioo (1) 33

Extrator de sucos (ud) 30

Cafeteira incustrial (]itmo) ${ }^{30}$

Carro térmico (ud) 29,30

\begin{tabular}{llll}
$\begin{array}{l}\text { Grupo } \\
\text { Grupo }\end{array}$ & $\begin{array}{l}\text { II } \\
\text { III }\end{array}$ & \multicolumn{1}{c}{ Grupo } \\
$1(200)$ & $1(300)$ & $1(300)$ & $1(500)$ \\
$1(20)$ & $1(25)$ & $2\left\{\begin{array}{l}1(25) \\
1(5)\end{array}\right.$ & $2\left\{\begin{array}{l}1(30) \\
1(5)\end{array}\right.$ \\
$1(250)$ & $1(250)$ & $2(300)$ & $3(500)$ \\
$3(27,6)$ & $3(30,0)$ & $4(50,0)$ & $4(70,0)$ \\
$1(0,8)$ & $1(1,5)$ & - & - \\
1 & 1 & 1 & 2 \\
- & 1 & 1 & 1 \\
1 & 1 & 1 & 1 \\
$1(4)$ & - & - & - \\
$1(8)$ & $2\left\{\begin{array}{lll}1(8) \\
1(6)\end{array}\right.$ & $2(8)$ & $3(8)$ \\
$1(1)$ & $1(3)$ & $1(3)$ & $2(3)$ \\
$3 \begin{cases}1(200) \\
2(100)\end{cases}$ & $4\left\{\begin{array}{l}2(200) \\
2(100)\end{array}\right.$ & $4(200)$ & $7\left\{\begin{array}{l}5(500) \\
2(300)\end{array}\right.$ \\
$1(100)$ & $1(100)$ & $1(150)$ & $2(100)$ \\
- & - & 1 & 1 \\
- & 2 & 2 & 2 \\
1 & 1 & 2 & 2 \\
1 & 1 & 1 & 1 \\
$1(10)$ & $1(20)$ & $1(40)$ & $2\left\{\begin{array}{l}1(50) \\
1(20)\end{array}\right.$ \\
$1(6)$ & $1(15)$ & $1(15)$ & $2(15)$ \\
$2(1,5)$ & $3(1,5)$ & $3(1,5)$ & $4(1,5)$ \\
1 & 1 & 1 & 1 \\
$1(30)$ & $1(30)$ & $1(50)$ & $1(100)$ \\
2 & 4 & 10 & 25 \\
& & &
\end{tabular}

(continua) 
(cont.)

Carro de prateleira (ud) ${ }^{30}$

Balcão térmico $(3,6 \times 0,6) \quad(u d)^{29}$

Triturador de residuos (ud) ${ }^{33}$

Maquina de lavar lauça (ud) 30

NQ médio diário de refeições

NQ médio diärio de dieta normal

Grupo Grupo Grupo Grupo

N8 médio diärio de dieta modificada

$2 \quad 4 \quad 10 \quad 30$

$\begin{array}{llll}1 & 1 & 1 & 1\end{array}$

$1 \quad 112$

1111

$\begin{array}{rrrr}773 & 1119 & 1850 & 4038 \\ 503 & 728 & 1291 & 2668 \\ 270 & 391 & 559 & 1370\end{array}$

* Cangelador passa a ser solicitado como câmara frigorífica nos Grupos III e IV.

** Bifeteira . é solicitada acoplada ao fogão industrial nos Grupos I e II. *** Fritadeiraé solicitada acoplada ao fogão industrial no Grupo I.

- Qualidade do Pessoal

Utilizando a Classificação Brasileira de Ocupações, ${ }^{32}$, reunimos as ocupações existentes no SND.

Em alguns hospitais, principalmente federais e municipais, algumas ocupações tinham denominações diferentes das constantes na Classificação. Por isso, verificamos a equivalência de funções para reunir então as vārias ocupações dos SND.

Não há parâmetros oficiais determinando as ocupações ideais para o SND. Daí estabelecemos, dentro das funções que são desenvolvidas, as ocupações necessárias nas instituiçōes hospitalares estudadas. São elas:

Nutricionista na chefia, nutricionista, tēcnico em nutrição, escriturārio, despenseiro, cozinheiro encarregado, cozinheiro, auxiliar de cozinheiro (ajudante de cozinha), auxiliar de cozinha, servente de cozinha (serviçal) e copeira (atendente de nutrição). 
18.

$\mathrm{Na}$ apuração de nossos dados no que se refere às ocupaçōes, partimos do número ideal (I.P.T.) de funcionários para cada SND (jā incluídos os substitutos de férias e folgas) e fizemos uma distribuição percentual, segundo Mezomo ${ }^{28}$, nos diversos setores de atividade do SND, conforme as ocupações pertinentes a esses setores; assim:

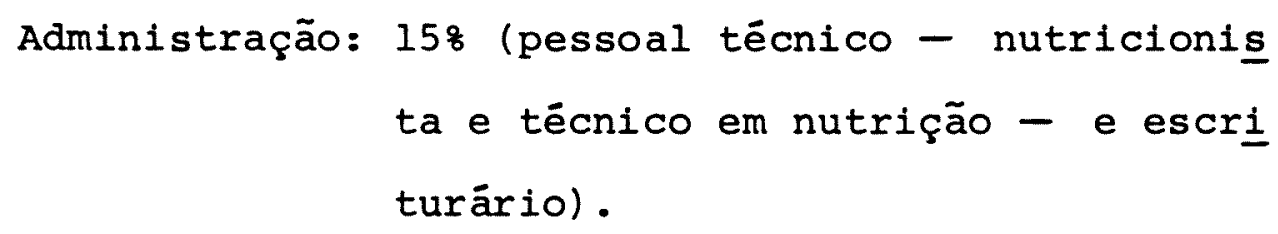
turário).

Armazenamento/recebimento: 88 (escriturārio e despenseiro).

Pré-preparo de carnes e vegetais: 118 (auxiliar de cozinha).

Preparo: 208 (cozinheiro encarregado, cozinheiro, auxiliar de cozinheiro).

Distribuição: (desjejum, merenda, lanches, refeitōrio) : 128 (auxiliar de cozinha).

Distribuição nas unidades de internação: $20 \%$ (copeiras).

Lavagem de louça, faxina: $8 \%$ (servente de cozinha). Serviço noturno: 68 (cozinheiro, auxiliar de cozinha).

o cotejamento do IDEAL com o REAL foi feito através de percentuais correspondentes a cada um. 


\subsection{Número de Leitos e Finalidade da Entidade Mantenedora}

Estudamos os hospitais gerais com 151 e mais leitos pois, segundo PASSOS, ${ }^{33} \circ$ SND aumenta em complexidade na mesma proporção em que aumenta o número de leitos; o planejamento, funcionamento e a administração desses serviços diferem quanto aos recursos humanos e materiais.

Encontramos, entre os 49 hospitais estudados, 8 hos pitais governamentais $(16,3 \%), 20$ hospitais lucrativos $(40,9 \%)$ e 21 hospitais não lucrativos $(42,88)$ (TABELA 1). Segundo a classificação por nūmero de leitos, 22 deles são do Grupo I, 13 hospitais são do Grupo II, 7 hospitais são do Grupo III e 7 pertencem ao Grupo IV. A maioria dos hospitais encontram-se nos grupos I e II.

Quanto aos hospitais governamentais, 2 deles são federais, 2 são autarquias estaduais e 4 são municipais. Entre os hospitais não lucrativos, 6 são beneficentes e 15 são filantrōpicos.

Queremos registrar que, desde a Tabela 1 até a última, os números escritos em algarismos romanos referem-se aos Grupos constituidos segundo o número de leitos dos hospitais estudados, para evitar repetições.desnecessárias. 
TABELA 1 - Hospitais gerais estudados, pertencentes ao Município de são Paulo, segundo a finalidade da entidade mantenedora

e o número de leitos. São Paulo, março de 1983.

\begin{tabular}{|c|c|c|c|c|c|c|c|c|c|c|c|}
\hline \multirow{3}{*}{$\begin{array}{l}\text { FINALIDADE } \\
\end{array}$} & \multicolumn{8}{|c|}{ NUMERO DE } & \multirow{3}{*}{$\begin{array}{r}\mathrm{T} \\
\mathrm{N} Q\end{array}$} & \multirow{3}{*}{$0 \mathrm{~T}$} & \multirow[b]{2}{*}{ I A L } \\
\hline & \multicolumn{2}{|c|}{ I } & \multicolumn{2}{|c|}{ I I } & \multicolumn{2}{|c|}{ I I I } & \multicolumn{2}{|c|}{ IV } & & & \\
\hline & No & $\%$ & No & $\%$ & No & $\%$ & N 8 & $\%$ & & & $\%$ \\
\hline \multirow{2}{*}{ Governament ais } & \multirow[t]{2}{*}{2} & 9,1 & 1 & 7,8 & 3 & 42,9 & 2 & 28,6 & 8 & & 16,3 \\
\hline & & $(25,0)$ & & $(12,5)$ & & $(37,5)$ & & $(25,0)$ & & & $(100,0)$ \\
\hline \multirow{2}{*}{ Lucrativos } & \multirow[t]{2}{*}{12} & 54,5 & 6 & 46,1 & 1 & 14,2 & 1 & 14,3 & 20 & & 40,9 \\
\hline & & $(60,0)$ & & $(30,0)$ & & $(5,0)$ & & $(5,0)$ & & & $(100,0)$ \\
\hline \multirow{2}{*}{ Não Lucrativos } & \multirow[t]{2}{*}{8} & 36,4 & 6 & 46,1 & 3 & 42,9 & 4 & 57,1 & 21 & & 42,8 \\
\hline & & $(38,1)$ & & $(28,6)$ & & $(14,3)$ & & $(19,0)$ & & & $(100,0$ \\
\hline TOTAL & 22 & 100,0 & 13 & 100,0 & 7 & 100,0 & 7 & 100,0 & 49 & & 100,0 \\
\hline
\end{tabular}

* Os números entre parênteses referem-se ao percentual de hospitais em relação às finalida des. 
Na Tabela 2 são apresentados o número médio total de funcionários dos hospitais e o número médio do pessoal esta giärio (internos, residentes e outros).

TABELA 2 - Número médio de funcionários dos hospitais e no médio de pessoal estagiário, segundo a finalidade da entidade mantenedora e o número de leitos.

São Paulo, março de 1983.

\begin{tabular}{|c|c|c|c|c|c|c|c|c|c|c|c|c|c|}
\hline \multirow{3}{*}{\multicolumn{2}{|c|}{$\begin{array}{l}\text { CATEGORIA } \\
\text { DO } \\
\text { PESSOAL }\end{array}$}} & \multicolumn{9}{|c|}{ FINALIDADE } & & & \\
\hline & & \multicolumn{4}{|c|}{ GOVERNAMENTAIS } & \multicolumn{4}{|c|}{ LUCRATIVOS } & \multirow{2}{*}{ 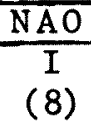 } & \multicolumn{3}{|c|}{ LUCRATIVOS } \\
\hline & & $\begin{array}{l}\bar{I} \\
(2) *\end{array}$ & $\begin{array}{l}\text { II } \\
\text { (1) }\end{array}$ & $\begin{array}{l}\text { III } \\
\text { (3) }\end{array}$ & $\begin{array}{c}\text { IV } \\
(2)\end{array}$ & $\begin{array}{c}\mathrm{I} \\
(12)\end{array}$ & $\begin{array}{c}\text { II } \\
(6)\end{array}$ & $\begin{array}{l}\text { III } \\
\text { (1) }\end{array}$ & $\begin{array}{l}\text { IV } \\
\text { (1) }\end{array}$ & & $\begin{array}{l}\text { II } \\
\text { (6) }\end{array}$ & $\begin{array}{l}\text { III } \\
\text { (3) }\end{array}$ & $\begin{array}{l}\text { IV } \\
(4)\end{array}$ \\
\hline \multirow{3}{*}{$\begin{array}{l}\text { Funcionā } \\
\text { rios do } \\
\text { Hospital }\end{array}$} & $\overline{\mathrm{x}}$ & 1026 & 1300 & 1596 & 4137 & 318 & 511 & 684 & 395 & 316 & 500 & 686 & 1809 \\
\hline & MIN & 937 & - & 802 & 3500 & 216 & 6360 & - & - & 140 & 381 & 526 & 1386 \\
\hline & MAX & 1115 & - & 2000 & 4775 & 71 & 0700 & - & - & 455 & 597 & 706 & 2000 \\
\hline Pessoal & $\bar{x}$ & 58 & 8 & 72 & 287 & 7 & 4 & - & - & 12 & 10 & 5 & 52 \\
\hline \multirow[t]{2}{*}{ Estagiārio } & MIN & 5 & - & 22 & 200 & - & - & - & - & - & - & - & - \\
\hline & $\operatorname{MAX}$ & 111 & - & 143 & 375 & 2 & 5 & - & - & 75 & 50 & 9 & 130 \\
\hline
\end{tabular}

* Os algarismos arábicos entre parênteses referem-se ao número de hospitais em cada Grupo.

Analisando a Tabela 2 podemos dizer que as instituições governamentais estão com número maior de funcionários em relação aos hospitais lucrativos e não lucrativos. Os hospitais não lucrativos possuem um número superior de funcionários em relação aos hospitais lucrativos e guardam uma certa proporção com o aumento de leitos dos hospitais.

Quanto ao número do pessoal estagiário, notamos que os hospitais governamentais também possuem um maior número, vin do a seguir os hospitais não lucrativos e os hospitais lucrati vos, sendo que alguns não têm este tipo de pessoal. 
No Anexo II estão relacionados todos os hospitais, onde poderão ser verificados o número total de funcionários de cada instituição e o número de pessoal estagiário, quando existente. Ainda em relação ao número de funcionários dos hospitais, calculamos a relação funcionārio por leito hospitalar.

Para alguns autores, ${ }^{1,2}$ um hospital geral necessita uma relação de 2,5 a 4 empregados por leito. Não existem, porém, padrões oficiais, e não hã padrões fixos quanto a esse pa râmetro, que poderá variar, principalmente de acordo com o tipo de assistência médico-hospitalar. (Tabela 3).

TABELA 3 - Distribuição dos hospitais segundo o nümero de funcionários/leito, a finalidade da entidade mantenedo ra e o número de leitos. São Paulo, março de 1983.

\begin{tabular}{|c|c|c|c|c|c|c|c|c|c|c|c|c|c|c|}
\hline \multirow{3}{*}{\multicolumn{3}{|c|}{$\begin{array}{l}\text { NUMERO DE } \\
\text { FUNCIONARIOS / } \\
\text { LEITO }\end{array}$}} & \multicolumn{12}{|c|}{ FINAL IDADE } \\
\hline & & & \multicolumn{4}{|c|}{ GOVERNAMENTAIS } & \multicolumn{4}{|c|}{ LUCRATIVOS } & \multicolumn{4}{|c|}{ NÃO LUCRATIVOS } \\
\hline & & & I & II & III & IV & I & II & III & IV & I & II & III & IV \\
\hline \multirow[t]{2}{*}{$<$} & 2,5 & & - & - & 1 & - & 11 & 5 & 1 & 1 & 6 & 6 & 3 & 2 \\
\hline & 2,5 & -4 & - & - & - & 2 & 1 & 1 & - & - & 2 & - & - & 2 \\
\hline$>$ & 4 & & 2 & 1 & 2 & - & - & - & - & - & - & - & - & - \\
\hline
\end{tabular}

* Os algarismos arábicos entre parênteses referem-se ao número de hospitais em cada grupo.

Distribuindo os hospitais estudados segundo essas ca racteristicas (Tabela 3), verificamos que entre os hospitais go vernamentais, 5 estão ạcima, 2 dentro e 1 abaixo das recomenda ções. O mesmo não ocorreu com os hospitais lucrativos, pois de 20 hospitais, só 2 estão dentro da recomendação; quanto aos hos 
pitais não lucrativos (21), apenas 4 estão dentro do preconiza do.

- Anexo II detalha a distribuição dos hospí tais, permitindo uma melhor visualização do conjunto.

\subsection{Pessoal do Serviço de nutriçäo e dietética}

Dois elementos que podem melhor caracterizar o SND são o número e as categorias de ocupações existentes; além dis so, o tipo de chefia e o nümero do pessoal técnico existente, assim como sua categoria, são fundamentais para um hospital ge ral, pelo fato deste atender pacientes com afecções mais varia das, que necessitam de um grande número de dietas modificadas.

Um dos padrões propostos para avaliar o número ' de funcionários do SND é um percentual de 10 a 158 do nümero dos funcionários do hospital. $1,2,33$ Podemos observar, na Ta bela 4, que essa recomendação não é seguida pelos hospitais go vernamentais, pois de 8 hospitais, somente 1 está dentro dessa recomendação. O mesmo acontece com os hospitais lucrativos,pois, de 20 hospitais, só 2 estão dentro do padrão; no entanto, deve mos ressaltar que 5 hospitais estão com valores ao redor de 98 . Os hospitais não lucrativos apresentam-se em situação não muito diferente: encontramos, de 21 hospitais, 6 dentro do padrão proposto e, acima de $9 \%, 4$ hospitais. O Anexo II detalha os resultados encontrados em cada hospital. 
TABELA 4 - Distribuição dos hospitais segundo o percentual do pessoal do SND em relação ao pessoal do hospital,fí nalidade da entidade mantenedora e o número de leitos dos hospitais. São Paulo, março de 1983.

\begin{tabular}{|c|c|c|c|c|c|c|c|c|c|c|c|c|}
\hline \multirow{3}{*}{$\begin{array}{l}\text { PERCENTUAL EM } \\
\text { RELAÇÃO AO } \\
\text { PESSOAL HOSPI } \\
\text { TALAR }\end{array}$} & \multicolumn{12}{|c|}{ FINAL IDADE } \\
\hline & \multicolumn{4}{|c|}{ GOVERNAMENTAIS } & \multicolumn{4}{|c|}{ LUCRATIVOS } & \multicolumn{4}{|c|}{ NÃO LUCRATIVOS } \\
\hline & $\begin{array}{c}I \\
(2) *\end{array}$ & $\begin{array}{l}\text { II } \\
\text { (1) }\end{array}$ & $\begin{array}{l}\text { III } \\
\text { (3) }\end{array}$ & $\begin{array}{l}\text { IV } \\
\text { (2) }\end{array}$ & $\begin{array}{l}\text { I } \\
(12)\end{array}$ & $\begin{array}{l}\text { II } \\
\text { (6) }\end{array}$ & $\begin{array}{l}\text { III } \\
\text { (1) }\end{array}$ & $\begin{array}{l}\text { IV } \\
\text { (1) }\end{array}$ & $\begin{array}{c}\mathrm{I} \\
(8)\end{array}$ & $\begin{array}{l}\text { II } \\
(6)\end{array}$ & $\begin{array}{l}\text { III } \\
\text { (3) }\end{array}$ & $\begin{array}{l}\text { IV } \\
\text { (4) }\end{array}$ \\
\hline$<10$ & 2 & 1 & 2 & 2 & 10 & 6 & 1 & 1 & 4 & 4 & 3 & 4 \\
\hline $10-15$ & - & - & 1 & - & 2 & - & - & - & 4 & 2 & - & - \\
\hline$>15$ & - & - & - & - & - & - & - & - & - & - & - & - \\
\hline
\end{tabular}

* Os algarismos arábicos entre parênteses referem-se ao número de hospitais em cada grupo.

Quanto às ocupaçōes, o pessoal existente nos SND: apresenta-se distribuido nas seguintes categorias: nutricionis ta, técnico em nutrição, escriturārio, despenseiro, cozinheiro, ajudante de cozinha, auxiliar de cozinha, serviçal (servente), atendente de nutrição, copeira e garçom.

Pela Tabela 5 pode-se observar a categoria da chefia dos SND. Todos os hospitais governamentais apresentam pelo menos um nutricionista na chefia. Já os hospitais lucrativos e não lucrativos, embora tendo nutricionistas na chefia, tambēm utilizam o técnico em nutrição, principalmente nos hospitais me nores, assim como leigos.

Na Tabela 6 encontra-se a distribuição do número médio de funcionários do SND.

Podemos observar a nitida diferença existente entre os hospitais governamentais e os demais, pois enquanto aqueles têm em seus quadros técnicos apenas nutricionistas, estes os 
utilizam em pequena escala, valendo-se tambēm dos técnicos em nutrição. Há casos de hospitais não governamentais onde os nutricionistas desempenham várias funções, além da chefia. A tabela 5 destaca essas considerações.

Os escriturários tambēm são vistos em maior nümero nos hospitais governamentais, assim como os despenseiros. E ni tida tambēm a diferença entre os hospitais governamentais e os lucrativos e não lucrativos quanto ao pessoal do preparo e dis tribuição dos alimentos. Assim, cozinheiros e auxiliares de co zinha encontram-se em número superior nos hospitais governamen tais (a exceção aparece entre os ajudantes de cozinha).(Tabela 6).

TABELA 5 - Distribuição das categorias das chefias dos SND dos hospitais estudados, segundo a finalidade da entidade mantenedora e o número de leitos. São Paulo, março de 1983.

\begin{tabular}{|c|c|c|c|c|c|c|c|c|c|c|c|c|}
\hline \multirow{3}{*}{$\begin{array}{c}\text { CATEGORIA } \\
\text { DA } \\
\text { CHEFIA }\end{array}$} & \multicolumn{12}{|c|}{ FINAL IDADE } \\
\hline & \multicolumn{4}{|c|}{ GOVERNAMENTAIS } & \multicolumn{4}{|c|}{ LUCRATIVOS } & \multicolumn{4}{|c|}{ NÃO LUCRATIVOS } \\
\hline & $\stackrel{I}{(2)^{2}}$ & $\begin{array}{l}\text { II } \\
\text { (1) }\end{array}$ & $\begin{array}{l}\text { III } \\
\text { (3) }\end{array}$ & $\begin{array}{l}\text { IV } \\
\text { (2) }\end{array}$ & $\begin{array}{l}I \\
(12)\end{array}$ & $\begin{array}{l}\text { II } \\
(6)\end{array}$ & $\begin{array}{l}\text { III } \\
\text { (1) }\end{array}$ & $\begin{array}{r}\text { IV } \\
\text { (1) }\end{array}$ & $\begin{array}{c}I \\
(8)\end{array}$ & $\begin{array}{l}\text { II } \\
(6)\end{array}$ & $\begin{array}{l}\text { III } \\
\text { (3) }\end{array}$ & $\begin{array}{l}\text { IV } \\
\text { (4) }\end{array}$ \\
\hline Nutricionista & 2 & 2 & 4 & 4 & 7 & 3 & 1 & 1 & 4 & 5 & 2 & 5 \\
\hline Téc.Nutrição & - & - & - & - & 3 & 2 & - & - & 1 & - & 1 & - \\
\hline Leigo & - & - & - & - & 2 & 1 & - & - & 3 & 1 & - & - \\
\hline
\end{tabular}

* Os algarismos arábicos entre parênteses referem-se ao número de hospitais em cada grupos 
TABELA 6 - Número médio de funcionários do SND (exclusive a Chefia), segundo a categoria da ocupação, a finalí dade da entidade mantenedora e o número de leitos dos hospitais. são Paulo, março de 1983.

\begin{tabular}{|c|c|c|c|c|c|c|c|c|c|c|c|c|}
\hline \multirow{3}{*}{$\begin{array}{l}\text { CATEGORIA } \\
\text { DA } \\
\text { OCUPAÇÃO }\end{array}$} & \multicolumn{12}{|c|}{ F IN AL IDADE } \\
\hline & \multicolumn{4}{|c|}{ GOVERNAMENTAIS } & \multicolumn{4}{|c|}{ LUCRATIVOS } & \multicolumn{4}{|c|}{ NÃO LUCRATIVOS } \\
\hline & $\begin{array}{c}\bar{I} \\
(2) *\end{array}$ & $\begin{array}{l}\text { II } \\
\text { (1) }\end{array}$ & $\begin{array}{l}\text { III } \\
\text { (3) }\end{array}$ & $\begin{array}{l}\text { IV } \\
\text { (2) }\end{array}$ & $\begin{array}{l}\mathrm{I} \\
(12)\end{array}$ & $\begin{array}{l}\text { II } \\
(6)\end{array}$ & $\begin{array}{l}\text { III } \\
\text { (1) }\end{array}$ & $\begin{array}{l}\text { IV } \\
\text { (1) }\end{array}$ & $\begin{array}{c}\text { I } \\
(8)\end{array}$ & $\begin{array}{c}\text { II } \\
(6)\end{array}$ & $\begin{array}{l}\text { III } \\
\text { (3) }\end{array}$ & $\begin{array}{c}\text { IV } \\
(4)\end{array}$ \\
\hline Nutricionista & 4,0 & 3,0 & 4,0 & 19,0 & 0,1 & 0,3 & - & - & 0,6 & 0,7 & - & 4,0 \\
\hline Tec.Nutrição & - & - & - & - & 0,4 & 0,2 & - & - & 0,4 & 1,3 & 0,7 & 4,0 \\
\hline Escriturārio & 5,0 & 3,0 & 8,0 & 13,0 & 3,0 & 1,0 & 1,0 & 2,0 & 0,2 & 1,0 & 1,3 & 3,0 \\
\hline Despenseiro & 1,5 & 1,0 & 1,0 & 3,0 & 0,4 & 0,5 & - & 1,0 & 0,4 & 1,2 & 0,3 & 0,7 \\
\hline Cozinheiro & 7,5 & 6,0 & 8,0 & 24,5 & 2,8 & 2,2 & 3,0 & 1,0 & 2,5 & 3,2 & 2,7 & 5,5 \\
\hline Ajud.Cozinha & - & - & - & 3,5 & 1,7 & 1,2 & 13,0 & 2,0 & 3,1 & 8,8 & 3,3 & 5,2 \\
\hline Aux.Cozinha & 7,0 & 8,0 & 13,6 & 17,5 & 4,1 & 5,0 & - & 1,0 & 4,4 & 3,2 & 6,0 & 6,2 \\
\hline Serviçal & 11,0 & 26,0 & 10,3 & 1,0 & 1,9 & 3,3 & - & 7,0 & 2,4 & - & 14,7 & 20,7 \\
\hline Atend.Nutr. & - & - & - & 63,0 & - & - & - & - & - & - & - & 5,9 \\
\hline Copeira & 31,0 & 2,0 & 43,7 & 43,0 & 13,2 & 16,2 & 24,0 & 14,0 & 16,8 & 29,5 & 9,3 & 53,7 \\
\hline Garçom & - & - & - & - & - & 1,0 & - & - & 0,4 & 1,0 & - & - \\
\hline
\end{tabular}

* Os algarismos arábicos entre parênteses referem-se ao nümero de hospitais em cada grupo.

Os hospitais governamentais mantēm ainda uma superioridade no nümero de serviçais, atendentes de nutrição e copeiras que são usados indistintamente na cozinha e na unidade de internação. Garçons são utilizados apenas por alguns hospi tais lucrativos e não lucrativos.

Do Anexo III constam as distribuições de todo o pessoal (técnico ou não).

Achamos importante destacar que o número de nutricionistas e dos técnicos em nutrição varia conforme a finalida 
de dos hospitais que os utilizam. Enquanto os hospitais govermentais concentram maior número de nutricionistas (73), os hospitais não lucrativos têm 41 desses profissionais e os lucrati vos têm apenas 15, o que corresponde às médias de $9,1,1,9$ e 0,75 nutricionistas por hospital, respectivamente. Enquanto os técnicos em nutrição são pouco utilizados pelos hospitais governamentais (1), os lucrativos e os não lucrativos os utilizam em maior escala ( 13 e 31, respectivamente). Cumpre-nos esclarecer que não existe o cargo de tēcnico em nutrição (denomi nação mais recente), nem de dietistas (denominação mais antiga) nos hospitais governamentais, quer sejam federais, estaduais ou municipais. 
28.

\section{RESULTADOS E COMENTÁRIOS}

Estudamos os Serviços de Nutrição e Dietētica (SND) de 49 hospitais gerais no Município de são Paulo, procurando verificar a adequação do número de funcionários existentes em cada um deles, segundo os indicadores de dimensionamento de pessoal já citados.

\subsection{Instrumentos de Avaliação}

\subsubsection{INDICADOR DE PESSOAL FIXO (I,P.F.)}

Este indicador utiliza o número de refeições diárias servidas, a jornada de trabalho dos funcionários e o tempo médio dispendido por refeição servida (15 minutos). ${ }^{17} 0$ valor encontrado refere-se a todo o pessoal do SND (técnico e não técnico), não incluindo o pessoal substituto.

Pela Tabela 7 observamos que os dois hospitais gover namentais de tamanho extra, têm o I.P.F. com valores bastante superiores ao único hospital lucrativo dessa capacidade e a 3 dos 4 hospitais não lucrativos. Não observamos diferenças acen tuadas entre os valores de I.P.F. dos hospitais dos outros gru pos. 
TABELA 7 - Valores do Indicador de Pessoal Fixo (I.P.F.) nos hospitais estudados, segundo a finalidade da entida de mantenedora e o número de leitos. São Paulo, mar ço de 1983.

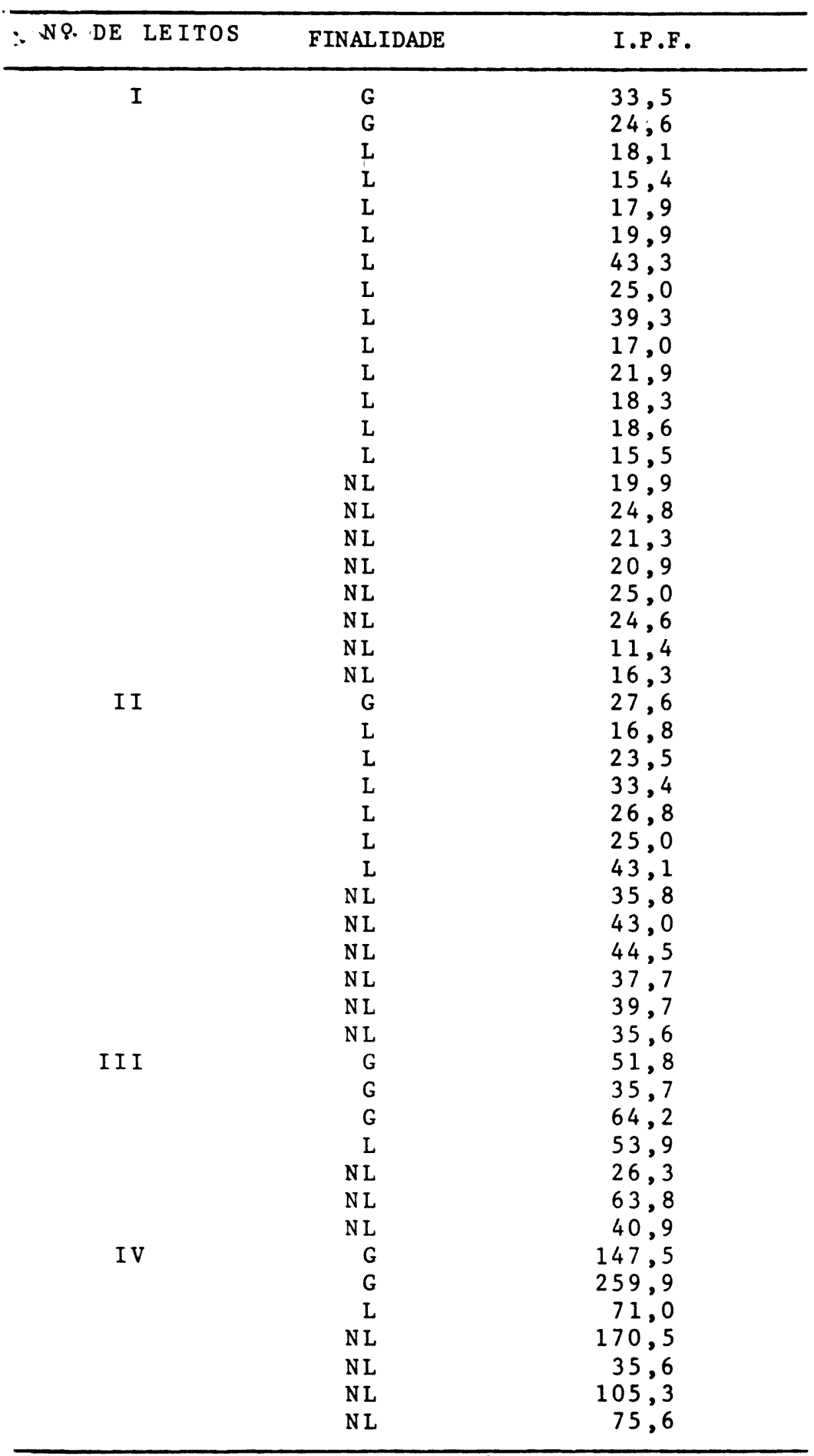


Para melhor se avaliar os resultados encontrados, utilizando esse indicador, achamos interessante estudar os três fatores componentes, que são:

a) Número de refeições servidas

A produção diāria de refeições (desjejum, almoço,me renda, jantar e refeição noturna) é, sem dūvida, um dos fatores que mais influem no resultado desse indicador. ${ }^{17}$ Pe la Tabela 8 , podemos observar as médias do movimento diário de refeições, dos hospitais estudados.

Nos dois hospitais governamentais de capacidade extra, onde o valor do I.P.F. foi superior ao dos demais, verificamos que sua própria natureza justifica uma produção elevada de refeições (mēdia de 6.518). Ambos são Hospitais de Ensino que recebem um grande número de estagiários, internos e residentes que tomam lá mais de uma refeição ao dia (12,48 da mēdia diāria servida); alēm disso, esses hospitais atendem um número considerável de pacientes externos,que às vezes lá recebem refeiçōes (um deles tambēm atende a uma creche).

Os hospitais lucrativos e não lucrativos de tamanho extra, embora apresentando um dimensionamento do I.P.F. infe rior aos governamentais (com exceção de um), têm certas peculiaridades: o único hospital lucrativo dessa dimensāo serve 95,98 de suas refeiçōes para pacientes e somente 3,98 aos funcionārios e "outros" (principalmente acompanhantes); e 0 percentual de $5,8 \%$ de refeições servidas a "outros" que se ob serva entre os hospitais não lucrativos origina-se principal mente do fato de um deles ser também um Hospital de Ensino.

Analisando ainda a Tabela 8 , podemos notar que a maioria dos demais hospitais lucrativos e os não lucrativos 
TABELA 8 - Médias e percentuals dos movimentos diārios de refeições dos hospitais estudados, segundo os destinatários, a finalidade da entidade mante nedora e o número de leitos. São Paulo, março de 1983.

\begin{tabular}{|c|c|c|c|c|c|c|c|c|c|c|c|c|}
\hline \multirow{2}{*}{$\begin{array}{l}\text { DESTINATARRIOS } \\
\text { DAS } \\
\text { REFEIÇÕES }\end{array}$} & \multicolumn{4}{|c|}{ GOVERNAMENTAIS } & \multicolumn{4}{|c|}{ LUCRATIVOS } & \multicolumn{4}{|c|}{ NÃO LUCRATIVOS } \\
\hline & $\begin{array}{c}\text { I } \\
(2) *\end{array}$ & $\begin{array}{l}\text { II } \\
(1)\end{array}$ & $\begin{array}{l}\text { III } \\
(3)\end{array}$ & $\begin{array}{l}\text { IV } \\
(2)\end{array}$ & $\begin{array}{c}\text { I } \\
(12)\end{array}$ & $\begin{array}{l}\text { II } \\
(6)\end{array}$ & $\begin{array}{l}\text { III } \\
(1)\end{array}$ & $\begin{array}{l}\text { IV } \\
(1)\end{array}$ & $\begin{array}{r}\text { I } \\
(8)\end{array}$ & $\begin{array}{l}\text { II } \\
(6)\end{array}$ & $\begin{array}{l}\text { III } \\
(3)\end{array}$ & $\begin{array}{l}\text { IV } \\
(4)\end{array}$ \\
\hline PACIENTES & $\begin{array}{c}632 \\
(56,2)^{\star \star}\end{array}$ & $\begin{array}{c}464 \\
(35,0)\end{array}$ & $\begin{array}{l}1365 \\
(56,2)\end{array}$ & $\begin{array}{l}4029 \\
(61,8)\end{array}$ & $\begin{array}{l}585 \\
(73,9)\end{array}$ & $\begin{array}{l}812 \\
(86,1)\end{array}$ & $\begin{array}{l}1322 \\
(76,6)\end{array}$ & $\begin{array}{l}2180 \\
(95,9)\end{array}$ & $\begin{array}{l}472 \\
(71,9)\end{array}$ & $\begin{array}{l}839 \\
(66,6)\end{array}$ & $\begin{array}{l}718 \\
(54,6)\end{array}$ & $\begin{array}{l}2402 \\
(74,1)\end{array}$ \\
\hline FUNCIONARIOS & $\begin{array}{c}359 \\
(31,9)\end{array}$ & $\begin{array}{c}787 \\
(59,3)\end{array}$ & $\begin{array}{c}896 \\
(36,9)\end{array}$ & $\begin{array}{l}1684 \\
(25,8)\end{array}$ & $\begin{array}{c}199 \\
(25,1)\end{array}$ & $\begin{array}{c}125 \\
(13,2)\end{array}$ & $\begin{array}{c}394 \\
(22,8)\end{array}$ & $\begin{array}{c}90 \\
(3,9)\end{array}$ & $\begin{array}{l}177 \\
(26,9)\end{array}$ & $\begin{array}{c}393 \\
(31,2)\end{array}$ & $\begin{array}{l}577 \\
(43,9)\end{array}$ & $\begin{array}{c}649 \\
(20,1)\end{array}$ \\
\hline OUTROS $^{\star * \star}$ & $\begin{array}{c}134 \\
(11,9)\end{array}$ & $\begin{array}{c}76 \\
(5,7)\end{array}$ & $\begin{array}{l}168 \\
(6,9)\end{array}$ & $\begin{array}{c}805 \\
(12,4)\end{array}$ & $\begin{array}{c}8 \\
(1,0)\end{array}$ & $\begin{array}{c}7 \\
(0,7)\end{array}$ & $\begin{array}{c}10 \\
(0,6)\end{array}$ & $\begin{array}{c}5 \\
(0,2)\end{array}$ & $\begin{array}{c}8 \\
(1,2)\end{array}$ & $\begin{array}{c}28 \\
(2,2)\end{array}$ & $\begin{array}{c}19 \\
(1,5)\end{array}$ & $\begin{array}{l}188 \\
(5,8)\end{array}$ \\
\hline MEDIA GERAL & 1125 & 1327 & 2429 & 6518 & 792 & 944 & 1726 & 2275 & 657 & 1260 & 1314 & 3239 \\
\hline
\end{tabular}

* Os algarismos arábicos entre parênteses, no cabeçalho, referem-se ao número de hospital em cada grupo.

** Os algarismos arābicos entre parênteses, no corpo da tabela, referem-se aos percentuais obtidos em relação à média geral.

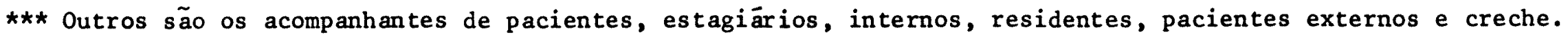


TABELA 9 - Médias diārias e percentuais das dietas destinadas a pacientes dos hospitais estudados, segundo a finalidade da entidade mantenedora e o número de leitos. São Paulo, março de 1983.

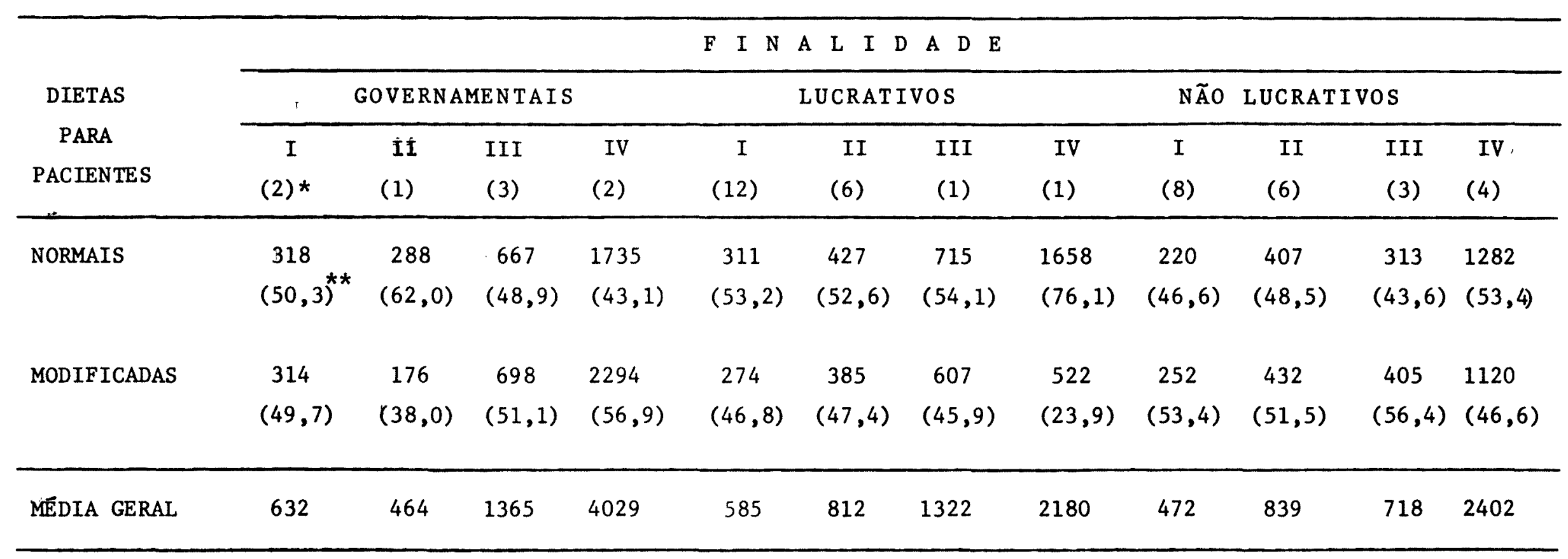

* Os algarismos arābicos entre parênteses, no cabeçalho, referem-se ao número de hospitais em cada grupo.

** Os algarismos arábicos entre parênteses, no corpo da tabela, referem-se aos percentuais obtidos em relação à média geral. 
também têm sua produção

voltada para o paciente (principalmente os lucrativos). O mesmo não ocorre com a maior parte dos hospitais governamentais. Uma explicação para esse fato poderia ser uma proporção menor de dietas modificadas que aqueles hospitais servem. Com os dados colhidos, cans truimos então a Tabela 9 , verificando-se que as dietas modificadas são mais empregadas nos hospitais governamentais (com exceção de um) e nos não lucrativos. Sabe-se que para a pre paração de dietas modificadas hã necessidade de uma mão-de-obra qualificada, especialmente de nutricionistas, que não é encontrada na maioria dos hospitais lucrativos (Ver Anexo III e Tabelas 5 e 6 ).

Não houve diferenças acentuadas na proporção das dietas modificadas, entre os hospitais de menor e maior capa cidade de leitos.

No Anexo IV podem ser vistos a produção diāria de cada hospital.

b) Jornada de Trabalho

Dos 49 hospitais estudados, 38 têm regime de trabą lho de 8 horas diárias, sendo 35 hospitais particulares (16 lucrativos e 19 não lucrativos) e 3 governamentais; 10 traba lhavam em regime de 12 horas diárias dos quais 5 particulares (4 lucrativos e um não lucrativo) e 5 governamentais. Um hospital não lucrativo trabalhava em regime de 6 horas diārias.

Para demonstrar a influência da jornada de trabaTho no cálculo do I.P.F., vamos tomar dois exemplos, ao acaso, retirados do Anexo IV. Lá encontraremos um hospital com uma produção diāria de 1711 refeições e com jornada de trabạ 
Iho de 12 horas (ante-penúltimo hospital do Anexo IV); encon traremos, também, um hospital produzindo 1726 refeiçōes. diárias e com jornada de trabalho de 8 horas (o único hospital lucrativo do Grupo III). o valor do I.P.F. é 35,6 para o prí meiro e 53,9 para o segundo. Isso salienta a importância da jornada diāria no dimensionamento de pessoal.

No Anexo IV poderá ser verificada a duração do trạ balho diārio e semanal de cada hospital.

c) Tempo médio gasto por refeição servida (15 minu tos)

Um dos modelos de avaliação em Serviços de Nutrição e Dietética do qual nos valemos para a utilização dos in dicadores estudados 17 refere que o tempo médio de 15 minutos, gasto na produção e distribuição de uma refeição, inclu sive trabalho nas copas (unidade de internação), foi adotado por ser de uso universal. Interessamo-nos, então, pela origem, entre nós, desse valor adotado e, devido a escassez de bibliografia sobre o assunto, consultamos a esse respeito vá rios profissionais atuantes na área. Obtivemos, então, uma informação de que o assunto foi aqui debatido pela primeira vez durante 0 II Congresso de Nutricionistas, ocorrido em São Paulo, em $1960^{*}$. O tempo então referido foi de 15 minutos, baseado em trabalhos realizados em hospitais americanos na década de $60.4,13,18,46$ A preocupação na época era a padronização dos serviços de nutrição. Em alguns trabalhos os autores realizaram a pesquisa "in 10c0", mas, na maioria, eram enviados questionărios aos Departamentos de Dietética

* Comunicação pessoal da Nutricionista olga Laskani. 
dos hospitais para serem preenchidos e posteriormente devolvidos.

Dados coletados em 10 hospitais em Wisconsin por Tuthill e Donaldson 46 referentes às tarefas especificas rea lizadas nos diferentes setores dos Departamentos de Dietética apontaram um resultado médio para o tempo por refeição de 13,31 minutos.

Bakken e Northrop 4 estudando 13 hospitais encontraram um tempo médio de trabalho total de 16,38 minutos. Posteriormente, Halter e Donaldson, 18 estudando o mesmo assunto em 175 hospitais da região nordeste americana, encontraram um tempo médio por refeição servida de 14,9 minutos, considerando o tempo de trabalho total (incluindo aqui o pessoal profissional, não profissional e de escritório) e 17,1 minutos como tempo de trabalho direto (incluindo apenas o pessoal não profissional diretamente envolvido com a produção, preparo e distribuição de alimentos).

Donaldson, 13 ainda pesquisando a utilização efí ciente do tempo de serviço no Departamento de Dietētica, estudou a informação proveniente de 225 hospitais representando todas as regiões dos Estados Unidos e com uma boa distribuição no que se referia aos tamanhos das instituições.o tem po médio obtido para o tempo de trabalho direto foi de 14,0 minutos, enquanto para o trabalho total foi de 16,3 minutos.

Apesar dos questionamentos surgidos por ocasião do II Congresso de Nutricionistas em virtude das diferenças exis tentes na época entre os Serviços de Dietētica de nossos hospitais com aqueles hospitais americanos, foi adotado, então, - tempo médio de 15 minutos, que até hoje é utilizado entre nós. Entretanto, esse tempo poderá variar de acordo çom vá- 
rios fatores, como: planta física, quantidade e qualidade das instalações, equipamentos e utensilios, tiposde cardāpio,qua lidade do pessoal auxiliar, sistemas de distribuição das refeições e de higienização de utensilios, I7fatores esses que serão destacados oportunamente.

\subsubsection{INDICADOR DE PERIODOS DE DESCANSO $(I, P, D$,}

Para a construção deste indicador, o conhecimento da duração do trabalho semanal è fundamental, pois, segundo esta, variará o I.P.D. Para a semana de 48 horas, existe uma folga semanal, enquanto para 40 horas semanais há duas folgas, quando a jornada diāria de trabalho é de 8 horas.

$\mathrm{Na}$ operacionalização deste indicador são computados os dias de folga, considerando a jornada de trabalho diário, e a duração do trabalho semanal, o periodo de férias dos fun cionários, os dias de feriados oficiais e os facultativos.

Nos nossos resultados observamos variações importantes (Tabela 10): encontramos 35 hospitais com I.P.D. de 3,24 (16 lucrativos, 18 não lucrativos e 1 governamental), to dos com duração de trabalho semanal de 48 horas e jornada de trabalho de 8 horas. Com um I.P.D. de 0,87 encontramos 5 hospitais (4 lucrativos e 1 não lucrativo) com duração de trabalho semanal de 48 horas e jornada diária de 12 horas. Um I.P.D. de 2,38 é de um hospital não lucrativo, com duração de trabalho semanal de 44 horas e diāria de 8 horas. Um valor de 2,07 do I.P.D. pertence a um hospital não lucrativo com 42 horas de trabalho semanal e 6 horas diárias durante 5 dias e 1 plantão de 12 horasino final de semana. Nos hospitais governamentais, os valores do I.P.D. foram de 0,68 (5 hospitais, com 12 horas diárias) e 1,68 ( 2 hospitais com 8 horas diárias), 
TABELA 10 - Valores encontrados para o Indicador de Períodos de Descanso (I.P.D.) nos hospitais estudados, se gundo a finalidade da entidade mantenedora e 0 número de leitos. São Paulo, março de 1983.

\begin{tabular}{|c|c|c|c|}
\hline No & DE LEITOS & F IN AL ID ADE & I.P.D. \\
\hline \multirow{22}{*}{\multicolumn{2}{|c|}{ I }} & G & 1,68 \\
\hline & & G & 0,68 \\
\hline & & L & 3,24 \\
\hline & & L & 3,24 \\
\hline & & L & 3,24 \\
\hline & & $\mathrm{L}$ & 0,87 \\
\hline & & L & 3,24 \\
\hline & & L & 3,24 \\
\hline & & $\mathrm{L}$ & 3,24 \\
\hline & & L & 3,24 \\
\hline & & L & 3,24 \\
\hline & & L & 3,24 \\
\hline & & L & 0,87 \\
\hline & & L & 0,87 \\
\hline & & $\mathrm{NL}$ & 3,24 \\
\hline & & $\mathrm{NL}$ & 3,24 \\
\hline & & $\mathrm{NL}$ & 3,24 \\
\hline & & $\mathrm{NL}$ & 3,24 \\
\hline & & $\mathrm{NL}$ & 3,24 \\
\hline & & $\mathrm{NL}$ & 3,24 \\
\hline & & $\mathrm{NL}$ & 3,24 \\
\hline & & $\mathrm{NL}$ & 3,24 \\
\hline \multirow{13}{*}{\multicolumn{2}{|c|}{ I I }} & G & 0,68 \\
\hline & & L & 0,87 \\
\hline & & L & 3,24 \\
\hline & & L & 3,24 \\
\hline & & L & 3,24 \\
\hline & & L & 3,24 \\
\hline & & $\mathrm{L}$ & 3,24 \\
\hline & & $\mathrm{NL}$ & 3,24 \\
\hline & & N L & 3,24 \\
\hline & & $\mathrm{NL}$ & 3,24 \\
\hline & & $\mathrm{NL}$ & 3,24 \\
\hline & & $\mathrm{NL}$ & 3,24 \\
\hline & & $\mathrm{NL}$ & 3,24 \\
\hline \multirow{7}{*}{\multicolumn{2}{|c|}{ I I I }} & G & 0,68 \\
\hline & & G & 0,68 \\
\hline & & G & 0,68 \\
\hline & & L & 3,24 \\
\hline & & $\mathrm{NL}$ & 3,24 \\
\hline & & N L & 2,07 \\
\hline & & NL & 3,24 \\
\hline \multirow{7}{*}{\multicolumn{2}{|c|}{ IV }} & G & 1,68 \\
\hline & & G & 3,24 \\
\hline & & $\mathrm{L}$ & 3,24 \\
\hline & & $\mathrm{NL}$ & 3,24 \\
\hline & & NL & 0,87 \\
\hline & & $\mathrm{NL}$ & 2,38 \\
\hline & & $\mathrm{NL}$ & 3,24 \\
\hline
\end{tabular}


todos com 40 horas semanais.

Os hospitais com 12 horas diārias acumulam as folgas, pois todos trabalham 12 por 36 (trabalham 12 horas e folgam 24 horas); pela Legislação Trabalhista deveriam trabalhar 8 horas diărias, acrescidas de 2 horas extras, 11 não devendo exceder 10 horas diárias de trabalho.

A distribuição dos hospitais pela duração semanal do trabalho e jornada diāria, constam do Anexo IV.

\subsubsection{INDICADOR DE PESSOAL SUBSTITUTO $\left(I, P, S_{*}\right)$}

Este indicador se vale dos indicadores anteriores (I.P.F. E I.P.D.); portanto, fatores que influenciam o valor daqueles, interferirão, conseqlentemente, nos resultados (uma produção elevada do serviço, por exemplo, interfé rirá no valor do I.P.F.).

Valores de I.P.D. mais elevados dão I.P.S. mais baixo. Assim, os hospitais com I.P.D. de 3,24 necessitam me nos funcionários do que aqueles com I.P.D. de 0,87 (ambos com 48 horas semanais). O mesmo podemos dizer dos hospitais governamentais com valores de I.P.D. de 1,68 e 0,68: os pri meiros apresentaram uma menor necessidade de funcionários do que os segundos.

Na Tabela 11 podemos verificar que os hospitais do Grupo I apresentaram para O I.P.S., um valor máximo de 36,1 e um valor mínimo de 3,5; no Grupo II o valor máximo foi de 40,6 e o valor mínimo de 7,2; no Grupo III o valor máximo foi de 94,4 e o mínimo de 8,1; no Grupo IV o valor máximo foi de 87,8 e o valor minimo de 21,9 funcionários. 
TABELA 11 - Valores encontrados para o Indicador de Pessoal Substituto (I.P.S.) nos hospitais estudados, segundo a finalidade da entidade mantenedora e 0 número de leitos. São Paulo, março de 1983.

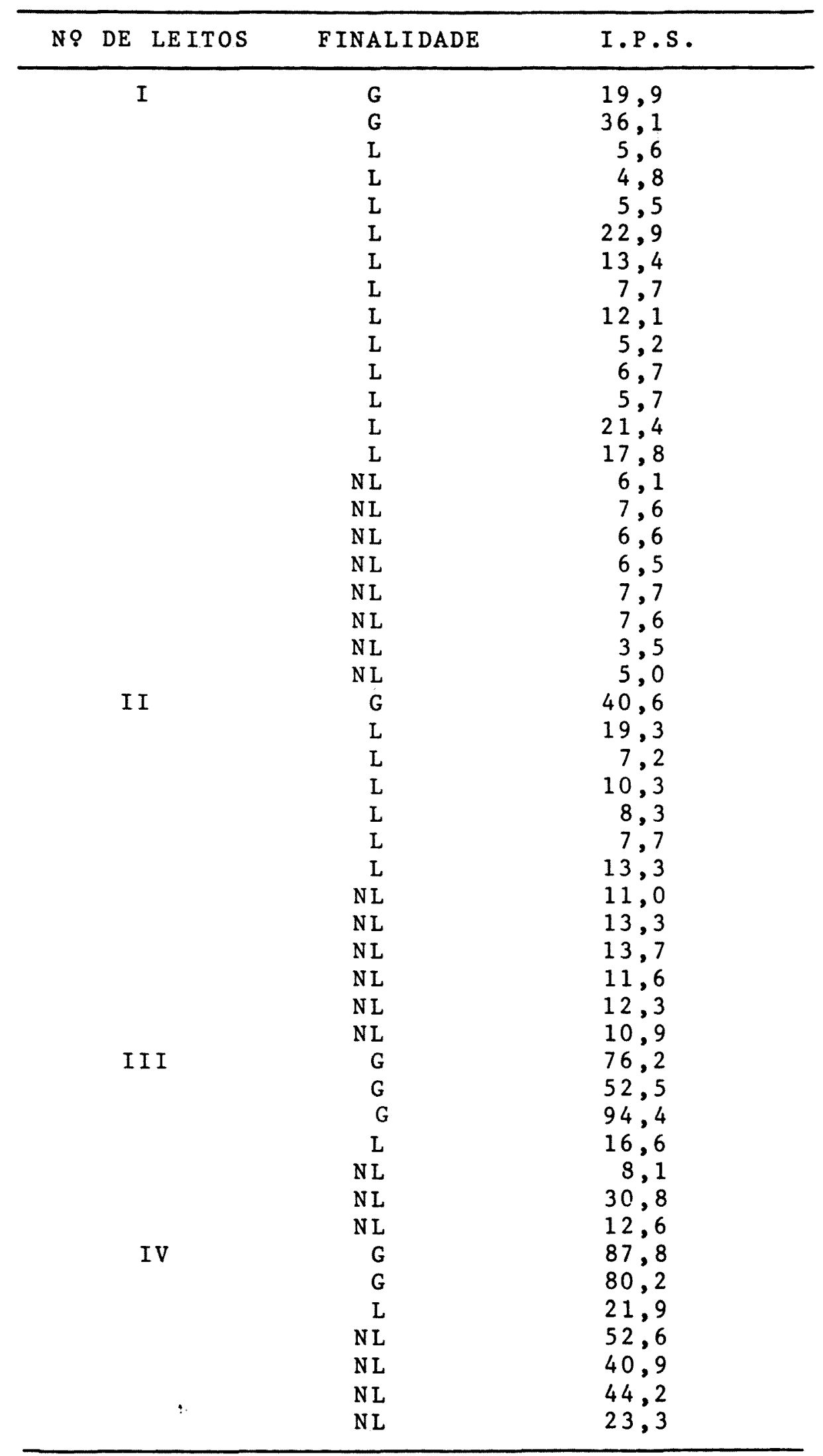




\subsubsection{INDICADOR DE ABSENTEISMO DIÁRIO (I,A.D.)}

O absenteismo pode ser considerado como um grave problema dentro de uma organização quando se torna cronico porque reduz a eficiência da produtividade do serviço.

E importante salientar que o absenteismo não ocorre apenas por motivos de saúde (licença médica, licença por gestação, acidentes de trabalho, etc.). Por isso compete à chefia do SND identificar as causas e os elementos envolvidos para, posteriormente, desenvolver medidas educativas, $22,23,45$ quando pertinentes.

Podemos observar na Tabela 12 que as maiores porcentagens de absenteismo foram encontradas em 2 hospitais go vernamentais (um do Grupo II, com valor de 25,08 e outro do Gru po IV, com valor de 23,08 ), e em 1 hospital lucrativo (Grupo II, com valor de $28,1 \%$ ); foram encontrados, ainda, 9 hospitais ( 2 governamentais, 2 lucrativos e 5 não lucrativos) com valores de I.A.D. superiores a 10,08. Por outro lado, houve ausência de absenteismo em 2 hospitais, o que não significa serem eles melhores que os demais quanto a essa característi ca, uma vez que esse estudo se refere a um período de apenas 31 dias no ano.

Há autores que, no cálculo do dimensionamento de pessoal não levam em consideração o absenteismo na instituição, atendo-se somente ao cálculo do pessoal fixo, de férias e folgas. $1,28,33 \quad$ evidente que $\circ$ ideal seria não exis tir absenteismo crônico nos serviços. Para evitar que isso ocorra, è importante haver treinamento-em-serviço, despertan do $\circ$ interesse do funcionário, fazendo-o compreender a impor tância da tarefa que the cabe, estimulando sua responsabili- 
TABELA 12 - Valores encontrados para o Indicador de Absenteísmo Diário (I.A.D.) nos hospitais estudados, segundo a finalidade da entidade mantenedora e o número de leitos. São Paulo, março de 1983.

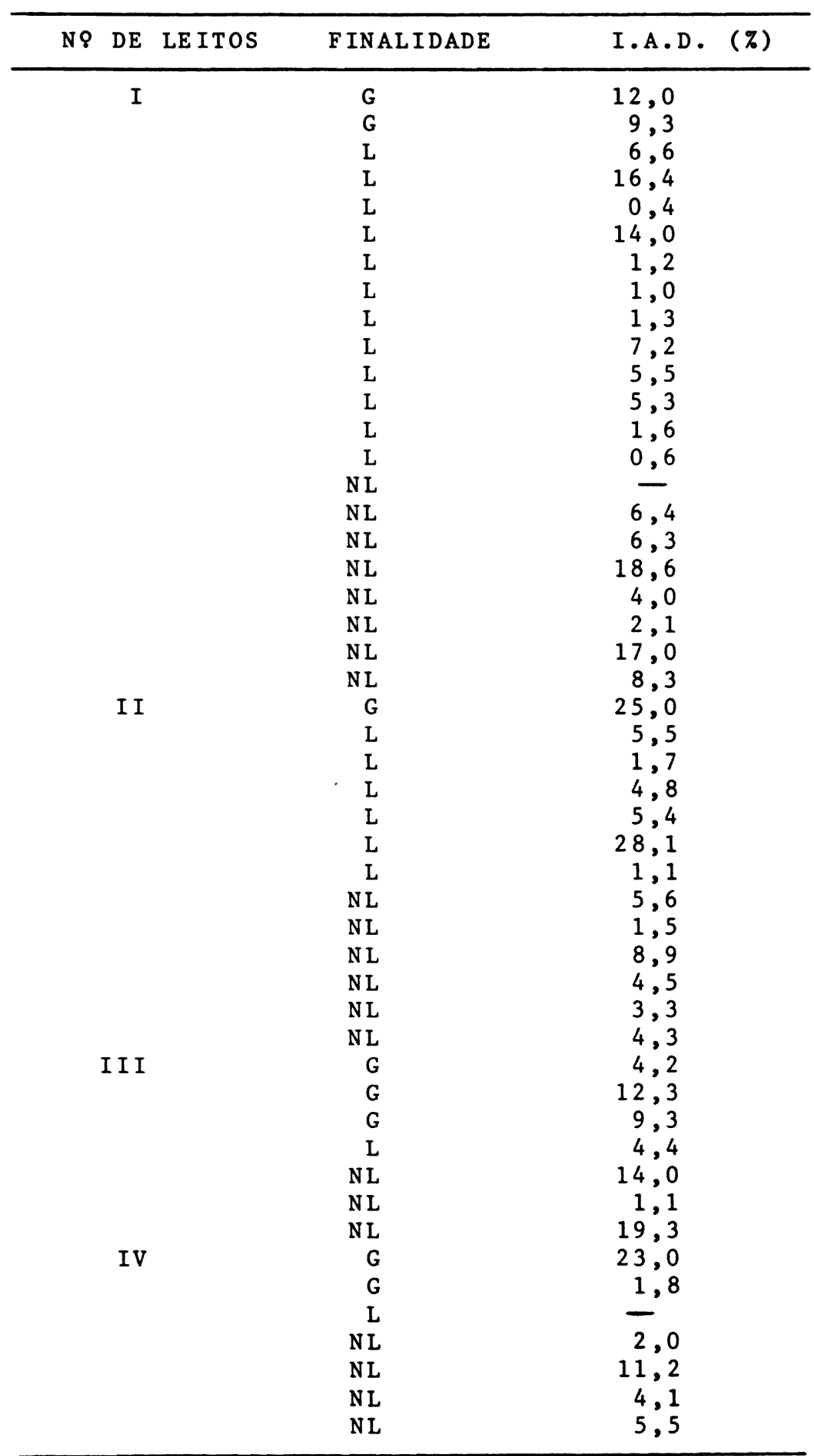


dade frente à Instituição, beneficiando o próprio hospital à medida em que melhora seu padrão de eficiência. 50

\subsubsection{INDICADOR DE PESSOAL TOTAL $(I, P, T$,}

Este indicador é calculado com base nos anteriores, servindo como parâmetro no cálculo do pessoal necessário para o SND. Os resultados encontram-se na Tabela 13 (ao lado dos indicadores precedentes, para facilitar comparações que se fizerem necessárias). O número de leitos parece não ser mesmo um bom indicador de pessoal total. Assim, vejamos pela Tabela 13 os dados referentes a dois hospitais similares quan to ao número de leitos (ambos com 250 leitos): o quinto (L) e o décimo (NL) do Grupo II. Embora, como jā dissemos, o nūmero de leitos seja o mesmo (Anexo II), isso não significa a mesma necessidade de funcionários; no primeiro hospital,o nū mero médio de refeições foi de 857 e no segundo, de 1425 refeiçōes (Anexo IV); os I.P.F. (Tabela 13) foram de 26,8 e 44,5 funcionārios, respectivamente e O I.P.T. teve valores de 36,5 e 62,2 , respectivamente. Esses resultados vêm ao encontro da opinião de Donaldson ${ }^{13}$ que achava não ser $\circ$ nūmero de leitos uma base "confiāvel para o cálculo de pessoal e que pareceria mais razoável considerar o número de refeições servidas diariamente, além de outros serviços fornecidos pelo departamento dietētico".

Analisando ainda a Tabela 13, com todos os indicadores, veremos que, sem dúvida, O I.P.F. é um indicador de grande peso, pois utiliza fatores muito importantes na sua construção: a produção diāria de refeições, a jornada de trâ balho e o tempo gasto por refeição servida; porém, não se poo de deixar de acrescentar o pessoal substituto. 
TABELA 13 - Valores dos Indicadores de Dimensionamento de Pessoal (I.P.F., I.P.D., I.P.S., I.A.D.) e o Indicador de Pessoal Total (I.P.T.) dos hospitais estudados, segundo a finalidade da entidade man tenedora e o número de leitos. São paulo, março de 1983.

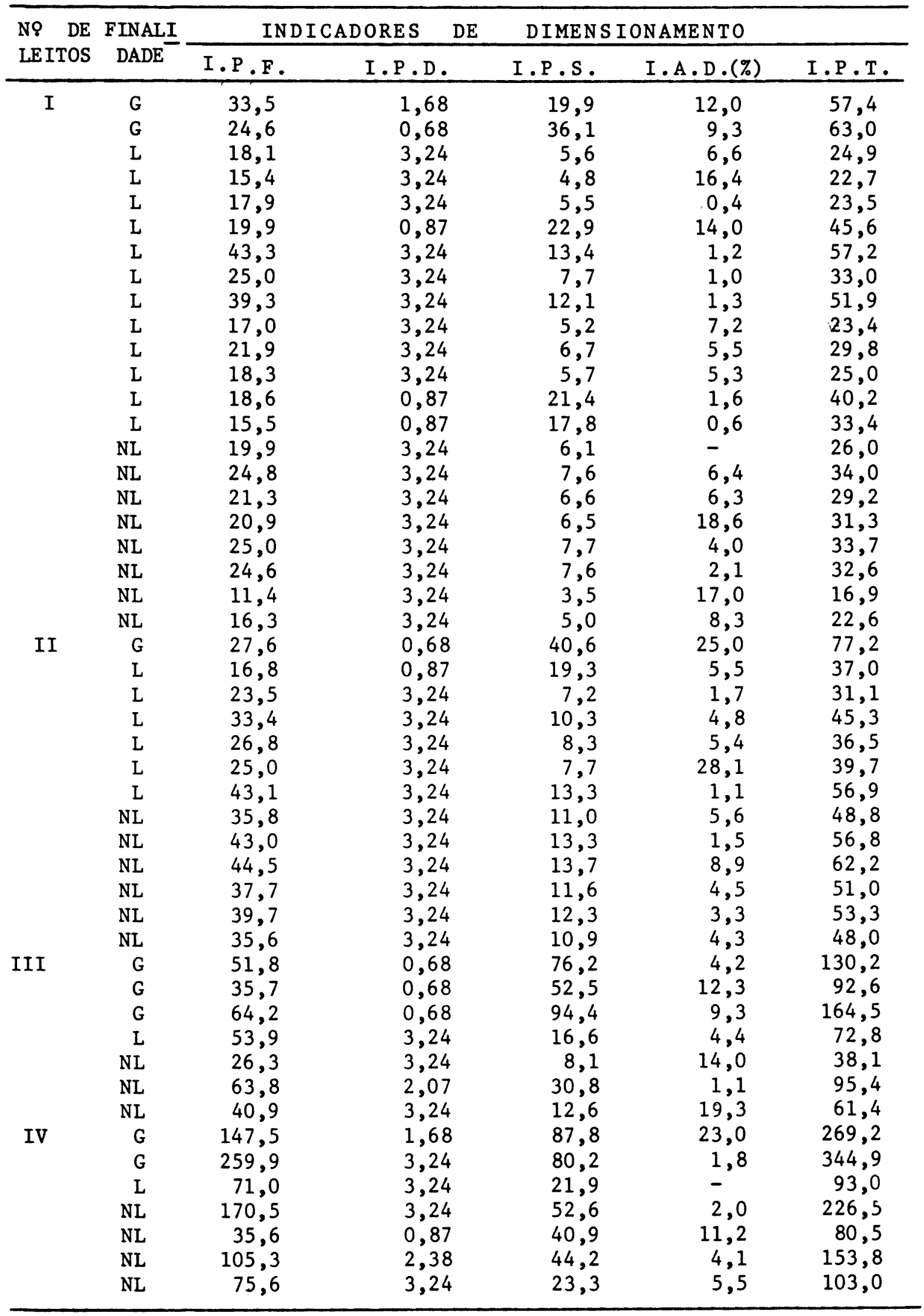


A importância do I.P.T. é inconteste na avaliação do número total de funcionários dos SND.

\section{2. İndice de Adequação do Pessoal do SND}

A partir do Indicador de Pessoal Total (I.P.T.) cal culamos a adequação do SND de cada hospital estudado em rela ção ao número de funcionários existentes em cada serviço (vâ lor real). Na Tabela 14 podemos observar os indices de adequação dos vários hospitais, comparando o número existente (Ex) de funcionários dos SND e o número esperado (Es) - obtị do do I.P.T. - em relação a 100, expresso da seguinte forma:

$$
I . A .=\left(\frac{E x}{E S} \times 100\right) \%
$$

Estabelecendo que consideraríamos adequados aqueles hospitais com valores variando de 90 a 1108 ( \pm 108 de diferen ça do valor ideal) onde teríamos um número adequado de funcionārios para realizar o preparo, distribuição e higienização dos utensillios, os valores abaixo de $90 \%$ poderiam indicar um número insuficiente de funcionários para realizar tais tarefas e aqueles superiores a 1108 um excesso de pessoal, in dicando, talvez, ociosidade do serviço.

Os Indices de adequação encontrados foram muito va riados, indo de $28 \%$ até $223 \%$.

Dentro do: intervalo considerado adequado (Tabela 14), encontramos 10 hospitais, sendo 4 do Grupo I ( 1 G, 1 L e $2 \mathrm{NL}$ ), 3 do Grupo II (I L e $2 \mathrm{NL}$ ), 1 do Grupo III (NL) e 2 não lucrativos entre os hospitais de capacidade extra. Os de mais hospitais distribuiram-se, 8 acima de $110 \%$ e os 31 restantes, abaixo de $90 \%$. 
TABELA 14 - Pessoal existente, pessoal esperado (obtido do I.P.T.) e o indice de adequação do pessoal do SND nos hospitais estudados, segundo a finalidade da entidade mantenedora e o no de leitos.S.Paulo, março de 1983

\begin{tabular}{|c|c|c|c|c|c|}
\hline \multirow{2}{*}{ NO $\mathrm{DE}$} & \multirow{2}{*}{ LEITOS } & \multirow{2}{*}{ FINALIDADE } & \multicolumn{2}{|c|}{ PESSOAL } & \multirow{2}{*}{$\begin{array}{c}\text { INDICE DE } \\
\text { ADEQUAÇÃO } \\
(\%)\end{array}$} \\
\hline & & & Existente & $\begin{array}{c}\text { Esperado } \\
\text { (I.P.T.) }\end{array}$ & \\
\hline \multirow{22}{*}{\multicolumn{2}{|c|}{ I }} & G & 69,0 & 57,4 & 120 \\
\hline & & G & 65,0 & 63,0 & 103 \\
\hline & & $\mathrm{L}$ & 33,0 & 24,9 & 132 \\
\hline & & $\mathrm{L}$ & 15,0 & 22,7 & 66 \\
\hline & & $\mathrm{L}$ & 12,0 & 23,5 & 51 \\
\hline & & $\mathrm{L}$ & 21,0 & 45,6 & 46 \\
\hline & & $\mathrm{L}$ & 47,0 & 57,2 & 82 \\
\hline & & L & 13,0 & 33,0 & 39 \\
\hline & & $\mathrm{L}$ & 38,0 & 51,9 & 73 \\
\hline & & $\mathrm{L}$ & 32,0 & 23,4 & 137 \\
\hline & & L & 21,0 & 29,8 & 70 \\
\hline & & $\mathrm{L}$ & 23,0 & 25,0 & 92 \\
\hline & & L & 29,0 & 40,2 & 72 \\
\hline & & L & 27,0 & 33,4 & 81 \\
\hline & & $\mathrm{NL}$ & 21,0 & 26,0 & 81 \\
\hline & & NL & 44,0 & 34,0 & 129 \\
\hline & & NL & 65,0 & 29,2 & 223 \\
\hline & & NL & 37,0 & 31,3 & 118 \\
\hline & & NL & 31,0 & 33,7 & 92 \\
\hline & & NL & 30,0 & 32,6 & 92 \\
\hline & & $\mathrm{NL}$ & 14,0 & 16,9 & 83 \\
\hline & & $\mathrm{NL}$ & 16,0 & 22,6 & 71 \\
\hline \multirow{13}{*}{\multicolumn{2}{|c|}{ I I }} & G & 49,0 & 77,2 & 63 \\
\hline & & $\mathrm{L}$ & 49,0 & 37,0 & 132 \\
\hline & & $\mathrm{L}$ & 23,0 & 31,1 & 74 \\
\hline & & $\mathrm{L}$ & 50,0 & 45,3 & 110 \\
\hline & & $\mathrm{L}$ & 27,0 & 36,5 & 74 \\
\hline & & $\mathrm{L}$ & 27,0 & 39,7 & 68 \\
\hline & & $\mathrm{L}$ & 16,0 & 56,9 & 28 \\
\hline & & $\mathrm{NL}$ & 89,0 & 48,8 & 182 \\
\hline & & $\mathrm{NL}$ & 46,0 & 56,8 & 81 \\
\hline & & $\mathrm{NL}$ & 57,0 & 62,2 & 92 \\
\hline & & $\mathrm{NL}$ & 54,0 & 51,0 & 106 \\
\hline & & $\mathrm{NL}$ & 38,0 & 53,3 & 72 \\
\hline & & $\mathrm{NL}$ & 26,0 & 48,0 & 54 \\
\hline \multirow{7}{*}{\multicolumn{2}{|c|}{ I I I }} & G & 89,0 & 130,2 & 68 \\
\hline & & G & 77,0 & 92,6 & 83 \\
\hline & & G & 101,0 & 164,5 & 61 \\
\hline & & L & 42,0 & 72,8 & 58 \\
\hline & & $\mathrm{NL}$ & 32,0 & 38,1 & 84 \\
\hline & & NL & 31,0 & 95,4 & 33 \\
\hline & & NL & 55,0 & 61,4 & 90 \\
\hline \multirow{7}{*}{\multicolumn{2}{|c|}{ IV }} & G & 196,0 & 269,2 & 72 \\
\hline & & G & 181,0 & 344,9 & 52 \\
\hline & & $\mathrm{L}$ & 29,0 & 93,0 & 31 \\
\hline & & $\mathrm{NL}$ & 141,0 & 226,5 & 62 \\
\hline & & NL & 75,0 & 80,5 & 93 \\
\hline & & $\mathrm{NL}$ & 139,0 & 153,8 & 90 \\
\hline & & N L & 83,0 & 103,0 & 80 \\
\hline
\end{tabular}


Ainda analisando a Tabela 14, verificamos, que os 8 hospitais com valores acima de 1108 pertencem somente aos Grupos I e II; no Grupo I ( 1 G, 2 L e $3 \mathrm{NL}$ ), os valores variaram de 118 a 2238 , enquanto no Grupo II (2 NL), os valores foram de 132 a 182\%. Quanto àqueles com indices de adequação abaixo de 908 , encontramos 12 nos hospitais no Grupo I ( $9 \mathrm{~L}$ e $3 \mathrm{NL}$ ), com valores entre 39 e $838 ; 8$ no Grupo II ( I G, 4 L e $3 \mathrm{NL}$ ), com valores entre 28 e $81 \% ; 6$ no Grupo III ( $3 \mathrm{G}, 1 \mathrm{~L}$ e $2 \mathrm{NL}$ ), com valores de 33 a 848 e 5 no Grupo IV ( $2 \mathrm{G}, 1 \mathrm{~L}$ e $2 \mathrm{NL}$ ) com valores de 31 a 808 .

Para melhor caracterizar os indices de adequação, nōs os dividimos em níveis, que classificamos como:

$$
\begin{aligned}
\leq-508-\text { deficiente } \\
51-898-\text { baixo } \\
90-1108-\text { adequado } \\
>1108-\text { excessivo }
\end{aligned}
$$

Na Tabela 15 podemos observar que 5 hospitais $(10,28)$ encontram-se no nível "deficiente" ( $\leq 50 \%$ da necessí dade de funcionários), isto é, o pessoal existente no SND não chegou sequer à metade do pessoal esperado (I.P.T.). No nível de adequação "baixo" (de 51 a 89\%), estão 26 hospitais $(53,18)$; portanto, a maioria dos hospitais estudados está com falta regular de pessoal em seus SND. Quanto ao nivel de 90 - 1108 (considerado "adequado"), encontramos apenas 10 hos pitais $(20,48)$. Portanto, somente cerca da quinta parte dos hospitais de grande porte e de tamanho extra estudados, que se situam entre os de maior demanda na Capital, è que se enquadra no nivel "adequado". Os 8 hospitais restantes, representando 16,38 , situam-se no nivel acima de $110 \%$ de adequação. 
TABELA 15 - Níveis de adequação referentes ao pessoal dos SND nos

hospitais estudados, segundo o número de leitos e a

finalidade da entidade mantenedora.São Paulo,março de 1983.

\begin{tabular}{|c|c|c|c|c|c|c|c|}
\hline \multirow{2}{*}{$\begin{array}{l}\text { NQ DE } \\
\text { LEITOS }\end{array}$} & \multirow{2}{*}{$\begin{array}{l}\text { FINAII } \\
\text { DADE }\end{array}$} & \multicolumn{2}{|c|}{ NIVEIS } & \multicolumn{2}{|c|}{ ADEQUAÇÃO } & \multicolumn{2}{|c|}{$\mathrm{T} O \mathrm{~T} A \mathrm{~L}$} \\
\hline & & Deficiente & Baixo & Adequado & Expessivo & No & 8 \\
\hline \multirow[t]{3}{*}{ I } & G & - & - & 1 & 1 & 2 & 4,1 \\
\hline & L & 2 & 7 & 1 & 2 & 12 & 24,6 \\
\hline & NL & - & 3 & 2 & 3 & 8 & 16,4 \\
\hline \multirow[t]{3}{*}{ II } & G & - & 1 & - & - & 1 & 2,0 \\
\hline & L & 1 & 3 & 1 & 1 & 6 & 12,2 \\
\hline & NL & - & 3 & 2 & 1 & 6 & 12,2 \\
\hline \multirow[t]{3}{*}{ III } & G & - & 3 & - & - & 3 & 6,1 \\
\hline & L & - & 1 & - & - & 1 & 2,0 \\
\hline & NL & 1 & 1 & 1 & - & 3 & 6,1 \\
\hline \multirow[t]{3}{*}{ IV } & G & - & 2 & - & - & 2 & 4,1 \\
\hline & L & 1 & - & - & - & 1 & 2,0 \\
\hline & NL & - & 2 & 2 & - & 4 & 8,2 \\
\hline TOTAL & & $\begin{array}{c}5 \\
(10,2) *\end{array}$ & $\begin{array}{c}26 \\
(53,1)\end{array}$ & $\begin{array}{c}10 \\
(20,4)\end{array}$ & $\begin{array}{c}8 \\
(16,3)\end{array}$ & $\begin{array}{c}49 \\
(100,0)\end{array}$ & 100,0 \\
\hline
\end{tabular}

* Os números entre parênteses referem-se ao percentual ob tido em se laçãa ao "no de hospitais estudados. 
Pela Figura 1 podemos visualizar os hospitais ade quados e os não adequados no que se refere ao pessoal do SND. Observamos que todos os hospitais com pessoal em excesso (acima de 110\%) e grande parte dos hospitais com pessoal adequado ( 7 hospitais) pertencem aos Grupos I e II (nümero de leitos inferior a 350). Já os hospitais com nível " "baixo" $(51$ - 89\%) e nível "deficiente" ( $\geq 50 \%)$ distribuiram-se pelos hospitais pertencentes aos quatro grupos.

Analisando os níveis de adequação em relação às en tidades mantenedoras, notamos que os hospitais não lucrativos concentraram a maior parte dos hospitais com niveis "ade quado", bem como aqueles com niveis considerados "excessivo". Quanto aos hospitais governamentais, 1 está no nível "adequa do", I no "excessivo" e os 6 restantes enquadrando-se no nivel "baixo". Dos 5 hospitais com níveis "deficiente", 4 são hospitais lucrativos. Isso sugere que os hospitais lucrativos estão mais voltados a outros setores que não o SND, uma vez que estes trabalham com um nümero reduzido de pessoal.Tal vez fosse oportuno propor futuras investigações sobre a qualidade dos serviços oferecidos pelos SND.

\subsection{FATORES INTERVEN IENTES}

Levando-se em consideração que apenas o número de funcionārios do SND não é o único fator que pode influenciar a qualidade dos serviços prestados, procuramos identificar, nos hospitais estudados, outros fatores que poderiam justifi car os resultados encontrados.

Os fatores apontados pelo Grupo de Trabalho ${ }^{17}$ da ārea hospitalar referem-se à planta física, equipamentos, qua lidade do pessoal auxiliar, tipos de cardápio, sistema de 
NIVEIS DE ADEQUACÃO DO DIMENSIONAMENTO

DO PESSOAL DOS SND DOS HOSPITAIS ESTUDADOS, SEGUNDO A FINALIDADE DA ENTIDADE MANTENEDORA E O NÚMERO DE LEITOS.

SAO PAULO, MARÇO DE 1983

GRUPO I

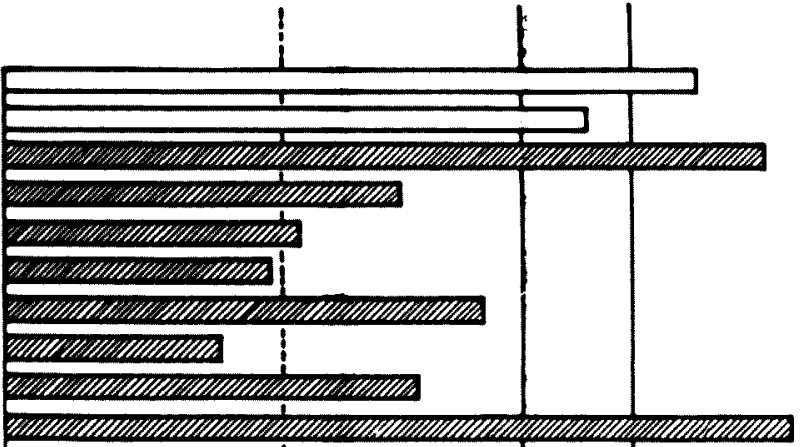

GRUPO II
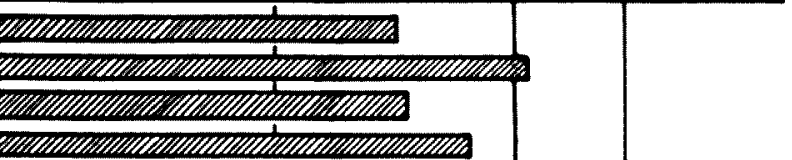

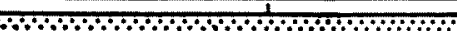

$\because \cdots \cdots$

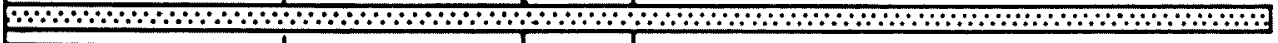

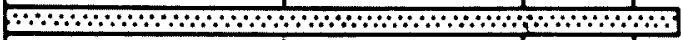

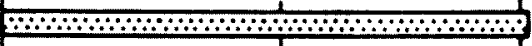

A.

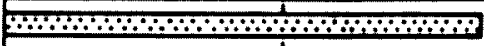

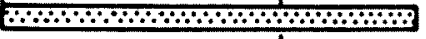

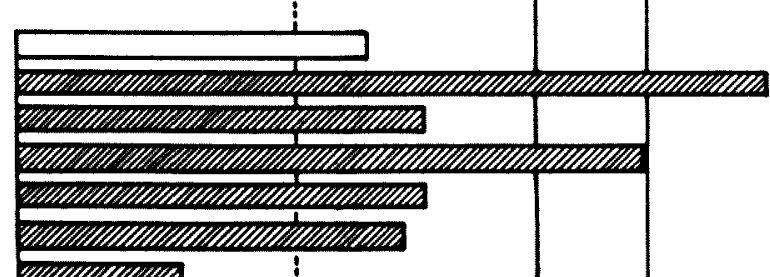

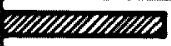

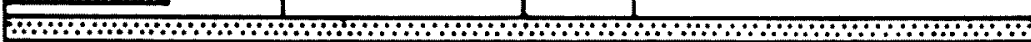

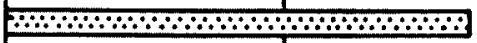

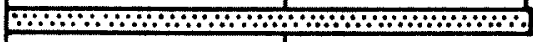

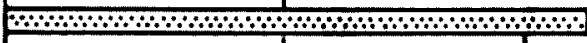

10ن \%

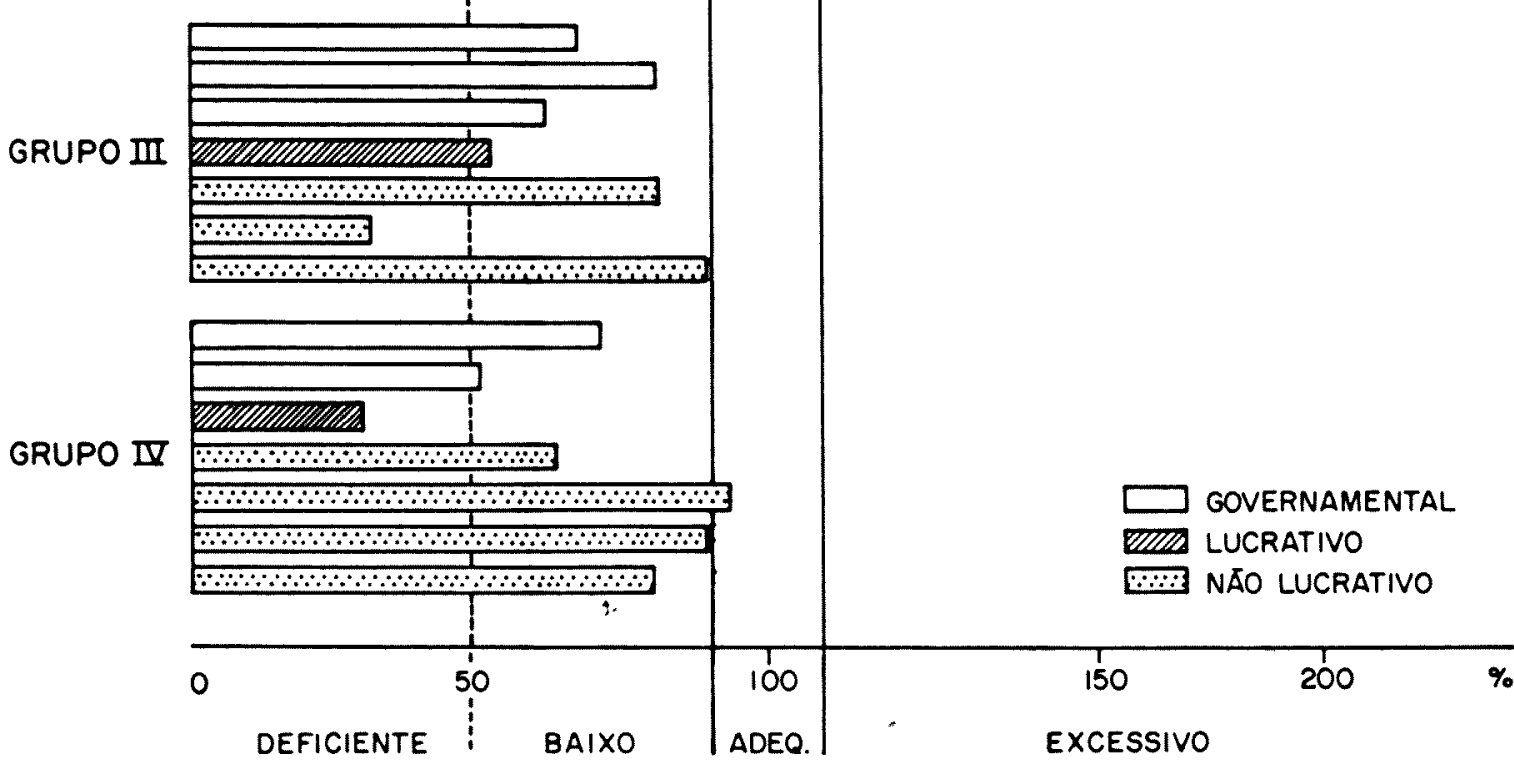


distribuição das refeições e sistema de higienização. Outros autores já haviam alertado para o mesmo problema; além de mencionarem esses mesmos fatores, advertiram que outros também poderiam influenciar, tais como: taxa de ocupação hospitalar, porcentagem de dietas modificadas, treinamento em ser viço, jornada de trabalho e o tipo de serviço oferecido. ${ }^{13,18,46}$

Esses fatores, que chamaremos de intervenientes, po dem ser diretos e indiretos. Os primeiros, quando influem di retamente no número de pessoal necessārio ao SND e os indire tos, quando dependem, principalmente, da qualidade do serviఢ̧०.

Os fatores intervenientes diretos considerados foram: taxa de ocupação hospitalar, categoria do paciente internado, tipos de cardāpio, sistema de distribuição das refei ções e sistema de higienização dos utensílios.

Os fatores intervenientes estudados foramplanta fí sica, equipamentos e qualidade do pessoal.

\subsubsection{Fatores INTERVEn IENTES DiRETOS}

\subsubsection{TAXA DE OCUPAÇÃO HOSPITALAR}

A taxa de ocupação poderia ser um dos fatores que alguns autores creem interferir no número dos funcionários do SND. 18,46 Apesar das flutuações que ocorrem na taxa de ocupação, os hospitais mantém seu quadro de pessoal completo. Segundo Halter ${ }^{18}$, o tempo de serviço dos funcionārios é usado mais eficientemente quando a taxa de ocupação é de $85 \%$ ou mais.

Na Tabela 16 podemos observar que a taxa de ocupação variou de 65 a 938 nos hospitais governamentais; de 60 a 
948 nos hospitais lucrativos e de 60 a 998 nos hospitais não lucrativos. Calculamos os valores médios da taxa e encontramos para os hospitais governamentais, lucrativos e não lucra tivos, respectivamente, $81 \%, 78 \%$ e $74 \%$. Não é supērfluo lembrar que nossos dados referem-se ao periodo de um mês.

Analisando os hospitais quanto ao nivel de adequa ção, encontramos nos hospitais "adequadc" (90-1108) taxas de ocupação que variaram de 668 a 928 , sendo 2 no intervalo de 608 a 698, 4 na de 708 a 798, 2 na de 808 a 898 e 2 na de $90 \%$ a $100 \%$. No grupo de hospitais com nível de adequação "de ficiente"(abaixo de 50\%), encontramos, paradoxalmente, as maio res taxas de ocupação hospitalar, que variaram de 80 a $99 \%$, ( 1 hospital com valor de $80 \%$ e os demais acima de 90\%). Os hospitais com nível "escessivo" (acima de 110\%)apresentaram valores que variaram de $60 \%$ a $94 \%$, sendo a maioria encon trada no intervalo de $70 \%$ a $79 \%$. Os hospitais com nível "baixo" (de 51 - 89\%) apresentaram-se assim distribuídos: 9 no intervalo de 60 a 698 da taxa de ocupação, 7 no de 70 a 798,5 no intervalo de 808 a 898 e 5 na de 90 a 1008 .

Naqueles hospitais com Indices de adequação de 132, 137 e 2238, foram encontradas taxas de ocupação ao redor de 70\%, enquanto nos hospitais com indices de adequação ao redor de $308(28,31$ e 338$)$ foram encontradas as maiores taxas de ocupação $(91,99$ e 808$)$. Dos dados, observa-se não ter hạ vido relação entre a taxa de ocupação e o número de pessoal existente nos SND. . 


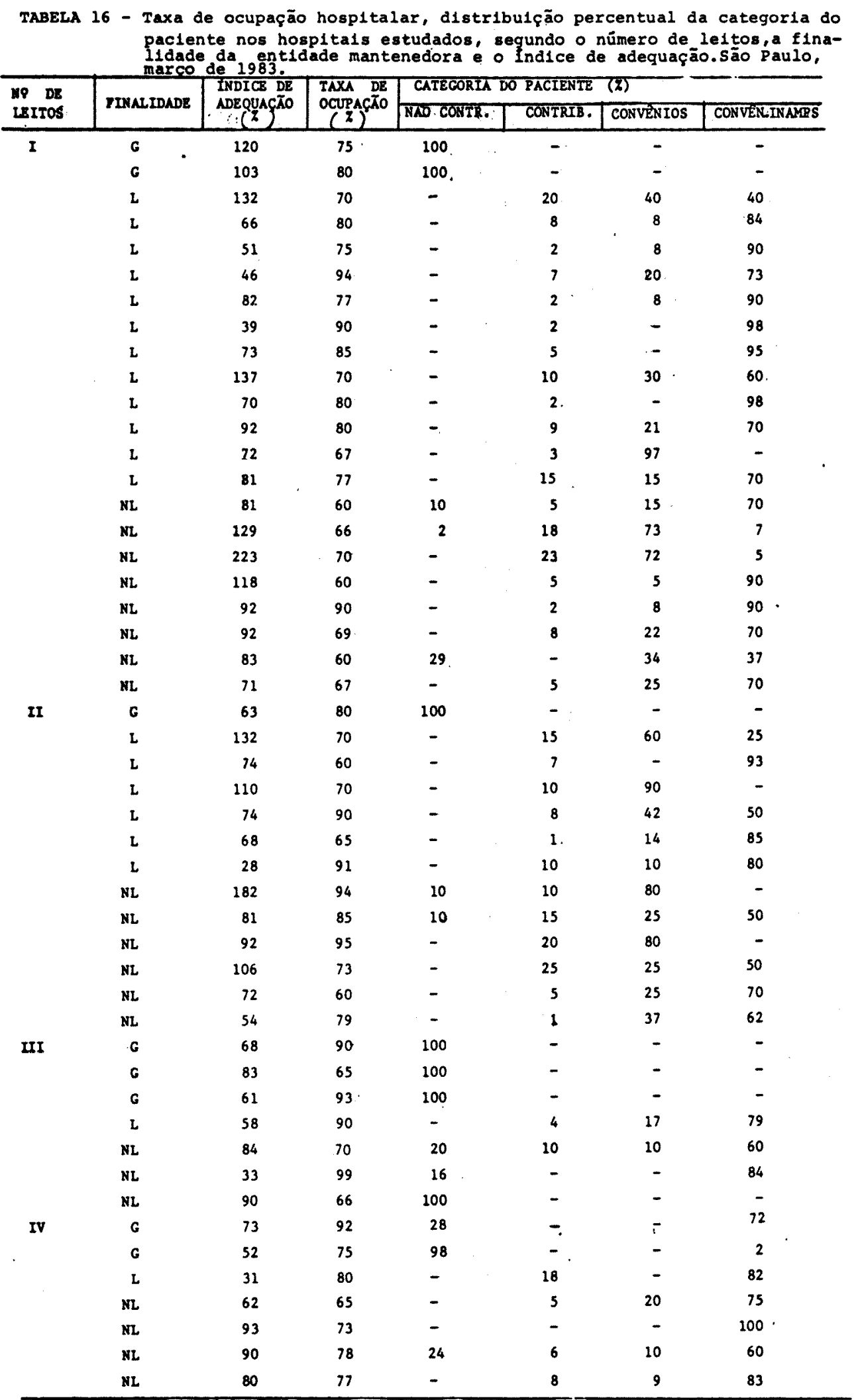




\section{3,1,2. Categoria do paciente internado}

Segundo Passos, ${ }^{33}$ o tipo de serviço oferecido pe lo SND variará de acordo com o paciente atendido,preconizando serviços diferenciados para pacientes contribuintes, me nos diferenciados para convênios diversos e paciente de convênio com Instituições de previdência social, (atualmente Ins tituto Nacional de Assistência Médica e Previdência Social INAMPS) e um serviço mais simples para pacientes não contribuintes.

Em 5 hospitais estudados 4 governamentais e 1 não lucrativo, consideramos seus pacientes como não contribuintes, muito embora eles paguem indiretamente a assistên cia médico-hospitalar recebida: 2 deles são do INAMPS, 2 atendem a funcionários públicos ( 1 estadual e 1 municipal) e o último presta assistência aos policiais da reserva da Policia Militar do Estado de São Paulo.

Procuramos verificar se as diferentes proporções dos vários tipos de pacientes internados atendidos pelos hos pitais não contribuintes, contribuintes, convênios diversos, convênios INAMPS) fariam com que os SND fossem adequados ou não em pessoal. Observamos, ainda à Tabela 16, que a maioria dos hospitais governamentais atenderam 1008 de pacientes não contribuintes; os hospitais lucrativos atenderam de 1 a $20 \%$ de pacientes contribuintes, de 0 a $98 \%$ de pacientes dos convênios do INAMPS e pelos outros convênios atenderam de 0 a 978. Os hospitais não lucrativos atenderam de 0 a 298 os não contribuintes (com exceção de um hospital que atende somen te militares reformados de 0 a $25 \%$ os pacientes contribuin tes, de 0 a 808 os pacientes oriundos de convênios diversos e os convēnios com o INAMPS de 0 a 1008 
Analisando os hospitais segundo o nivel de adequação, vamos encontrar no nível "adequado", um percentual dos pacientes contribuintes de 0 a $25 \%$, dos convênios diversos de 8 a 908 e dos convênios com o INAMPS uma variação de 50 a 1008, enquanto 2 hospitais atenderam 1008 de pacientes não contribuintes ( 1 governamental e 1 não lucrativo). Com nível "deficiente" encontramos 168 de pacientes não contribuintes em 1 hospital, de 2 a $18 \%$ de pacientes contribuintes, de 10 a 208 oriundos de convênios diversos e do convênio com o INAMPS de 73 a $84 \%$. Nos hospitais com nível "excessivo" encontramos três hospitais com pacientes não contribuintes: 2 não lucrativos (com 2 e 108) e l governamental (1008); o percentual de pacientes contribuintes variou de 5 a 238, o de pacientes com convênios diversos, de 30 a $80 \%$ e os dos convênios com o INAMPS, de 0 a $90 \%$. Os hospitais com nível "baixo" apresenta ram pacientes não contribuintes numa proporção de 90 a 1008 nos hospitais governamentais e de 0 a 298 nos hospitais não lucrativos; a proporção dos contribuintes variou de 1 a $18 \%$ e a dos pacientes de convênios diversos, de 0 a $97 \%$ (hospitais lucrativos) e de 9 a $37 \%$ nos hospitais não lucrativos; quanto aos conveniados com o INAMPS, a proporção variou de 0 a 988 .

Podemos notar que na maioria daqueles hospitais on de o nivel de adequação é superior a 110\%, o atendimento é feito principalmente para pacientes contribuintes e pacientes conveniados com instituições outras que não ○ INAMPS. 0 inverso ocorre naqueles hospitais onde o nivel de adequação do pessoal do SND è considerado "deficiente", ou seja, onde a maioria dos pacientes pertence ao convênio com o INAMPS. Queremos acrescentar que, na época da coleta de dados, obser vamos em hospitais que atendiam clientela em proporção supe- 
55.

rior a $60 \%$ de filiados ao INAMPS, que eram servidas a estes apenas 3 refeições diārias, enquanto aos pacientes contribuintes, 5 refeiçōes ao dia. Talvez por esse motivo, o número de funcionārios dos SND seja inferior ao que calculamos.

\section{$5,3,1,3$. TIPOS DE CARDÁPIO}

O cardápio determina o tipo de alimento a ser preparado, o equipamento e o pessoal necessārio para sua confec ção. Uma diversificação nos tipos de cardápio trará a necessidade de maior número de pessoal, equipamentos mais sofistí cados, maior quantidade e variedade de alimentos. 50

Os cardāpios deverão ser planejados dentro das nor mas nutricionais, adequando-os às necessidades dos individuos, aos seus hábitos alimentares e às suas condições de saúde. Tambēm tem que se levar em conta os recursos financei ros disponíveis em cada instituição e o estilo do serviço. 33,50

A Tabela 17 podemos observar que os cardápios mais usados para a dieta normal eram do tipo popular. Dos 49 hospitais estudados, 33 serviços $(67,38)$ o utilizaram (7 G, 15 L e $11 \mathrm{NL}$ ), enquanto $9(18,48)$ utilizaram o tipo médio ( $1 \mathrm{G}$, $4 \mathrm{~L}$ e $4 \mathrm{NL}) ; 5$ hospitais $(10,28)$ utilizaram os três tipos de cardäpio, simultaneamente $(4 \mathrm{G}$ e 1 L) e $2(4,1 \%)$ utilizaram apenas o tipo luxo ou liberal (ambos NL).

Analisando os hospitais quanto ao indice de adequa ção do pessoal do SND, encontramos nos hospitais de nivel "adequado" uma predominância dos cardápios do tipo popular, pois dos 10 hospitais, 7 usaram o popular, 1 o médio, 10 li beral e 1 fornecia os três tipos de cardāpio. Nos hospitais com nivel "deficiente", todos usávam o tipo popular. Naqueles hospitais com nível "excessivo", 3 forneciam os três ti- 
pos de cardápio, 2 forneciam o tipo médio, 2 o tipo popular e 1 o tipo liberal. Nos hospitais com nível "baixo", 19 forneciam o cardápio popular, 6 o médio e 1 os três tipos.

Pelos resultados, podemos dizer que o tipo de cardápio representa um fator importante para o cálculo do pessoal necessário para O SND; quanto mais diversificado for, maior a necessidade de pessoal adequado para as vārias prepa raçōes. PASSOS ${ }^{33}$ dá exemplos de algumas preparações nos diversos cardāpios a serem utilizados na dieta normal (já que as dietas modificadas requerem um planejamento à parte) e, segundo a Autora, um hospital, mesmo de grande porte, poderá ter condições de realizar um planejamento dos três tipos de cardápio ao dia e oferecer, assim, um serviço mais requintado.

Os hospitais com niveis "excessivos" foram aqueles que apresentaram maior variação nos tipos de cardápio, sendo o tipo popular encontrado em apenas 2 deles. E interessan te notar que são todos hospitais dos Grupos I e II, portanto, hospitais de menor capacidade de leitos. Encontramos em apenas 1 hospital do Grupo IV, a utilização dos três tipos de cardápio. Além disso, nos hospitais de nível "adequado" foi onde encontramos o outro cardápio do tipo liberal e 1 fornecendo os três tipos de cardápio, o que vem reforçar que, pa ra a utilização de vários tipos de cardápio ao dia, necessita-se de um número de funcionārios adequado à diversificação na produção. 
TABELA 17 - Tipos de cardápio, sistema de distribulçāo das refeiçōes e o sistena de higlenlzaçāo dos utensilios nos hospltals estudados, segundo o número de leitos, a finalidade da entidade mantenedora e indice de ade quaçäo. säo paulo, março de 1983.

\begin{tabular}{|c|c|c|c|c|c|c|c|c|c|c|c|}
\hline \multirow{2}{*}{$\begin{array}{l}\text { NP DE } \\
\text { LITOS }\end{array}$} & \multirow{2}{*}{ FINALIDADE } & \multirow{2}{*}{$\begin{array}{c}\text { INDICE DE } \\
\text { ADEQUAÇÃO } \\
(X)\end{array}$} & \multicolumn{2}{|c|}{ IIPOS DE } & \multicolumn{2}{|l|}{ CARDRPIO } & \multicolumn{3}{|c|}{ SISTEMA DISTRIBUIC,ĀO } & \multicolumn{2}{|c|}{ SISTEMA HICIENIZACCTC } \\
\hline & & & POPULAR & Medo & LIBERAL/LUXO & OS TRES & CENTRALIZADO & DESCENTR. & MSTO & CENTRALIZADO & DESCEMTR. \\
\hline \multirow[t]{22}{*}{1} & c & 120 & $x$ & - & - & - & $x$ & - & - & - & $\mathbf{x}$ \\
\hline & 6 & 103 & $x$ & - & - & - & - & - & $x$ & $=$ & $\mathrm{x}$ \\
\hline & $\mathbf{L}$ & 132 & $\bar{x}$ & - & - & - & $\mathbf{x}$ & - & - & - & $\mathbf{x}$ \\
\hline & $\mathbf{\imath}$ & 66 & $\bar{x}$ & - & - & - & $=$ & - & $\mathbf{x}$ & - & $\mathbf{x}$ \\
\hline & $\bar{L}$ & 51 & $=$ & $\mathbf{x}$ & - & - & $x$ & - & $=$ & - & $\mathbf{x}$ \\
\hline & $\mathbf{L}$ & 46 & I & $=$ & - & - & $=$ & - & $\mathbf{x}$ & $\mathbf{x}$ & $=$ \\
\hline & i & 82 & $\mathbf{x}$ & - & - & - & - & $\mathbf{x}$ & $=$ & $=$ & $\mathbf{x}$ \\
\hline & $\mathbf{L}$ & 39 & $\mathrm{x}$ & - & - & - & $x$ & $=$ & - & - & $\vec{x}$ \\
\hline & $\mathbf{L}$ & 73 & $\bar{x}$ & - & - & - & - & $\mathbf{x}$ & - & - & $\bar{x}$ \\
\hline & L & 137 & $=$ & $x$ & - & - & - & & $x$ & - & $x$ \\
\hline & L & 70 & $x$ & - & - & - & - & - & $x$ & $x$ & - \\
\hline & $\mathrm{L}$ & 92 & $x$ & - & - & - & - & $\mathbf{x}$ & - & - & $x$ \\
\hline & 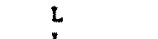 & 72 & $=$ & $x$ & - & - & - & - & $x$ & - & $\bar{x}$ \\
\hline & $\mathbf{L}$ & 81 & $x$ & - & - & - & - & - & $x$ & - & $\bar{x}$ \\
\hline & $\mathrm{ML}$ & 81 & $x$ & - & $=$ & - & $x$ & - & - & $x$ & - \\
\hline & $\mathrm{NL}$ & 129 & - & - & $\mathbf{x}$ & - & $x$ & - & - & $x$ & - \\
\hline & M & 223 & $=$ & - & - & $x$ & - & $x$ & - & - & $x$ \\
\hline & $\mathbf{x L}$ & 118 & - & $x$ & - & - & - & $x$ & - & $x$ & $=$ \\
\hline & $\mathbf{~} \mathbf{L}$ & 92 & $x$ & $=$ & - & - & $x$ & $=$ & $=$ & $\bar{x}$ & - \\
\hline & $\mathbf{n}$ & 92 & $x$ & - & - & - & $=$ & - & $x$ & $=$ & $x$ \\
\hline & $\mathrm{sz}$ & 83 & $x$ & - & - & - & - & I & $=$ & - & $i$ \\
\hline & $\mathrm{VI}$ & 71 & $x$ & - & - & - & - & - & $x$ & - & $\bar{x}$ \\
\hline \multirow[t]{13}{*}{ II } & G & 63 & $x$ & - & - & - & - & $x$ & $=$ & - & $x$ \\
\hline & L & 132 & $=$ & - & - & $x$ & $x$ & - & - & - & $\mathrm{I}$ \\
\hline & $i$ & 74 & $x$ & - & - & - & $=$ & I & - & - & $x$ \\
\hline & $i$ & 110 & - & $x$ & - & $=$ & $x$ & - & $=$ & $=$ & $x$ \\
\hline & $i$ & 74 & $\mathrm{I}$ & $=$ & - & $=$ & $x$ & - & - & $=$ & $x$ \\
\hline & I & 68 & $x$ & - & - & $=$ & $=$ & $x$ & $=$ & $=$ & $x$ \\
\hline & L & 28 & $x$ & - & - & - & - & $=$ & $x$ & - & $\bar{x}$ \\
\hline & wL & 182 & $=$ & & - & $x$ & $x$ & - & $=$ & $x$ & $=$ \\
\hline & $\mathrm{NL}$ & 81 & - & $x$ & - & $=$ & $=$ & - & $x$ & $=$ & I \\
\hline & ML & 92 & - & $=$ & $\mathbf{x}$ & - & - & - & $\bar{x}$ & - & $\vec{x}$ \\
\hline & $\mathrm{NL}$ & 106 & $x$ & - & $=$ & - & - & - & $\bar{x}$ & $x$ & $=$ \\
\hline & $\mathrm{mL}$ & 72 & $=$ & $x$ & - & - & - & - & $\bar{x}$ & $\bar{x}$ & - \\
\hline & $\mathrm{m}$ & 54 & - & - & - & $x$ & - & - & $\bar{x}$ & $x$ & $=$ \\
\hline \multirow[t]{7}{*}{ IIII } & 6 & 68 & $I$ & - & - & - & X & $=$ & - & - & $x$ \\
\hline & G & 83 & 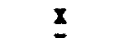 & - & - & - & - & $x$ & $=$ & - & $x$ \\
\hline & 6 & 61 & $\underline{I}$ & - & - & - & - & - & $x$ & - & $\mathbf{z}$ \\
\hline & $\mathbf{L}$ & 58 & $I$ & - & - & - & $=$ & - & $x$ & - & $x$ \\
\hline & $\mathbf{m}$ & 84 & $x$ & - & - & - & $x$ & - & - & $=$ & $x$ \\
\hline & NL & 33 & I & - & - & - & - & $=$ & $x$ & $x$ & - \\
\hline & mL & 90 & $x$ & - & - & - & - & $x$ & $=$ & $x$ & - \\
\hline \multirow[t]{8}{*}{ IV } & c & 72 & $x$ & $\bar{z}$ & - & - & - & $=$ & $x$ & $x$ & $\bar{z}$ \\
\hline & c & 52 & $=$ & $x$ & - & - & - & $x$ & - & $=$ & $x$ \\
\hline & $\mathbf{l}$ & 31 & $x$ & - & - & - & - & X & - & $x$ & $=$ \\
\hline & $\mathbf{m L}$ & 62 & I & - & - & - & - & $=$ & $x$ & - & $x$ \\
\hline & WL & 93 & $\bar{x}$ & - & - & $=$ & - & $x$ & $=$ & - & $y$ \\
\hline & $\mathrm{m}$ & $\begin{array}{l}90 \\
80\end{array}$ & $=$ & $\bar{z}$ & - & x & - & $x$ & $\bar{z}$ & $=$ & $x$ \\
\hline & $\mathrm{gL}$ & 80 & 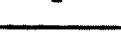 & 1 & 5 & - & - & - & 1 & - & $\boldsymbol{x}$ \\
\hline & TOE TL & & 33. & 9 & 2 & 5 & 13 & 15 & 21 & 14 & 35 \\
\hline
\end{tabular}




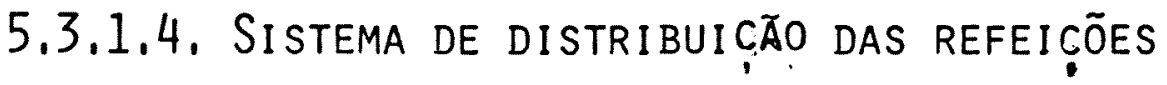 E SISTEMA DE HIGIENIZAÇÃO}

Um bom sistema de distribuição è aquele que permite que o alimento preparado chegue ao seu destino no menor tempo possivel, apresentando-se tal qual saiu do setor de pre paro. A maioria dos serviços procura sempre a melhor maneira de preservar a qualidade do produto final (supondo-se, claro, ter usado matéria prima de boa qualidade). Cada qual procura adaptar seus equipamentos às necessidades do serviço, quer se utilizando de carros térmicos de prateleiras, carros térmicos com recipientes (cada qual para 50 porções), pratos térmicos (baixelas) ou pratos descartáveis; o objetivo é sempre - mesmo: oferecer ao paciente um alimento com características que o tornem aceitável e que preencha sua finalidade.

Essencialmente, existem dois sistemas de distribui ção de refeiçōes: o centralizado e o descentralizado. Enquanto o primeiro requer maior supervisão do nutricionista no setor de preparo - distribuição, o descentralizado requer maior supervisão na unidade de internação. 50

O sistema de distribuição descentralizado seria mais eficiente, segundo Passos, ${ }^{33}$ se pudesse contar com um nutricionista na supervisão das unidades de internação (copas); quando isso não for possível, o problema pode ser solucionado com um sistema de distribuição misto, onde as dietas modifi cadas vêm prontas e identificadas do setor de cozinha dietétí ca (sistema centralizado) e a dieta normal vem no carro tér mico (sistema descentralizado), sendo o porcionamento feito nas unidades de internação (copa).

o sistema de higienização dos utensillios, segundo Passos $^{33}$, segue o mesmo sistema de distribuição das refeições. Para a Autora, no sistema centralizado de distribuição não 
existem copas nas unidades de internação, necessitando, portanto, que a lavagem dos utensilios se dê em uma copa central, geralmente anexada ao refeitório no próprio SND; a execução da lavagem caberá a funcionārios do setor de lavagem de louça. No sistema descentralizado de distribuição, as copeiras lavarão os utensílios nas copas das unidades de internação.

A Tabela 17 podemos observar que o sistema misto de distribuição fol o mais utilizado pelos hospitais estudados pois, dos $49,21(42,98)$ o empregavam; $15(30,68)$ utilizavam o sistema descentralizado e $13(26,5 \%)$ o centralizado. O sis tema de higienização dos utensílios descentralizado foi o mais utilizado pois, dos 49 hospitais, $35(71,58)$ o utilizavam e $14(28,58)$ utilizavam o centralizado.

Analisando o sistema de distribuição dos hospitais segundo o indice de adequação do pessoal do SND, verificamos que dos 10 hospitais com nível"adequado" 4 utilizavam o sistema misto, 4 o sistema descentralizado e 2 o sistema centra lizado. Quanto à higienização nesses 10 hospitais, verificamos que o sistema descentralizado foi usado por 8 hospitais (inclusive um que usava sistema centralizado de distribuição). Nos 5 hospitais com nível "deficiente" encontramos 1 com sis tema centralizado de distribuição, 1 com descentralizado e os demais com sistema misto. Quanto à higienização dos utensilios, 3 deles utilizavam o sistema centralizado e 2 o descentralizado. O único hospital que utilizava o sistema centralizado de distribuição, também usava o centralizado para higienização dos utensilios. Nos 8 hospitais com nível "excessivo", 5 utilizavam o sistema centralizado de distribuição dos alimentos, 2 o sistema descentralizado e 1 o sistema misto. Quanto à higienização, 3 hospitais usavam o sistema centralizado e 5 o descentralizado. Quanto aos 26 hospitais 
com nivel "baixo", 13 utilizavam o sistema misto, 8 utilizavam o sistema descentralizado e 5 o sistema centralizado.Quan to à higienização, o sistema mais utilizado foi o descentralizado ( 21 hospitais). Dos 5 hospitais que utilizavam o sistema centralizado de distribuição, apenas um utilizou o sistema centralizado de higienização; os demais utilizavam o sistema descentralizado.

Portanto, nem todos os hospitais que empregavam 0 sistema centralizado de distribuição, usavam o sistema centralizado de higienização; o inverso também se verificou. Os hospitais que utilizavam sistema. centralizado para distribui ção e higienização eram dos Grupos I e II e só um deles tinha nível de adequação de pessoal classificado como "excessí vo".

\subsubsection{FATORES INTERVEN IENTES INDIRETOS $5,3,2,1$. Planta física}

Segundo alguns autores, 25,50 a ārea física teria que ser planejada levando-se em consideração: o número de re feições servidas, o tipo de serviço, a quantidade e o tipo de equipamentos, o número de pessoal a ser requisitado, o es paço para o armazenamento dos alimentos e uma área suficiente para o preparo e distribuição dos alimentos.

A ărea física teria que ser suficiente para propiciar um bom fluxograma do serviço, sem haver estrangulamento em algum setor, proporcionando escoamento rápido do alimento preparado.

Sabemos dos problemas que muitos hospitais enfrentam no momento, pois foram construídos em épocas onde não ha 
via padrōes e normas oficiais de construção para a área físi ca do SND. Procuramos, então, cotejar os valores encontrados nos hospitais estudados com os padrões existentes.

- SND

Verificamos (Tabela 18) que, quanto ao elemento SND, 21 hospitais $(42,88)$ estão dentro do padrão recomendado e $28(57,18)$ fora; desses 21 hospitais, 10 são do Grupo I, 5 do Grupo II, 4 do Grupo III e 2 do Grupo IV. Em relação à fí nalidade da entidade mantenedora, 7 são governamentais, 3 lu crativos e 11 não lucrativos.

Analisando os hospitais segundo o Indice de adequa ção, vamos encontrar, dos 10 hospitais "adequado", apenas a metade dentro do padrão recomendado. Quanto aos 5 hospitais com níveis "deficiente", só um alcançou esse padrão. Nos 8 hospitais com níveis "excessivo", 6 estão dentro do padrão re comendado. Dos 26 hospitais com níveis "baixo", apenas 9 estão dentro do padrão recomendado.

Notamos uma grande diversidade entre as metragens dos SND, não só entre os hospitais pertencentes ao mesmo gru po, como tambēm entre as diferentes entidades mantene doras dentro do mesmo grupo, talvez pela dificuldade de padronização e determinação de padrões mínimos que havia por ocasião de suas construções. O padrão de $1 \mathrm{~m}^{2}$ por leito foi ultrapassado pela maioria dos hospitais governamentais.

\section{- Despensa}

Utilizamos a única recamendação oficial publicada, $20 \mathrm{~m}^{2}$ para todos os grupos estudados. Consideramos a ārea física da despensa e não computados a área física do depósito, existente em muitos SND.

* Código de Edificação de abras. Lei Múnicipal n8 8266, de 20/06/1972, do Município de São Paulo. 
TABELA 18 - Comparação entre os elementos da pläta flsica e os padrōes recomendados* nos hospitals estudados, segundo o nümero do leltos, a finalidade da entidade mantenedora e o indice de adequação. São Paulo, março de 1983 .

\begin{tabular}{|c|c|c|c|c|c|c|c|c|c|c|c|}
\hline \multirow{2}{*}{$\begin{array}{l}\text { NP DE } \\
\text { LEITOS }\end{array}$} & \multirow{2}{*}{ PIMALIDADE } & \multirow{2}{*}{\multicolumn{2}{|c|}{$\begin{array}{l}\text { GNDICE DE } \\
\text { ADEQUAÇĀo } \\
(\bar{Z})\end{array}$}} & \multicolumn{8}{|c|}{ ELEMERTOS DA PLANTA FISICA (AREA FISICA $\mathrm{M}^{2}$ ) } \\
\hline & & & & $\frac{\text { SII }}{\text { REAI }}$ & & $\frac{\text { DESPEN }}{\text { REAL }}$ & & $\frac{\text { REFI }}{\text { REAL }}$ & ORIO & $\frac{\text { SECRETARIA }}{\text { REAL }}$ & $\frac{\text { COPA/U.I.T- }}{\text { REAL }}$ \\
\hline \multirow[t]{22}{*}{$\mathbf{I}$} & G & & 120 & 450 & & 42 & & 88 & - & 18 & 15 \\
\hline & $\mathbf{G}$ & & 103 & 292 & & 23 & & 56 & - & 28 & 14 \\
\hline & $\mathbf{L}$ & & 132 & 217 & - & 8 & - & 58 & & 6 & 9 \\
\hline & $\mathbf{L}$ & & 66 & 64 & • & 10 & - & 43 & & 4 & 4 \\
\hline & $\mathbf{L}$ & & s1 & 100 & - & 18 & - & 66 & & 22 & 13 \\
\hline & L & & 46 & 187 & & 9 & . & 33 & . & 8 & 9 \\
\hline & L & & 82 & 91 & • & 12 & - & 24 & . & 14 & 11 \\
\hline & L & & 39 & 116 & . & 6 & . & 67 & & 10 & 14 \\
\hline & L & & 73 & 119 & • & 7 & • & 67 & & 9 & 20 \\
\hline & L & & 137 & 176 & . & 21 & & 35 & . & 4 & 15 \\
\hline & L & & 70 & 127 & - & 32 & & 37 & & 13 & - \\
\hline & L & 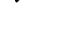 & 92 & 90 & $\therefore$ & 20 & & 105 & & 8 & 8 \\
\hline & L & & 72 & 357 & & 20 & & 47 & • & 12 & 19 \\
\hline & L & & 81 & 82 & - & 6 & - & 71 & & - & 8 \\
\hline & NL & & 81 & 270 & & 31 & & 132 & & 8 & 6 \\
\hline & NL & & 129 & 348 & & 24 & & 135 & & 28 & 16 \\
\hline & NL & & 223 & 438 & & 45 & & 108 & & 10 & 11 \\
\hline & $\mathrm{NL}$ & & 118 & 442 & & 35 & & 60 & & 11 & 18 \\
\hline & NL & & 92 & 120 & • & - & . & 82 & & - & 13 \\
\hline & $\mathrm{NL}$ & & 92 & 444 & & 24 & & 96 & & 16 & 20 \\
\hline & NL & & 83 & 175 & & 7 & • & 72 & & 7 & 14 \\
\hline & NL & & 71 & 86 & . & 15 & . & - & . & 7 & 17 \\
\hline \multirow[t]{13}{*}{ II } & G & & 63 & 210 & - & 23 & & 87 & . & 16 & 7 \\
\hline & L & & 132 & 283 & $\cdot$ & 29 & & 90 & . & 20 & 8 \\
\hline & L & & 74 & 120 & . & 12 & • & 16 & . & - & 10 \\
\hline & L & & 110 & 271 & . & 47 & & 85 & . & 24 & 12 \\
\hline & $\mathbf{L}$ & & 74 & 236 & - & 35 & & 69 & & 5 & 10 \\
\hline & L & & 68 & 133 & . & 5 & . & 64 & . & 2 & 6 \\
\hline & L & & 28 & 121 & . & 32 & & 58 & : & 13 & 11 \\
\hline & NL & & 182 & 511 & & 19 & • & 86 & . & 13 & 12 \\
\hline & NL & & 81 & 174 & . & 14 & - & 31 & . & 16 & 15 \\
\hline & NL & & 92 & 385 & & 52 & & 130 & & 17. & 7 \\
\hline & NL & & 106 & 288 & & 54 & & 120 & & 6 & 20 \\
\hline & NL & & 72 & 129 & • & 7 & • & 70 & & 7 & 9 \\
\hline & NL & & 54 & 570 & & 40 & & 240 & & 17 & 12 \\
\hline \multirow[t]{7}{*}{ II } & G & & 68 & 642 & & 25 & & 220 & . & 86 & 11 \\
\hline & G & & 83 & 473 & & 20 & & 103 & • & 46 & 6 \\
\hline & G & & 61 & 630 & & 22 & & 565 & & 45 & 22 \\
\hline & $L$ & & 58 & 98 & • & 16 & . & 55 & • & - & 4 \\
\hline & NL & & 84 & 183 & . & 22 & & 144 & & 7 & 8 \\
\hline & NL & & 33 & 358 & . & 20 & & 42 & . & 7 & 12 \\
\hline & NL & & 90 & 746 & & 24 & & 203 & & 25 & 21 \\
\hline \multirow[t]{7}{*}{ IV } & $G$ & & 72 & 1675 & & 20 & & 297 & • & 167 & 15 \\
\hline & G & & 52 & 2219 & & 82 & & 451 & . & 133 & 25 \\
\hline & $L$ & & 31 & 161 & . & 36 & & 202 & & 7 & 15 \\
\hline & NL & & 62 & 864 & - & 54 & & 365 & & 53 & 18 \\
\hline & NL & & 93 & 398 & - & 20 & & 80 & - & 23 & 21 \\
\hline & NL & & 90 & 770 & - & 103 & & 255 & - & 40 & 26 \\
\hline & NL & & 80 & 531 & $\cdot$ & 36 & & 320 & & 24 & 30 \\
\hline \multirow{2}{*}{ TOIAL } & DENTRO DO P & PADRÃOO & $\begin{array}{l}\mathrm{N} \\
\mathrm{Z}\end{array}$ & & $\begin{array}{c}21 \\
(42, \theta)\end{array}$ & & $\begin{array}{c}32 \\
(65,3)\end{array}$ & & $\begin{array}{c}26 \\
53,1)\end{array}$ & $\begin{array}{c}32 \\
(65,3)\end{array}$ & $\begin{array}{c}41 \\
(83,7)\end{array}$ \\
\hline & ABAIXO DO P & PADRÃO & N & & $\begin{array}{c}28 \\
(57,1)\end{array}$ & & $\begin{array}{c}17 \\
(34,7)\end{array}$ & & $\begin{array}{c}23 \\
46,9)\end{array}$ & $\begin{array}{c}17 \\
(34,7)\end{array}$ & $\begin{array}{c}8 \\
(16,3)\end{array}$ \\
\hline
\end{tabular}

* Padräo recomendado descrito aa metodologia.

- velor real abaixo do padräo recomendado.

In U.I. - Doidade de Internaçäo. 
Dos 32 hospitais $(65,38)$ (Tabela 18) dentro do padrão recomendado, 11 são do Grupo I, 8 do Grupo II, 6 do Grü po III e 7 do Grupo IV. Considerando a finalidade da entidade mantenedora, encontramos 8 hospitais governamentais, 9 lu crativos e 15 não lucrativos.

Segundo o Indice de adequação, vamos encontrar nos 10 hospitais "adequado", 9 dentro do padrão recomendado. Dos 5 hospitais com nível "deficiente", 3 atingiram o padrão recomendado. Nos 8 hospitais com nível "excessivo", 6 alcançaram o padrão. Nos 26 hospitais com nível "baixo", encontramos 14 dentro do padrão. Houve uma grande variedade nas metragens, desde aqueles que não atingiram o padrão atē aqueles que o ultrapassaram em 5 vezes seu valor. Cremos que esse padrão talvez seja insuficiente para hospitais com mais de 350 leitos, porque não atende a necessidade de espaço ade quado para o armazenamento dos alimentos.

\section{- Refeitório}

No elemento refeitório surgiram dúvidas quanto à metragem recomendada pela Ministério da Saúde, ${ }^{31}$, pois se fôssemos aplicā-la na íntegra, não encontraríamos nenhum ser viço de Nutrição e Dietética dentro desse padrão. Pensando assim, adotamos o critério de $1 \mathrm{~m}^{2}$ por comensal e por turno, que é o preconizado na CLT. ${ }^{11}$

A Tabela 18 podemos observar que 26 hospitais $(53,1$ 웜 estudados alcançaram $\circ$ padrão recomendado e $23(46,98)$ não $\circ$ atingiram. Desses 26, 15 são do Grupo I, 5 do Grupo II, 3 do Grupo III e 3 do Grupo IV. Quanto à finalidade da entidade mantenedora, 1 é governamental, 10 são lucrativos e 15 não 1u crativos. 
Analisando hospitais quanto ao Indice de adequação, encontramos nos 10 hospitais "adequado", 6 que alcançaram o padrão; dos 5 hospitais com nÍvel "deficiente", 2 alcançaram - padrão; nos 8 hospitais com nível "excessivo", 4 atingiram - padrão. Dos 26 hospitais com nivel "baixo", encontramos 14 dentro do padrão.

Apesar de adotarmos para o elemento refeitório o sistema por turnos, 11 muitos hospitals não atingiram esse padrão $(7 \mathrm{G}, 10 \mathrm{~L}$ e $6 \mathrm{NL})$, e 1 deles não tinha sequer esse elemento. Pela $\mathrm{CLT}^{\star}$ é obrigatōria a existência de refeitório em todo estabelecimento onde trabalhem mais de 300 funcionários, para seu conforto na hora das refeições.

- Secretaria

Não existe nenhuma recomendação oficial para secre taria. Utilizamos a metragem de $8 \mathrm{~m}^{2}$ (para encarregada do Lactārio) que é insuficiente; no entanto, poderá caracterizar os hospitais que possuem esse elemento.

A Tabela 18 podemos verificar que 32 hospitais $(65,38)$ alcançaram o padrão e $17(34,78)$ não o atingiram;des ses 32 hospitais, 15 são do Grupo I, 8 do Grupo II, 3 do Grü po III e 6 do Grupo IV. Segundo a entidade mantenedora, 8 de les são governamentais, 11 lucrativos e 13 não lucrativos.

Analisando os hospitais quanto ao Indice de adequa ção, vamos encontrar 7 hospitais dentro dos padrões recomendados, dos 10 hospitais considerados "adequado". Nos hospitais com nível "deficiente", 3 alcançaram o padrão. Dos 8 hos pitais com nivel "excessivo", 6 alcançaram o padrão recomendado. E dos hospitais, com nivel "baixo", encontramos 16 .

* Portaria no 13, de 6 de junho de 1972. Dispõe sobre a insta lação de refeitórios. (D.O.U. 7/7/1972). 
Apesar do padrão ser destinado a hospitais com até 150 leitos, 17 hospitais não o atingiram. Observamos que os hospitais governamentais acima de 350 leitos foram os que apresentaram a maior área física para esse elemento.

- Copa (unidade de internação)

Pelo Ministērio da Saúde ${ }^{31}$ a área destinada à copa especifica que se destina a hospitais de até 150 leitos e o Código de obras da Prefeitura de são Paulo*, embora adotando a mesma metragem nem se refere à capacidade de leitos do hospital.

Embora alguns autores, como PASSOS ${ }^{33}$ considerem que no sistema de distribuição centralizado não haveria necessidade de existência de copas nas unidades de internação, encontramos na maioria dos hospitais com serviço centraliza do, copas nas unidades de internação.

Observamos à Tabela 18 que 41 hospitais $(83,6 \%$ al cançaram o padrão recomendado, enquanto $8(16,3 \%)$ não o atin giram. Desses 41 hospitais, 19 são do Grupo I, 10 do Grupo II, 5 do Grupo III e 7 do Grupo IV. Quanto à Finalidade da entidade mantenedora, esses hospitais estão assim distribuídos: $6 \mathrm{G}, 16$ L e $19 \mathrm{NL}$.

Analisando os hospitais quanto ao indice de adequa ção, encontramos, dos 10 hospitais com nível "adequado", 9 hospitais dentro dos padrões recomendados. Nos 5 hospitais com nivel "deficiente", todos apresentaram-se dentro do padrão; o mesmo ocorreu com todos os hospitais com nivel "excessivo". Dos 26 hospitais com nível "baixo", encontramos 19 hospitais dentro das recomendações.

* Código de Edificações de Obras: Lei Municipal n8 8266, de 20 de junho de 1975 . 
Embora a ārea física possa não influenciar a quali dade do serviço, ela é de extrema importância para possibilí tar um bom fluxograma, ocasionando bom rendimento do traba1ho. Pelo que vimos, os elementos SND e refeitório foram os que tiveram maior proporção de casos fora dos padrões, mesmo entre os hospitais com níveis de pessoal "adequado" e "exces sivo".

\section{3 .2 .2 . EQUi PAMENTOS}

Este trabalho não tem a intenção de generalizar a quantidade e o tipo de equipamentos necessários para o Servi ço de Nutrição e Dietētica, mas sim observar se eles têm alguma influência no cálculo do dimensionamento de pessoal.

As necessidades de equipamentos irão variar com os tipos de cardápio a serem servidos, a forma como os alimentos serão preparados, o número e o tipo de comensais, 0 estilo do serviço, o número de horas/homem disponíveis e os recursos financeiros que dispõem as instituições.' 25,50

Para verificar esse elemento da qualidade do sex viço, valemo-nos de padrões oficiais ${ }^{30}$ e aqueles não oficiais $^{29,33}$ que podem ser considerados apenas recomendações.Há equipamentos que podem ser classificados como básicos, que deverão estar presentes em todos os serviços, havendo apenas variação no número e na capacidade dos mesmos, na dependência do porte dos hospitais.

Na Tabela 19 poderemos observar que os equipamentos mais frequentes encontrados nos hospitais estudados foram: extrator de sucos $(91,8 \%)$ - 4 serviços não o possuiam; cortador de frios $(81,68)$ - 9 serviços não o possuiam; descascador de tubérculos $(81,6 \%)-6$ não os têm no serviço e 3 


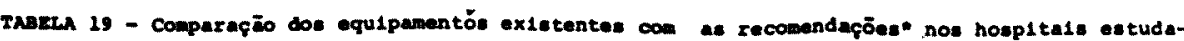

dos, segundo antidade mantenedora, o nümero de leiton - o Indice de adequaģäo.

säo Paulo, março do 1983.

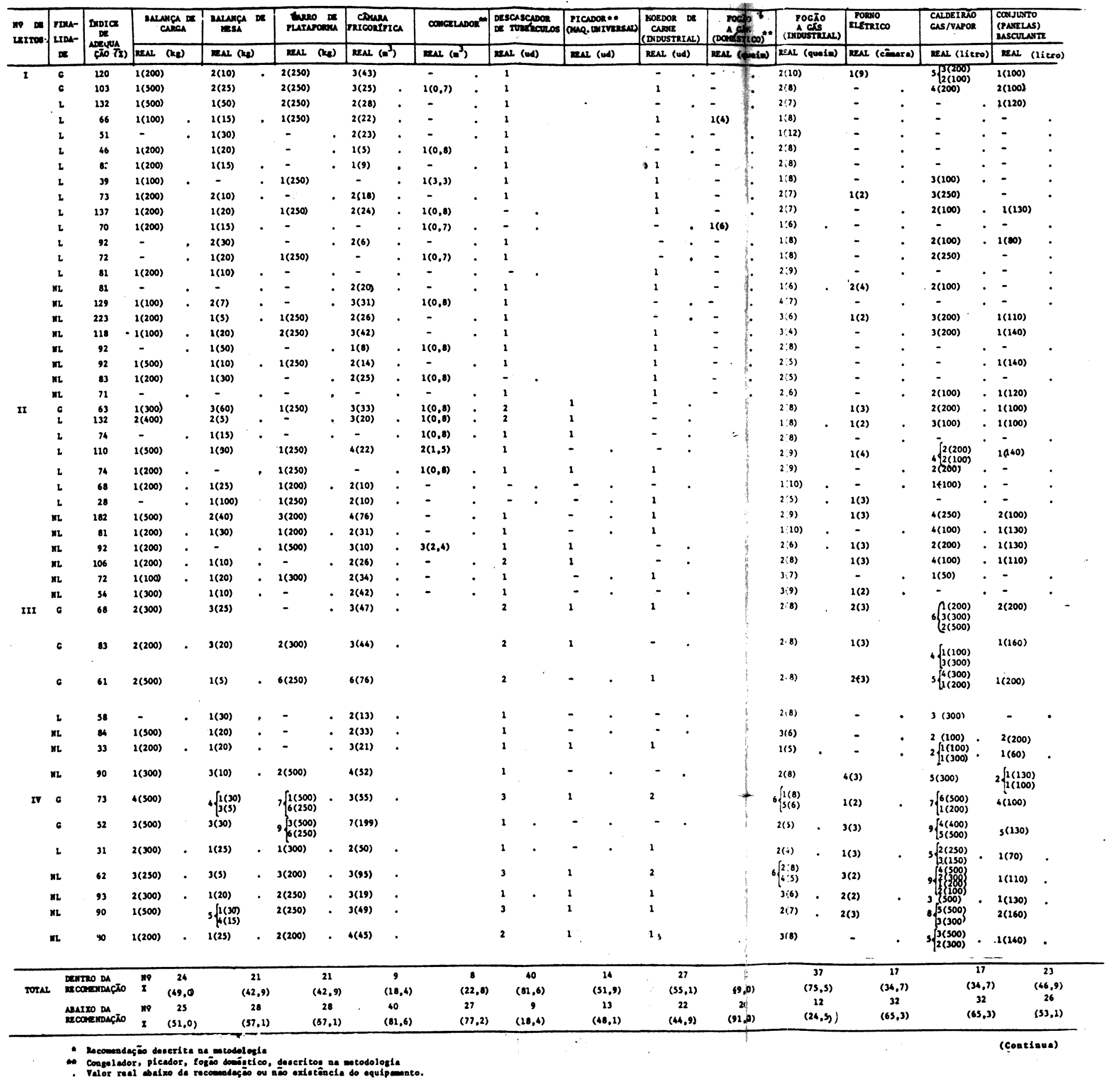


68.

TAssLu 19 (Continuação)

\begin{tabular}{|c|c|c|c|c|c|c|c|c|c|c|c|c|c|c|c|c|c|c|}
\hline \multirow{2}{*}{$\begin{array}{ll}\text { we } & \text { dE } \\
\text { Leitos }\end{array}$} & \multirow{2}{*}{$\begin{array}{c}\text { manil } \\
\text { ande }\end{array}$} & \multirow{2}{*}{$\begin{array}{c}\text { Inptce } \\
\text { of } \\
\text { apgoungio } \\
(x)\end{array}$} & \multirow{2}{*}{ 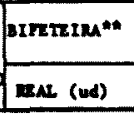 } & \multirow{2}{*}{ 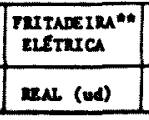 } & \multirow{2}{*}{ 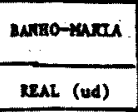 } & \multirow{2}{*}{ 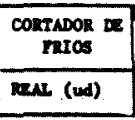 } & \multirow{2}{*}{ 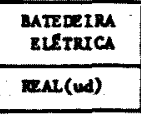 } & \multirow{2}{*}{ 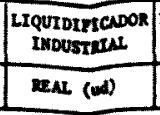 } & \multirow{2}{*}{\multicolumn{2}{|c|}{\begin{tabular}{|c|}
$\begin{array}{c}\text { LIQUIDIYICADOR } \\
\text { DOFIESTICO }\end{array}$ \\
REAL (Ud) \\
\end{tabular}}} & \multirow{2}{*}{\begin{tabular}{|c|}
$\begin{array}{c}\text { ExTuTOR DE } \\
\text { sucos }\end{array}$ \\
ERAL (Ud) \\
\end{tabular}} & \multirow{2}{*}{\begin{tabular}{|l|} 
caretrira \\
REAL (Ij tro) \\
\end{tabular}} & \multicolumn{2}{|c|}{$\begin{array}{c}\text { CArRo } \\
\text { IERrICO }\end{array}$} & $\begin{array}{c}\text { CARzo } \\
\text { PRuTruxira }\end{array}$ & $\begin{array}{l}\text { intcīo } \\
\text { Inncico }\end{array}$ & $\begin{array}{l}\text { RRITURAdoon } \\
\text { fe REstovos }\end{array}$ & $\begin{array}{l}\text { MRQVUIXA DE } \\
\text { LVVAR LOVGA }\end{array}$ \\
\hline & & & & & & & & & & & & & neas. & (ud) & Rens (ud) & $\operatorname{pesc}(u d)$ & REAL (Ud) & REN (ud) \\
\hline I & c & 120 & & & - & 1 & $1(20)$ & $1(6)$ & $2(1,5)$ & & 2 & $2\left\{\begin{array}{l}1(50) \\
1(50)\end{array}\right.$ & 5 & & 12 & 1 & 1 & 1 \\
\hline & c & 103 & & & 2 & 1 & $1(20)$ & $2(6)$ & - & . & 1 & $1(50)$ & 1 & & 10 & 1 & - & 1 \\
\hline & $\mathbf{L}$ & 132 & & & 1 & 1 & + & 1(6) & - & : & 1 & - & 4 & & 9 & 1 & - & - \\
\hline & ᄂ & 66 & & & - & 1 & - & $1(6)$ & $1(1,5)$ & . & 1 & - & 2 & & 3 & 1 & - & - \\
\hline & 2 & 51 & & & . & - & - & $1(8)$ & - & . & 1 & : & 4 & & 1 & 1 & - & - \\
\hline & 2 & 46 & & & . & 1 & - & - & $1(1,5)$ & . & 1 & - & 4 & & 4 & 1 & - & 1 \\
\hline & 2 & 82 & & & . & - & . & $2(6)$ & - & . & 1 & - & 4 & & 4 & - & - & - \\
\hline & $\mathrm{L}$ & 39 & & & . & - & . & $1(6)$ & - & . & 1 & - & 2 & & 3 & 1 & - & - \\
\hline & L & 73 & & & . & 1 & $1(20)$ & $1(6)$ & $1(1,5)$ & . & 1 & - & 4 & . & 9 & 2 & - & - \\
\hline & L & 131 & & & 1 & 1 & $I(20)$ & $1(6)$ & - & . & 2 & - & 2 & & 4 & 1 & - & 1 \\
\hline & L & 70 & & & - & - & $1(20)$ & $1(6)$ & - & . & 1 & $1(30)$ & 4 & & 3 & - & - & - \\
\hline & 2 & 92 & & & 1 & 1 & - & $3(15)$ & $1(1,5)$ & - & 1 & - & 1 & . & 2 & 1 & - & - \\
\hline & L & 72 & & & $\cdot$ & 1 & - & $1(15)$ & - & • & 1 & $I(50)$ & 2 & & 2 & - & - & 1 \\
\hline & $\mathbf{L}$ & 81 & & & - & 1 & - & $1(12)$ & - & - & 1 & - & 3 & & 3 & 1 & - & - \\
\hline & $\mathrm{n}$ & 81 & & & - & 1 & $1(15)$ & $1(6)$ & $1(1,5)$ & . & 1 & $1(30)$ & - & . & 6 & 1 & 1 & 1 \\
\hline & $\mathrm{m}$ & 129 & & & - & 1 & $2(20)$ & $3(6)$ & $3(1,5)$ & & 1 & - & 10 & & 5 & 1 & 1 & 1 \\
\hline & $\mathrm{xL}$ & 223 & & & 1 & 1 & $1(20)$ & $1(6)$ & $=$ & . & 2 & $1(50)$ & 5 & & 1 & 1 & 2 & 1 \\
\hline & NL & 218 & & & 1 & - & - & $1(6)$ & $2(1.5)$ & & 1 & - & 8 & & - & - & - & - \\
\hline & ML & 92 & & & - & 1 & . & - & $2(1,5)$ & & 1 & - & 2 & & - & - & - & - \\
\hline &. $\mathrm{KL}$ & 92 & & & 1 & 1 & $1(20)$ & - & $1(1,5)$ & . & 1 & $1(50)$ & 2 & & 2 & - & - & 1 \\
\hline & $\mathrm{nL}$ & 83 & & & - & 1 & - & $1(6)$ & - & . & 1 & $2(30)$ & 2 & & 2 & 1 & - & - \\
\hline & $\mathbf{M L}$ & $n$ & & & 1 & - & $1(20)$ & - & $1(1,5)$ & . & . & - & 3 & & 2 & - & - & - \\
\hline II & 6 & 63 & & 2 & + & 1 & $1(20)$ & $2(6)$ & $1(1,5)$ & . & 2 & - & 3 & . & 3 & 1 & - & 1 \\
\hline & t & 132 & & 2 & 8 & 1 & $1(40)$ & $1(6)$ & $3(1,5)$ & & 2 & $2(30)$ & 10 & & 5 & 1 & 2 & - \\
\hline & $\mathrm{L}$ & 74 & & - & - & 1 & - & $1(6)$ & - & . & 1 & $1(30)$ & 7 & & - & - & - & - \\
\hline & L & 110 & & - & - & 1 & $1(20)$ & $1(6)$ & $2(1,5)$ & . & 1 & $1(50)$ & 11 & & 3 & 1 & 4 & 1 \\
\hline & L & 74 & & 1 & 2 & - & $1(20)$ & $1(6)$ & $1(1,5)$ & . & 1 & - & 7 & & 2 & 1 & - & . \\
\hline & L & 68 & & - & 1 & 1 & $1(20)$ & $1(6)$ & $1(1,5)$ & . & - & - & 3 & . & s & 1 & - & - \\
\hline & L & 28 & & - & 2 & - & - & $1(6)$ & $1(1,5)$ & . & - & - & 2 & . & 2 & 1 & - & - \\
\hline & $\mathbf{w}$ & 182 & & 1 & . & 1 & $1(20)$ & $3(15)$ & $6(1,5)$ & & 1 & . & 10 & & , & - & - & 1 \\
\hline & NL. & 81 & & - & . & 1 & - & $1(20)$ & - & . & 1 & $1(50)$ & 3 & . & 8 & 1 & 1 & 1 \\
\hline & ML & 92 & & 1 & 2 & 1 & $1(20)$ & $2(6)$ & $1(1,5)$ & . & 2 & $1(50)$ & 6 & & 8 & 1 & - & 1 \\
\hline & NL & 206 & & 2 & 1 & 1 & $1(20)$ & $1(10)$ & $1(1,5)$ & . & 3 & $1(30)$ & 7 & & s & 1 & 6 & 1 \\
\hline & NL & 72 & & 1 & 1 & 1 & $1(20)$ & $1(6)$ & - & . & 1 & - & 3 & . & $s$ & 1 & - & - \\
\hline & $\mathbf{w r}$ & 54 & & . & - & 1 & $1(20)$ & $2(6)$ & $1(1,5)$ & . & 1 & - & 4 & & 4 & - & - & - \\
\hline III & 6 & 68 & - & . & . & 1 & $1(40)$ & $2(20)$ & $1(2,5)$ & . & 2 & - & 13 & & 17 & 1 & - & 1 \\
\hline & $G$ & 83 & - & . & - & 1 & $1(20)$ & $3(10)$ & - & . & - & $1(50)$ & 9 & . & 12 & 1 & - & 1 \\
\hline & $c$ & 61 & . & . & 2 & 2 & $1(40)$ & $1(6)$ & $3(1,5)$ & & 1 & $\left.2\right|_{1(30)} ^{1(50)}$ & 9 & . & 8 & 2 & - & 2 \\
\hline & $I$ & 38 & . & . & - & - & $1(20)$ & - & $2(1,5)$ & - & 1 & $2\left\{\begin{array}{l}(30) \\
1(30)\end{array}\right.$ & 4 & - & 6 & 1 & - & - \\
\hline & m & 84 & . & . & - & 1 & $1(20)$ & $1(6)$ & $1(1,5)$ & . & 1 & - & 2 & . & 5 & 1 & - & 1 \\
\hline & WL & 33 & . & - & 1 & 1 & $1(20)$ & $1(6)$ & $2(1,5)$ & $\ddots$ & 1 & $3(100)$ & 3 & . & 5 & 1 & - & 1 \\
\hline & wr & 90 & . & . & 1 & 1 & $2(20)$ & $1(6)$ & $3(1,5)$ & & 2 & $2\left\{\begin{array}{l}1(100) \\
1(30)\end{array}\right.$ & 14 & & 25 & 1 & - & 1 \\
\hline IV & $c$ & 73 & . & • & 2 & 1 & $1(40)$ & $3(15)$ & $2(1,5)$ & $\cdot$ & 1 & $1(50)$ & 19 & . & 39 & 1 & 1 & 1 \\
\hline & $c$ & 32 & . & 4 & 1 & 1 & $1(40)$ & $1(10)$ & $1(1,5)$ & . & 1 & $1(50)$ & 38 & & 43 & 1 & - & 1 \\
\hline & 2 & 31 & . & - & 1 & 1 & - & $1(6)$ & - & $\cdot$ & 1 & $1(100)$ & 9 & . & "9 & - & - & 1 \\
\hline & $\mathrm{nL}$ & 62 & I & 2 & 2 & 2 & $4 \sqrt{1}(40)$ & - & $3(1,3)$ & . & 3 & $2(100)$ & 28 & & 60 & 1 & - & 1 \\
\hline & iL & 93 & - & - & . & 1 & $1(50)$. & $1(6)$ & - & . & 1 & $2\left\{\begin{array}{l}1(100) \\
1(50)\end{array}\right.$ & 13 & * & 7 & .1 & 1 & 1 \\
\hline & $\mathbf{m L}$ & 90 & . & - & 2 & 1 & $2(20)$ & $1(20)$ & $s(1,5)$ & & 2 & $2\left[\begin{array}{l}1(100) \\
1(30)\end{array}\right.$ & 24 & . & 2 & 1 & 1 & 1 \\
\hline & xL. & 80 & 1 & 2 & - & 1 & $1(40)$ & $3(6)$ & $3(1,5)$ & . & 1 & (100) & 8 & $\cdot$ & 28 & - & $\cdot$ & . \\
\hline & $\begin{array}{l}\text { Dentro } \\
\text { Reconend }\end{array}$ & $\begin{array}{ll}\text { DA } & \text { No } \\
\text { Açio } & \end{array}$ & $\stackrel{2}{(14,3)}^{2}$ & $\begin{array}{c}11 \\
(40,7)\end{array}$ & $\begin{array}{c}21 \\
(42,9)\end{array}$ & $\begin{array}{c}10 \\
(81,6)\end{array}$ & $\begin{array}{c}23 \\
(46,9)\end{array}$ & $\begin{array}{r}23 \\
(46 .\end{array}$ & & $\stackrel{9}{(18,4)}$ & $\begin{array}{c}45 \\
(91,8)\end{array}$ & $\begin{array}{c}24 \\
(49,0)\end{array}$ & & $\begin{array}{c}32 \\
(65,3)\end{array}$ & $\begin{array}{c}33 \\
(67,4)\end{array}$ & $\begin{array}{c}37 \\
(75,5)\end{array}$ & $\stackrel{8}{(16,3)}$ & $\begin{array}{c}27 \\
(55,1)\end{array}$ \\
\hline TOTAL & $\begin{array}{l}\text { ANArJo D } \\
\text { Recorevid }\end{array}$ & 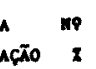 & $\begin{array}{c}12 \\
(05,7)\end{array}$ & $\begin{array}{c}16 \\
(59,3)\end{array}$ & $\begin{array}{c}28 \\
(57,1)\end{array}$ & $\stackrel{9}{(18,4)}$ & $\begin{array}{c}26 \\
(33,4)\end{array}$ & $\begin{array}{r}26 \\
\text { (33. }\end{array}$ & & $\begin{array}{l}40 \\
(81,6)\end{array}$ & $(8,2)$ & $\begin{array}{l}25 \\
(51,0)\end{array}$ & & $\begin{array}{l}17 \\
(34,7)\end{array}$ & $\begin{array}{c}16 \\
(32,6)\end{array}$ & $\begin{array}{c}12 \\
(24,5)\end{array}$ & $\begin{array}{l}41 \\
(83,7)\end{array}$ & $\begin{array}{c}22 \\
(44,9)\end{array}$ \\
\hline
\end{tabular}

- kecomed ación deccrite nat metodologis

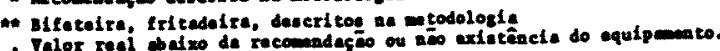


não atingiram a recomendação; fogão a gás industrial $\left(75,5 \frac{8}{)}\right.$ - 12 serviços não alcançaram a recomendação; balcão térmico (cafeteria)-(75,58) - 12 serviços não o têm; carro de pratẹ leira $(67,38)$ - 3 serviços não o têm e 13 não alcançaram a recomendação; carro térmico $(65,0 \%)$ - 1 serviço não o tem e 16 não atingiram a recomendação; liquidificador industrial $(46,9 \%)$ - 5 serviço não o têm e 21 não alcançaram a recomen dação; cafeteira $(49,0 \%)$ - 23 serviços não a têm e 3 não atingiram a recomendação; balança de carga $(49,0 \%)$ - 9 serviços não a têm e 16 não alcançaram a recomendação; liquidificador doméstico $(46,9 \%)$ - 5 não o têm e 21 não alcançaram a recomendação.

Os equipamentos menos freqtentes dentro dessas recomendações foram: bifeteira $(14,3 \%)$, triturador de lixo $(16,3 \%)$, liquidificador doméstico $(18,4 \%)$, câmara frigorífica $(18,4 \%)$, congelador $(22,88)$, caldeirão a vapor/gãs $(34,78)$. Observamos uma variação entre alguns equipamentos existentes, segundo a capacidade dos hospitais;enquan to os hospitais do Grupo I foram os que mais se destacaram pela ausência de equipamento, os hospitais do Grupo IV, embo ra tivessem o equipamento, o tinham em número insuficiente. Os equipamentos em questão foram: balança de carga, carro de plataforma, câmara frigorífica, congelador, forno elétrico, caldeirão a vapor/gás e conjunto de panelas basculantes.

Analisando os hospitais quanto ao Indice de adequa ção, vamos encontrar nos hospitais de nível "adequado" uma frequência semelhante àquela acima citada. (Tabela 19). Os equipamentos são: extrator de sucos, cortador de frios, descascador de tubérculoś, fogão a gás industrial, cafeteira, carro térmico, balcão térmico, panela basculante, batedeira elétrica, máquina de lavar louça, carro de prateleira, moe-- 
dor de carne e balança de mesa. Foram encontrados, em média, 14 equipamentos mais frequlentes (dentro das recomendações). Aque les que menos atingiram as recomendações foram, tambēm, os mes mos já mencionados anteriormente, principalmente câmaras frí gorificas (dos 10 hospitais "adequado", somente 2 alcançaram a recomendação); caldeirão a vapor/gás: dos 10 hospitais, só 4 atingiram a recomendação; triturador de lixo: 3 alcançaram a recomendação, 1 não a alcançou, e em 6 hospitais não havia - equipamento; liquidificador industrial: dos 10 hospitais, só 2 estavam dentro da recomendação; forno elētrico: 4 estavam dentro da recomendação, 1 não a alcançou e 5 não contavam com o equipamento; bifeteira: em nenhum serviço foi encontrado; fritadeira: somente 2 alcançaram a recomendação, 4 não e 4 não a possuiam. Nos 5 hospitais com nível "deficiente", foram encontrados, em média, 8 equipamentos mais freqten tes (dentro das recomendações). São eles: extrator de sucos, moedor de carne, balcão tērmico, māquina de lavar louça, con tador de frios, fogão industrial, liquidificador industrial e carro térmico. Os equipamentos que menos atingiram a recomendação, foram os seguintes: câmara frigorífica: 1 serviço não tem esse equipamento e 4 deles ficaram abaixo da recomen dação; caldeirão a vapor/gãs: 2 serviços não têm e 3 não alcançaram a recomendação; panela basculante: 3 serviços não contam com o equipamento e 2 não atingiram a recomendação; li quidificador doméstico: 2 serviços não têm e 3 não alcançaram a recomendação; bifeteira e fritadeira: nenhum serviço conta com esses equipamentos. Nos hospitais com nivel "exces sivo" foram encontrados, em média, 16 equipamentos mais frequlentes (dentro das recomendações); são eles: extrator de su cos, carro térmico, panela basculante, fogão industrial, des cascador de tubérculos, liquidificador industrial, balcão tér 
mico, batedeira elétrica, balança de plataforma, banho-maria, máquina de lavar louça, liquidificador doméstico, tritụ rador de lixo, caldeirão a vapor/gás, câmara frigorífica e balança de mesa. Os equipamentos menos frequentes dentro das recomendações foram: moedor de carne: 5 hospitais não o possuem; forno elētrico: 1 não alcançou a recomendação e 4 não possuem o equipamento; cafeteira: idem. Os hospitais com nivel "baixo" apresentaram, em média, 10 equipamentos mais frequlentes; são eles: extrator de sucos, descascador de tubérculos, cortador de frios, balcão térmico,fogão industrial, moedor de carne, carro de prateleira, carro térmico, balança de carga, liquidificador industrial e cafeteira. Entre os equipamentos ausentes no serviço ou aqueles que não alcançaram a recomendação, encontramos: triturador de lixo: 24 serviços não o possuem (dos 26 hospitais, 2 alcançaram a recomendação); liquidificador doméstico: 10 serviços não o possuem e 16 não alcançaram a recomendação; câmara frigorífica: 6 serviços não contam com esse equipamento e 17 não alcançaram a recomendação; fritadeira: 11 serviços não a têm (exceção ao Grupo I, pois está acoplado ao fogão) e 8 não alcan çaram a recomendação; bifeteira: 9 serviços não a possuem (ex ceção aos Grupos I e II, pois jā estão acoplados ao fogão); somente 2 hospitais do Grupo IV alcançaram a recomendação.

Todos os hospitais, com exceção daqueles com nível "excessivo" mostraram-se fora das recomendaçōes para alguns equipamentos considerados importantes, destinados ao armazenamento dos gêneros perecíveis (câmara frigorífica e congela dor) e ao preparo dos alimentos (caldeirão a vapor/gás, pane la basculante e forno elétrico). O mesmo não ocorreu com equipamentos destinados ao pré-preparo dos alimentos (descascador de tubérculos, moedor de cárne, liquidificador, extra- 
tor de sucos, cortador de frios) e à distribuição dos alimen tos (balcão térmico e carro tērmico).

E interessante observar que os equipamentos balcão tērmico (cafeteria) e carro térmico, constantes no RECLAR, pelo qual o INAMPS credencia os hospitais para convênio, são mais frequentes em alguns hospitais, em detrimento de equipa mentos usados na cocção (caldeirão a vapor/gás e panela basculante). Encontramos 14 hospitais sem caldeirão a vapor/gās 8 contavam com balcão térmico no refeitório); de 20 hospitais sem panelas basculantes, 14 tinham balcão térmico.Parece que - problema não é a falta de combustivel,uma vez que o balcão também utiliza o mesmo tipo de combustível do panelão e das panelas basculantes. A solução talvez resida numa maior racionalização por ocasião da aquisição dos equipamentos.

Os hospitais com nível "excessivo" apresentaram uma média mais alta de equipamentos indispensáveis ao armaze namento, preparo e distribuição dos alimentos e também equipamentos mais importantes dentro do SND, o que não encontramos, por exemplo, nos hospitais de nivel "adequado" e de nivel "deficiente". Considerando os hospitais quanto à finali dade da entidade mantenedora, não houve diferenças acentuadas entre eles, apesar dos lucrativos apresentarem maior ausência de equipamentos indispensāveis.

\section{3 .2 .3 . QuALIDADE DO PESSOAL}

Qualidade, segundo uma definição de FERREIRA, ${ }^{15}$ sig nifica "a propriedade, atributo ou condição das coisas ou das pessoas capaz de distingui-los das outras e que lhes determina a natureza". De acordo com essa definição, a qualidade do pessoal seria determinada pelas diversas categorias existentes em uma instituição. 
A qualificação do pessoal, no entanto, vai alēm:"é - cabedal de conhecimentos ou atributos que habilitam alguém ao desempenho de uma função". ${ }^{15}$. Segundo essa definição, na qualificação existem certos requisitos essenciais que se exí gem do candidato àquela função e que são elaborados pela pró pria instituição, em decorrência de seus objetivos e necessi dades. $^{35}$

Geralmente não há uma distinção nitida entre esses dois termos, pois muitas vezes são usados indistintamente para designar a qualidade do pessoal. No entanto,eles são diferentes: enquanto o primeiro determina a natureza da fun ção, o segundo apresenta os atributos necessários para que o indivíduo possa exercê-la. A qualidade de pessoal seria dada pela diversificação na categoria das ocupações existentes e a qualificação do pessoal seria uma exigência para se obter - funcionário ideal, principalmente através de títulos (habi litação formal).

A Tabela 20 podemos observar que todos os SND tive ram número adequado de copeiras $(100 \%)$. Dos 44 SND com cozinheiros, somente $21(42,98)$ apresentaram-se dentro do recomendado; destes, pelo menos $18(36,7 \%)$ SND tinham um cozinheiro encarregado. Nutricionista na chefia foi encontrado dentro da recomendação, em 35 hospitais $(71,4 \%)$, enquanto nu tricionista em função técnica foi encontrada em 20 SND, mas somente 2 alcançaram a recomendação. O tēcnico em nutrição foi encontrado em 22 SND mas, dentro da recomendação enquadraram-se $17(34,7 \%)$. A ocupação de escriturário foi verificada em 30 SND, mas apenas $15(30,6 \%)$ deles alcançaram a reco mendação. Auxiliar de cozinheiro foi encontrado em 22 SND, mas somente $14(28,6 \%)$ alcançaram a recomendação. A ocupação de auxiliar de cozinha foi encontrada em 31 SND, mas somente 
Dagu 20 - Comparaçio de qualidade do pessosl existente com a recomendação* nos hospltals estudados, segundo a flnelldade da entidade mantenedora, o número de leltos o Indice de adequaçäo.

são paulo, março de 1983.

\begin{tabular}{|c|c|c|c|c|c|c|c|c|c|c|c|c|c|}
\hline $\begin{array}{l}\text { ue de } \\
\text { Leitoo }\end{array}$ & TIHALIDND & 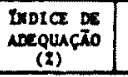 & 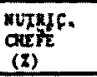 & $\underset{(x)}{\text { mutaiciax. }}$ & $\underset{(\pi)}{\pi C, N u T R I C \bar{D}}$ & $\underset{(x)}{\operatorname{escatruR} .}$ & $\begin{array}{c}\text { DESPENSE IRO } \\
(\mathrm{z})\end{array}$ & $\begin{array}{c}\text { COZLNRE IRO } \\
\text { ENCARRZGADO } \\
(x)\end{array}$ & $\begin{array}{c}\text { COZ INKE1RO } \\
(\mathrm{z})\end{array}$ & $\begin{array}{c}\text { AUX. DE CO- } \\
\text { Z WWEE IRO } \\
(Z)\end{array}$ & \begin{tabular}{|c} 
Aux, De \\
cozrmuk \\
$(2)$
\end{tabular} & $\begin{array}{c}\text { SERVENTR oE } \\
\text { Coz IMRa } \\
(x)\end{array}$ & $\begin{array}{c}\text { COPE IRS } \\
(\mathrm{x})\end{array}$ \\
\hline \multirow[t]{22}{*}{1} & c & 120 & 11 & ? & - & 6 & 1 & 1 & 11 & $-\quad$. & 20 & 23 & 30 \\
\hline & 6 & 103 & 1 & 4 & - & 9 & 3 & - & 9 & - & - & 41 & 32 \\
\hline & 2 & 132 & 3 & 3 & - & - & - & 3 & 6 & - & 9 & 15 & 61 \\
\hline & 1 & 66 & , & - & - & 1 & - & - & , & 26 & - & - & 53 \\
\hline & 2 & $s i$ & - & - & - & $\cdot$ & $\therefore$ & - & 17 & - & 17 & - & 58 \\
\hline & 2 & 46 & - & - & 5 & . & - & - & 9 & - & 29 & - & $\$ 7$ \\
\hline & 2 & 62 & - & - & - & 2 & 4 & - & 6 & - & 17 & 27 & 46 \\
\hline & 2 & 39 & 5 & - & $y$ & . & - & - & 16 & - & 23 & - & 45 \\
\hline & 1 & 73 & - & - & 3 & . & - & - & 3 & 3 & 31 & - & 58 \\
\hline & 2 & 137 & 3 & - & 3 & . & 3 & - & 6 & - & 12 & , & 64 \\
\hline & 2 & 70 & $s$ & . & - & - & - & 3 & 9 & - & 28 & - & 53 \\
\hline & t & 92 & - & . & 4 & 4 & . & - & 9 & 9 & 22 & - & 32 \\
\hline & $\mathfrak{c}$ & 72 & 3 & . & 7 & - & 3 & 3 & 13 & 27 & - & 3 & 41 \\
\hline & t & 11 & - & - & - & - & 4 & 4 & 23 & 23 & - & - & 46 \\
\hline & NL & 81 & - & - & . & - & . & - & - & - & - & 65 & 35 \\
\hline & $\mathrm{NL}$ & 129 & - & . & 7 & 2 & 2 & 2 & 9 & , & - & 7 & 65 \\
\hline & $\mathrm{ML}$ & 223 & 1 & 6 & 1 & . & 3 & 1 & 3 & 26 & 13 & . & 45 \\
\hline & NL & 118 & 3 & . & . & . & . & - & $s$ & $s$ & 30 & 3 & 51 \\
\hline & NL & 92 & - & " & . & - & . & - & 13 & 12 & - & 10 & 64 \\
\hline & $\mathrm{uL}_{\mathrm{L}}$ & 92 & - & . & - & . & . & - & - & - & 45 & - & ss \\
\hline & NL & 83 & 7 & . & - & . & - & 7 & 14 & - & - & 36 & 36 \\
\hline & WL & $n$ & 6 & - & - & - & - & - & 25 & - & 19 & - & so \\
\hline \multirow[t]{13}{*}{11} & $\mathrm{c}$ & 63 & 2 & 8 & - & 0 & 2 & - & 12 & - & 16 & 12 & 42 \\
\hline & L & 132 & 2 & - & 4 & 4 & 2 & - & 4 & - & 39 & - & 45 \\
\hline & 1 & 74 & - & - & 4 & 4 & - & - & 9 & . & - & 22 & 61 \\
\hline & $t$ & 110 & 2 & 4 & 4 & 2 & - & 2 & 2 & - & 20 & - & 64 \\
\hline & 2 & 36 & - & . & 4 & - & 4 & 4 & 7 & 22 & - & - & 59 \\
\hline & l & 68 & - & - & . & 4 & . & 4 & - & - & 11 & 4 & 37 \\
\hline & i & 28 & 6 & - & - & 6 & . & 6 & 12 & 6 & $=$ & 6 & 32 \\
\hline & WL. & 182 & 1 & 1 & 4 & 1 & . & 1 & 1 & 27 & 4 & - & 58 \\
\hline & NL & 81 & 2 & 2 & . & - & . & - & 4 & 27 & - & 6 & 57 \\
\hline & $\mathrm{nL}$ & 92 & 2 & 2 & 4 & 9 & - & 2 & 11 & - & 22 & 11 & 37 \\
\hline & NL & 106 & 2 & 2 & - & - & $s$ & - & 5 & 23 & 7 & - & 56 \\
\hline & $\mathrm{wL}$ & 72 & - & - & 3 & $=$ & 3 & - & 8 & - & 3 & 40 & 43 \\
\hline & NL & $\$ 4$ & 4 & - & 4 & 4 & . & - & 11 & 23 & - & - & 54 \\
\hline \multirow[t]{7}{*}{ III } & 6 & 68 & 1 & , & . & $B$ & . & - & 5 & - & 28 & 10 & 41 \\
\hline & 6 & 83 & 2 & 6 & . & 6 & 1 & - & u & - & 20 & 24 & 30 \\
\hline & 6 & 61 & 1 & 1 & . & 12 & . & - & 10 & - & , & 41 & 33 \\
\hline & 2 & 56 & 2 & - & . & 2 & . & 2 & 5 & 31 & + & - & 58 \\
\hline & $\mathrm{NL}$ & 24 & 3 & - & 3 & 3 & . & - & 12 & 28 & - & - & $5:$ \\
\hline & NL & 33 & 3 & - & - & 6 & - & 3 & - & 3 & 48 & - & 37 \\
\hline & $N_{2}$ & 90 & - & - & 4 & 2 & 2 & 2 & $s$ & . & 5 & 44 & 36 \\
\hline \multirow[t]{8}{*}{ IV } & $c$ & 12 & 2 & 11 & - & 6 & 4 & . & 12 & . & - & 24 & 40 \\
\hline & G & 52 & 1 & 8 & 1 & 2 & 3 & . & 14 & 4 & 29 & - & 48 \\
\hline & ᄂ & 31 & 3 & - & . & , & 3 & - & 3 & 7 & 3 & 32 & 42 \\
\hline & NL & 62 & 1 & 6 & - & 3 & - & - & 3 & 3 & 8 & 16 & 60 \\
\hline & NL & 93 & 1 & 4 & 4 & 4 & 3 & - & - & - & $s$ & 32 & 67 \\
\hline & $\mathrm{NL}$ & 90 & 1 & 3 & 6 & 1 & - & 1 & 7 & - & - & 25 & 56 \\
\hline & ML & 10 & 1 & . & 6 & . & . & - &. & 19 & 11 & 1 & 32 \\
\hline & Devtro da & econemdacío & w9 35 & 2 & 17 & 15 & - & 18 & 21 & 14 & 8 & 21 & 49 \\
\hline \multirow[t]{2}{*}{ TOTAL } & & & $=(71,4)$ & $(4.1$ & $(34,7)$ & $(30,6)$ & $(0)$ & $(36,7)$ & $(42,9)$ & $(28,6)$ & $(16,3)$ & $(62,9)$ & $(100,0)$ \\
\hline & roen in ase & corembuģio & $\begin{array}{l}\text { No } 16 \\
2(28,6)\end{array}$ & $\begin{array}{c}47 \\
(95,9)\end{array}$ & $\begin{array}{c}32 \\
(65.3)\end{array}$ & $\begin{array}{c}36 \\
(69.6)\end{array}$ & $\begin{array}{c}49 \\
(100,0)\end{array}$ & $\begin{array}{c}31 \\
(63,3)\end{array}$ & $\begin{array}{c}28 \\
(5), 1)\end{array}$ & $\begin{array}{c}35 \\
(71,4)\end{array}$ & $\begin{array}{c}41 \\
(83.1)\end{array}$ & $\begin{array}{c}28 \\
(57,1)\end{array}$ & 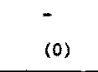 \\
\hline
\end{tabular}

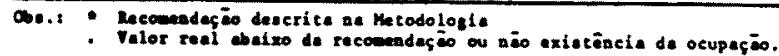


8 alcançaram a recomendação. Despenseiro foi encontrado em 24 SND, todos fora da recomendação. Dos 28 SND que contam com a ocupação de servente, 21 deles alcançaram a recomendação.

Quanto ao número de leitos, observamos que na maio ria dos hospitais dos Grupos I e II, havia a ausência de nutricionistas na chefia e em função técnica, e escriturarios. Nos hospitais dos Grupos III e IV essas ocupações eram sempre exercidas, mas fora das recomendaçōes. Encontramos 6 hos pitais (dos Grupos I e II) com ausência total de pessoal téc nico (nutricionista e o técnico em nutrição), ficando o SND sob a direção de leigos.

Analisando os hospitais quanto ao indice de adequa ção, verificamos que os hospitais com nivel "adequado" apresentaram insuficiência quanto à qualidade de pessoal (Tabela 20). Dos 10 hospitais, 4 não contavam com nutricionista quer na chefia quer em função técnica; em 2 desses hospitais havia falta tambēm do tēcnico em nutrição. Dos 8 hospitais com escrituārio, 4 estavam dentro da recomendação. Quanto ao des penseiro, 4 SND contavam com ele, mas nenhum alcançou a reco mendação. Cozinheiro encarregado foi encontrado em 4 serviços, todos dentro da recomendação. Pessoal do preparo dos alimentos: 8 serviços possuiam cozinheiro, a metade dentro da reco mendação; o auxiliar de cozinheiro foi encontrado em apenas 13 serviços e o auxiliar de cozinha em 7. Servente de cozinha e copeira, principalmente esta última, foram as ocupações encontradas em todos os SND (serventes em menor proporção) . Nos hospitais com nivel "deficiente" constatamos que as ocupa ções ou não existiam ou não foram alcançadas as recomendações, principalmente no que: se refere às ocupações técnicas de nutricionista e do técnico em nutrição. Dos 5 hospitais, 4 têm nutricionista na chefia e nenhum tem nutricionista em função 
tēcnica. Escriturārios foram encontrados só em 3 serviços, to dos dentro da recomendação. Despenseiros foram encontrados em 2 hospitais, fora da recomendação. As ocupações de cozinheiro encarregado, cozinheiro, auxiliar de cozinheiro e auxiliar de cozinha, não apresentaram diferenças em relação ao grupo anterior; dessas 4 ocupações, a de cozinheiro é a mais frequlente em todos os serviços (4), embora não atingindo a reco mendação em 2 deles. Dois serviços tinham servente de cozinha, só 1 dentro da recomendação. Copeira foi a única ocupação constante em todos os serviços $(100,0 \%)$, sempre dentro da recomendação. Nos 8 hospitais com nível "excessivo", a ché fia foi ocupada por nutricionistas em todos eles (com exceção de um). Nutricionista (função técnica), tēcnico em nutrí ção e escriturärio estiveram ausentes em 3 serviços. Encontramos despenseiro em 2 hospitais, ambos não alcançando a recomendação. Das ocupações da ārea de preparo a mais freqten te foi a de cozinheiro, embora só 2 hospitais tenham alcançą do a recomendação. Cozinheiro encarregado, auxiliar de cozinheiro e auxiliar de cozinha, estiveram ausentes em 3,4 e 1 serviço, respectivamente; mesmo assim, o cozinheiro encarregado foi o mais encontrado dentro da recomendação. Servente de cozinha presente em 5 serviços. Copeira foi a única ocupa ção presente, dentro da recomendação, em todos os hospitais. Nos 26 hospitais com nível "baixo" a qualidade de pessoal não foi diferente dos anteriores. Para as ocupações técnicas, en contramos nutricionista na chefia em 18 hospitais, todos den tro da recomendação; os 8 hospitais restantes não contavam com o profissional nessa ocupação. Dos 26 hospitais, 9 tinham nutricionista em furção tēcnica, mas dentro da recomendação, somente 2 deles; quanto ao técnico em nutrição, escriturário e despenseiro, 16,10 e 13 serviços, respectivamente,não con 
tavam com ninguém nessas ocupações. Das ocupações do setor de preparo, o cozinheiro foi o mais frequentemente encontrado: 12 serviços não alcançaram a recomendação e 2 serviços não contavam com ele, no caso de cozinheiro encarregado,auxiliar de $00 z i-$ जheiro e auxiliar de cozinha,18,13 e 10 serviços, respectivamente, não ti nham essas ocupações. Servente de cozinha estava presente em 15 serviços. Como no grupo anterior, copeira esteve presente dentro das recomendações nos 26 hospitais.

Em resumo, a maioria dos hospitais não alcançou as recomendações. Aqueles com nível "adequado" mostraram-se com pessoal insuficiente, principalmente nas ocupações técnicas alēm de outras não técnicas, como despenseiro, auxiliar de cozinheiro e auxiliar de cozinha. Notamos que quase todos os hospitais com nível "deficiente" estavam com quase todas as ocupações abaixo das recomendações; no entanto, cozinheiro, copeira e nutricionista na chefia, estavam presentes em todos eles (com exceção de um, que não tem nutricionista). Nos hospitais com nível "excessivo" houve ausência de algumas ocupações (despenseiro, escriturärio, servente), mas nas ocu pações técnicas (nutricionista e técnico em nutrição) e outras não técnicas (cozinheiro encarregado, auxiliar de cozinheiro, auxiliar de cozinha), foi encontrado um maior número do que nos demais hospitais. Os hospitais com nivel "baixo" não estiveram muito diferentes dos anteriores; no entanto, nu tricionista na chefia, quase todos possuiam; cozinheiro, ser vente e copeira, foram as ocupações mais freqlentes.

Pelo que vimos, não houve variação muito grande quanto à qualidade de pessoal entre os hospitais classificados nos 4 níveis. Mesmo os hospitais com nível "excessivo" de pessoal que possuiam nutricionista na chefia e cozinheiro den tro da recomendação, não contavam com pessoal técnico em nū- 
mero suficiente. Parece que a adequação no I.P.T. nem sempre vem acompanhada da qualidade do pessoal.

o profissional nutricionista, parte integrante da equipe de saúde, desempenhando papel fundamental na recupera ção dos pacientes, foi encontrado, de maneira geral, em todos os hospitais governamentais, em menor escala nos não lucrativos e em pequeno número nos lucrativos (na chefia e/ou em função tēcnica).

Pupo e col..$^{34}$ em trabalho realizado em hospitais que prestavam assistência médica geral e especializada, no Estado de São Paulo, constataram nos 191 hospitais de todos os tamanhos da Região da Grande São Paulo, que só 38 tinham nutricionistas, sendo assim distribuídos: 7 hospitais filantrōpicos, 17 lucrativos e 14 governamentais; o número des ses profissionais foi, respectivamente, 13, 19 e 80 . Isso mos tra a insuficiência de nutricionistas e, embora passados 11 anos, (1ક72-1983) Darece que a situação não se modificou.

E imprescindivel que a direção dos Serviços de Nu彑 trição e Dietética esteja sempre a cargo de um nutricionista, que poderá ser auxiliado por profissional também qualifica do (o técnico em nutrição) para supervisionar o pessoal não técnico.

Os Conselhos Regionais de Nutricionistas (CRN), tal vez pudessem requerer que todos os hospitais, independente do número de leitos, tivessem nutricionistas na chefia dos SND.

Outro profissional qué poderia ser melhor aproveitado em nossos hospitais seria o técnico em nutrição, que poo 
deria atuar na área de produção liberando o nutricionista pạ ra outras atividades que requerem mais sua participação, como o estudo de caso, orientação dietética a paciente e educação nutricional a este e familiares. Geralmente, os hospi tais governamentais que utilizam o nutricionista em seus SND não utilizam o técnico em nutrição, talvez por desconhecer suas possibilidades. Como bem disse soto 42 "pelo fato das funções desenvolvidas pelo nutricionista e tēcnico em nutrição serem pouco conhecidas e, na maioria das vezes confundidas, torna-se necessārio que as atividades do nutricionista, profissional de nível superior, e do técnico em nutrição,pró fissional de nível médio, sejam esclarecidas e divulgadas aos setores públicos e privados, de forma que as Instituições pos sam utilizar seus serviços, com maior economia, vantagens e beneficios".

Em 1972, Passos ${ }^{33}$ já alertava para a dificuldade de se trabalhar com pessoal não preparado, cuja experiência era adquirida no dia-a-dia. Por exemplo, a copeira hospitalar é treinada em serviço; o cozinheiro de hospital não tem cursos de preparação específicos, como ocorre na área industrial e de hotelaria. E necessário pensar na formação do pessoal não técnico, para que possa cumprir, com eficiência, seus deveres e responsabilidades perante $O$ SND e, principalmente, perante o paciente.

Seria interessante pensar na participação das esco las técnicas e, principalmente, das escolas de nível superior (utilizando os alunos) na capacitação do pessoal auxiliar.En quanto isso não se der e os cursos não forem iniciados por escolas profissionais, as prōprias associações de classe poderiam assumi-los temporariamente, a exemplo do que ocorre nos Estados Unidos, onde várias associações trabaiham 
nessa linha, ${ }^{3,47}$ colaborando na formação do pessoal auxiliar ne cessário ao mercado de trabalho, assim como criando normas para a descrição de cargos e a qualificação dos indivíduos que deverão ocupá-los. Isso obriga o mercado de trabalho a exigir a qualificação no momento da admissão do funcionário. 


\section{CONCLUSÕES}

Utilizando indicadores especificos para avaliar 0 dimensionamento de pessoal de Serviços de Nutrição e Dietétí ca de 49 hospitais gerais de grande porte e de capacidade ex tra no município de São Paulo, chegamos às seguintes conclusões:

- Encontramos 10 hospitais $(20,48)$ com nümero de funcionários do SND no nível considerado "adequado"; 5 hospi tais $(10,28)$ no nivel "deficiente"; 26 hospitais $(53,18)$ no nível "baixo" e 8 hospitais $(16,3 \%)$ no nível "excessivo".

- Dos hospitais com níveis de adequação além do considerado "adequado" (> 1108), todos (8) pertenciam aos Gru posI e II; quanto à finalidade, 4 eram não lucrativos, 3 lucrativos e 1 era governamental.

- Os 10 hospitais considerados "adequado" estão dis tribuídos nos quatro grupos, sendo 7 nosGruposI e II; quanto à finalidade, 7 eram não lucrativos, 2 lucrativos e 1 governamental.

- Os 26 hospitais com nível "baixo" também estão distribuidos nos quatro grupos. A maioria dos hospitais governamentais (6) estão nesse nível, assim como pouco mais da metade dos lucrativos (11) e 9 dos não lucrativos.

- Dos 5 hospitais com nível "deficiente" distribui dos pelos quatro grupos, 4 eram lucrativos e 1 não lucrativo.

- Não houve relação entre a taxa de ocupação e o número de pessoal existente nos SND.

- A maioria dos hospitais com nível de adequação de pessoal "superior" a $110 \%$ atendia proporcão mais elevada de pacientes contribuintes e pacientes conveniados com ou- 
tras instituições que não o INAMPS.

- Os tipos de cardápio com maior variação,que exí gem na sua elaboração mais funcionārios, foram mais encontrados nos serviços com níveis "adequado" e "excessivo" (prin cipalmente neste).

- O sistema misto de distribuição das refeições foi utilizado em 42,98 dos hospitais estudados, tendo sido o mais adotado naqueles serviços com nível de adequação de pessoal "deficiente", "baixo" e "adequado"; no nivel "excessivo" predominou o sistema centralizado.

- Quanto ao sistema de higienização dos utensilios, apenas nos serviços com nível de pessoal "deficiente" predomí nou o sistema centralizado.

- Os hospitais que utilizaram sistema centralizado para distribuição e para higienização eram dos Grupos I e II.

- A maioria dos hospitais que alcançaram os padrões e recomendações para planta física, equipamentos e qualidade do pessoal foram aqueles com nível de adequação de pessoal "ex cessivo".

- Embora os hospitais lucrativos tenham apresentado maior ausência de equipamentos indispensáveis ao bom funcionamento dos SND, não houve diferenças acentuadas entre aqueles e os não lucrativos e governamentais.

- Nem sempre a adequação do I.P.T. lou mesmo o excesso) vem acompanhada da qualidade do pessoal do SND. 
1. AMORIM,B.R. Prāticas de controle em serviços de nutrição. Recife, 1972. (mimeografado).

2. AtÁla, A. Cálculo de pessoal para serviços paramédicos de um hospital geral de 300 leitos. Rev. paul. Hosp., 26: $244-256,1978$.

3. AUGSPURGER, J.A. Vocational opportunities for food servi ce personnel. J.Amer. Diet. Ass., 47:44-47, 1965.

4. BAKKEN, E.I. \& NORTHROP, M.W. Labor in the dietary department. J.Amer. diet. Ass., 32:953-958, 1956.

5. BARQUIM, M. Direccion de hospitales: organización de atencion médica. 3 3 a ed., México, Ed. Interamericana, 1972.

6. BARTSCHT, K.G. Man-minute computations form the basis for new staffing methodology. Hospitals, 40: 62-66, 1966.

7.BEACH, B.L. \& OSTENCO, G.L. Entrēe serving times. J. Amer. diet. Ass. , 54:290-296, 1969.

8. BURGOS, L.G. et al. El departamento de alimentacion de um hospital general. Tecn. Hosp. , 28:83-86, 1971.

9. CARVALHO, L.F. Considerações do administrador no planejamento de Serviço de Nutrição e Dietética. Rev. paul. Hosp. , 8: $18-20,1960$.

10. CAVALCANTI, M.L. e Col. Sugestões para avaliação do serviços de alimentação em instituições. Bol. inf. ABIA/ SAPRO, $23: 40-44,1976$.

11. CONSOLIDAÇÃo das leis do trabalho. 6- ed.. são Paulo, Edições LTR, 1976. p. 22-24; p. 305-306.

12. DICKIE, R. \& GORMICAN, A. FOOd service and dietetics. Hospitals, $\underline{42}: 61-66,1968$.

13. DONALDSON, B. Labor hours in the dietary department. J. Amer. diet. Ass. , 33:1239-1243, 1957.

14. DONALDSON, B. The future in food administration. J. Amer. diet. Ass., 46:357-360, 1965.

15. FERREIRA, A.B. H. Novo Dicionārio da língua portuguesa. Rio de Janeiro, Ed. Nova Fronteira, 1975. 
16. GRUPO de trabalho da ārea hospitalar. In: MESA REDONDA SO BRE FORMULAÇÃO E PADRONIZAÇÃO DE AVALIAÇÃO DE SERVIÇOS DE NUTRIÇÃO EM DIFERENTES ENTIDADES, São Paulo, 1976. São Paulo, ABIA/SAPRO, 1976. p. 30-49.

17. GRUPO de trabalho da ärea hospitalar. In: GANDRA, Y.R., Coord. Avaliação de serviços de nutrição e alimentação. são Paulo, Sarvier, 1983, p. 39-74.

18. HALTER, E. \& DONALDSON, B. Labor in the dietary department. Hospitals in the East North Central Region. J. Amer. diet. Ass., 33:583-587, 1957.

19. HARRINGTON, M.M. Work simplification at work. J. Amer. diet. Ass., 29:796-798, 1953.

20. HO, A.K. Activity sampling in two nursing home foodservice sistems. J. Amer. diet. Ass., 73: 647-653, 1978.

21. HUBBARD, R.M. Hospital food service adapts to systems approach and industrial methods. Hospitals, 44: 87-92, 1970.

22. IACOBELL, F. Inservice education program stresses administrative skills. Hospitals, 41:59-62, 1967.

23. KARKECK, J.M. et al. A training program to meet affirmative action gools in a dietary department. J. Amer. diet. Ass., 71:46-48, 1977.

24. KENT, W.J. \& OSTENSO, G.L. Productivity relationships of hospital dietary departments. J. Amer. diet. Ass., 47: 104-109, 1965.

25. KOTSCHEVAR, L.H. \& TERRELL, M.F. Food service planning: layout and equipment. $4 \underline{a}$ ed., New York, John Willey, 1967.

26. LLEWELYN DAVIES, R. \& MACAULAY, H.N.C. Planification y administracion de hospitales. Washington, D.C., Organizacion Panamericana de la Salud, 1969. (OPAS - Publ. Cient., 191).

27. MCCARTHY, E.F. Food service and dietetics. J. Amer. diet. Ass., 43:101-104, 1969.

28. MEzOMO, I.F.в. O serviço de nutrição: administração e organização. São Paulo, CEDAS, 1983.

29. MINISTERIO DA PREVIDENCIA E ASSISTENCIA SOCIAL. Modelos: formulários de classificação hospitalar: relatório de 
classificação hospitalar (RECLAR), comprovante de classificação hospitalar. Rio de Janeiro, 1974.

30. MINISTÉRIO DA SAODE. Hospital geral de pequeno porte e médio porte, equipamento e material. 2a ed., Brasilia, 1979 .

31. MINISTERIO DA SAODE. Normas e padrões de construções e instalações de serviços de saūde. 2ạ ed. Brasília, 1982.

32. MINISTERIO DO TRABALHO. Classificação brasileira de ocupações. Brasilia, 1982 .

33. PASSOS, C.M. Organização de cozinhas hospitalares. São Pau 10. Associação Paulista de Hospitais, 1972.

34. PUPO, Y.K.A. e Col. Nutricionistas e técnico em nutrição nos hospitais do Estado de São Paulo. Rev. paul. Hosp.' 20: $4-12,1972$.

35. RIBEIRO, A.B.C. Administração de pessoal nos hospitais. 2 a ed. São Paulo, LRT/Fename, 1977.

36. ROSS, A. Evaluating dietary department management. Hospitals, $\underline{42}=109-114,1968$.

37. ROSS, L. Work simplification makes food service easy, fast and economical. Hospitals, 42:124-127, 1968.

38. ROTHENBUHLER, E.F. \& BARTSCHT, K.G. Determining dietary staff in hospitals: metodology. J. Amer. diet. Ass., 47:25-27, 1965 .

39. SANFORD, J. \& CUTLAR, K. Work sampling of activities of food service managers. J. Amer. diet. Ass., 44:182-185, 1964 .

40. SCHELL, M.L. Work sampling: a approach to a problem. J. Amer. diet. Ass., 41:456-458, 1962.

41. SCHULZ, R. \& JOHNSON, A.C. Administração de hospitais. São Paulo, Pioneira, 1979.

42. Sото, S.M. Clínica de nutrição em ambulatório de hospital de ensino. São Paulo, 1980. (Dissertação de Mestrado Faculdade de Saúde Pública USP).

43. STAMM,E.K. Guidelines for determining staffing needs in hospitals and nursing home food service. Hospitals, 43:60, 1969. 
44. STUMPT, G.L. \& DONALDSON, B. Better management by control of direct expenses. J. Amer. diet. Ass., 33:117-122, 1957.

45. TAYLOR, W.C. Absenteeism in health care food service. J. Amer. diet. Ass. , 79:699-701, 1981.

46. TUTHILL, B.H. \& DONALDSON, B. Labor in the dietary depart ment. J. Amer. diet. Ass., 32:541-545, 1956.

47. UNITED STATES. Department of Labor. Job descriptions and organizational analysis for hospitals and related health services. Rev. ed. Washington, D.C., 1970.

48. WALDVOGEL, C.F. Quantity food production labor time. J. Amer. diet. Ass., 70:172-177, 1977.

49. WALDVOGEL, C.F. Labor time per portion and volume in food service. J. Amer. diet. Ass., 70:178-180, 1977.

50. WEST, B.B. et al. Food service in institutions. 4 a ed. New york, John Wiley, 1966.

51. WILSON, M. Determining work loads by random ratiodelay sampling. J.Amer. diet. Ass., 32:719-723, 1956.

52. WISE, B.T. \& DONALDSON, B. Work sampling the dietary department. J. Amer. diet. Ass. , 39:327-332,1961.

53. WRIGHT, M.J. Work simplification in the dietary department. J. Amer. diet. Ass., 29:790-796, 1953.

54. ZEMEL, P.C. \& MATTHEWS,M.E. Determining labor production time for roast entrées in hospital food service. J. Amer. diet. Ass., 81:709-714, 1982. 
8. ANEXIS 


\section{ANEXO 1}

FORMULARIO DE AVALIAÇÃO DO DIMENSIONAMENTO DE PESSOAL DO SND DE HOSPITAIS GERAIS

No

Data:

1. IDENTIFICAÇÃO DO HOSPITAL

1.1. NOME

1.2. ENDEREÇO FONE

1.3. FINALIDADE DA ENTIDADE MANTENEDORA

- governamental

- FEDERAL ESTADUAL MUNICIPAL OUTRO

- PARTICULAR COM FINS LUCRATIVOS

- particular SEM FiNS lUCRATIVOS

1.4. NOMERO DE LEITOS TAXA DE OCUPAÇÃO

PACIENTES-DIA NO PERIODO CONSIDERADO X 100

NOMERO DE LEITOS-DIA, NO MESMO PERIODO

1.5. NUMERO TOTAL DE FUNCIONARIOS

1.6. OS FUNCIONARIOS TOMAM REFEIÇÕES NO HOSPITAL? SIM _ NÃO _ CASO SIM, QUANTOS?

1.7. O HOSPITAL TEM PESSOAL ESTAGIÁRIO? INTERNOS: SIM _ NÃO __ CASO SIM, QUANTOS? RESIDENTES: SIM _ NÃO _ CASO SIM, QUANTOS? OUTROS: SIM N NÃO _ CASO SIM, QUANTOS?

1.8. O PESSOAL ESTAGIARIO TOMA REFEIÇÕES NO HOSPITAL? SIM _ NÃO _ CASO SIM, QUANTAS REFEIÇÕES?

1.9. O HOSPITAL ATENDE A PACIENTES INTERNADOS EM QUE PROPOR ÇÃO?

NÃO CONTRIBUINTES CONTRIBUINTES CONVENIOS DIVERSOS CONVENIO INAMPS

2. IDENTIFICAÇÃO DO SERVIÇO DE NUTRIÇÃO E DIETETICA (SND)

2.1. O SND ESTA SUBORDINADO:

DIRETOR TEONICO ADMINISTRADOR OUTRA CHEFIA

2.1.1. CHEFIA DO SND NUTRICIONISTA TEONIDO EM NUTRIÇÃO OUTRO 
2.2. PESSOAL EXISTENTE

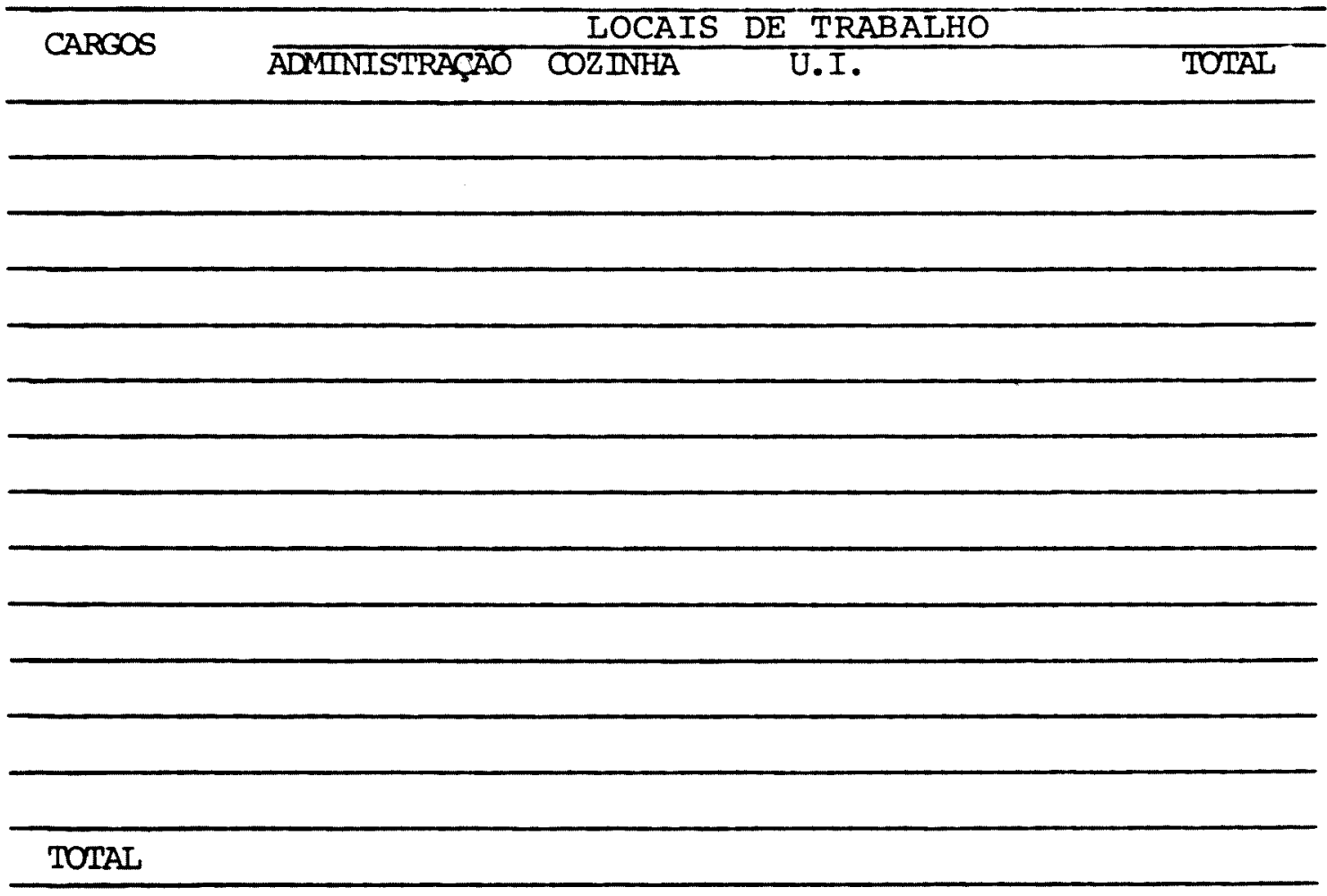

2.3. DISTRIBUIÇÃO DO PESSOAL POR UM DIA DE TRABALHO

\begin{tabular}{|c|c|c|c|c|}
\hline $\begin{array}{l}\text { SETOR DE } \\
\text { ATIVIDADE }\end{array}$ & $\begin{array}{l}\text { CARGO } \\
\text { OU } \\
\text { FUNÇÃO }\end{array}$ & $\begin{array}{l}\text { N\& DE } \\
\text { FUNCIONA } \\
\text { RIOS POR } \\
\text { DIA }\end{array}$ & $\begin{array}{ll}\text { No } & \text { DE } \\
\text { HORAS } & \text { DE } \\
\text { TRABAIHO } \\
\text { POR } & \text { DIA }\end{array}$ & $\begin{array}{l}\text { \% DAS HORAS } \\
\text { DE TRABNIHO } \\
\text { SOBRE O TO- } \\
\text { TAL DE H.DE } \\
\text { TRAB.DO DIA }\end{array}$ \\
\hline \multicolumn{5}{|l|}{$\begin{array}{l}\text { Previsão } \\
\text { Recebimento } \\
\text { Estoque }\end{array}$} \\
\hline \multicolumn{5}{|l|}{$\begin{array}{l}\text { Pré-Preparo } \\
\text { Vegetais }\end{array}$} \\
\hline \multicolumn{5}{|l|}{$\begin{array}{l}\text { Pré-Preparo } \\
\text { Cames }\end{array}$} \\
\hline \multicolumn{5}{|l|}{$\begin{array}{l}\text { Preparo: } \\
\text { Cozinha Geral }\end{array}$} \\
\hline \multicolumn{5}{|l|}{$\begin{array}{l}\text { Preparo: } \\
\text { Cozinha Dietética }\end{array}$} \\
\hline \multicolumn{5}{|l|}{$\begin{array}{l}\text { Distribuição de café } \\
\text { leite, sabremesa, su- } \\
\infty \text {, notumo }\end{array}$} \\
\hline \multicolumn{5}{|l|}{$\begin{array}{l}\text { Distribuição na } \\
\text { Unidade de Internação. }\end{array}$} \\
\hline \multicolumn{5}{|l|}{$\begin{array}{l}\text { Faxina/Lavagem } \\
\text { de Panelas }\end{array}$} \\
\hline & TOTAL & & & \\
\hline
\end{tabular}


2.4. PLANTA FISICA

- localização ANOS DE FUNCIONAMENTO

- area total do snd PE DIREITO

- areas especificas:

- RECEPÇÃo DE GENEROS

- FRIGORIFICOS: CARNES:

- PRE-PREPARO VEGETAIS

PRE-PREPARO CARNES

- PREPARO MASSAS E SOBREMESAS PREP.DESUEJUM E MERENDA

- PREPARO cOZINHA geral PREPARO COZINHA DIETETICA

- DISTRIB.DE REF. CENTRALIZADA

- COPA DE lavagem centralizada

- REFEITÓRTO DE FUnCIONÁRIOS

- ESCRITORIO NUTRICONISTA

- COPA DE UNIDADE DE INTERNAção

- MATERIAL DE LIMPEXA DESCENTRALTZADA _ DESCENTRAIIZADA

- gUARDA DE LIXO: REFRIGERADO LAVAGEM DE CARROS NÃO REFRdGERADO

2.5. EQUIPAMENTOS

- balanças: plataforma no DE MESA NQ PACIENTES SECRETARIA DESPENSA VEGETAIS:__ OVOS/LATICINICOS

- CARRO: tIPO PLATAFORMA No CAPACIDADE CAPACIDADE

- REFRIGERADOR TIPO: DOMESTICO NQ CAPACIDADE

COMERCIAL No

- CONGELADOR: NQ CAPACIDADE

- descascador de tuberculos: no

- picador de carne, VEgetal, Queijo: no CAPACIDADE

- amaciador DE bIFE: No

- MOEDOR DE CARNE: No

- FOGÃo ELETRICO: DOMESTICO NQ CAPACIDADE CAPACIDADE

- FOGÃO ELETRICO: DOMESTICO NQ

- FOGÃO GÁS INDUSTRIAL N?

INDUSTRIAL No

- FORNO ELETRICO: DOMESTICO NO INDUSTRIAL NO

- fritadeira eletrica No CAPACIDADE

$-$
CAPACIDADE CAPACIDADE — CAPACIDADE CAPACIDADE CAPACIDADE BIFETEIRA NQ

- CALDEIRÕEs/PANELÃo: VAPOR/PREssão CAPACIDADE

- BANHO-MARIA: ELETRICO No VAPOR NO

- BATERIA DE PANELAS BASCULANTES: VAPOR N? CAPACIDADE

- colfas e aparelhos de exaustão no

- cortador de frios no

- BATEDEIRA: INDUSTRIAL NQ CAPACIDADE DOMESTICA NQ CAPACIDADE 
- LIQUIDIFICAR: INDUSTRIAL N8 CAPACIDADE DOMESTICO NQ CAPACIDADE

- extrator DE SUCOS No

- CAFETEIRA: INDUSTRIAL No CAPACIDADE TIPO BAR N\%

- carro termico no CAPACIDADE CAPACIDADE

- carro dE pRATELEIRA No

- esteira rolante no

- balcão térmico (cafeteria) no

- tRITURAdOR DE RESIdUOS (LIXO) No

- máguina de lavar louça no

2.6. MOVIMENTO DE REFEIÇÕES

2.6.1. NQ TOTAL DE REFEIÇÕES SERVIDAS POR DIA

2.6.2. NQ DE RFEIÇÕES SERVIDAS A PACIENTES (média mensal) (media mensal)

2.6.3. NQ DE REFEIÇÕES SERVIDAS A OUTROS (media mensal)

2.6.4. NQ DE DIETAS MODIFICADAS SERVIDAS P/PACIENTES

3. OPERACIONALIZAÇAOO DOS INDICADORES DE DIMENSIONAMENTO

- INDICADOR DE PESSOAL FISICO (I.P.F.)

3.1. I.P.F. N\& DE REFEIÇÕES SERVIDAS X 15 MINUIOS JORNADA DE TRABALHO X 60 MINUTOOS

I.P.F. $=$
3.2. I.P.D. $=\frac{\text { DIAS DO ANO }- \text { DIAS DE DESCANSO }}{\text { DIAS DE DESCANSO }}$

- DIAS DE FERIAS

- FERIADOS oficiais No ANO

- FERIAdos facultativos

- regime de trabalho semanal

- FOLGAS SEMANAIS

- I.P.D. =

3.3. INDICADOR DE PESSOAL SUBSTITUTO (I.P.S.)

$$
\begin{aligned}
& \text { I.P.S. }=\frac{\text { I.P.F. }}{\text { I.P.D. }} \\
& \text { I.P.S. }=
\end{aligned}
$$


3.4. INDICADOR DE ABSENTEISMO DIARIO (I.A.D.)

$$
\text { I.A.D. }=\frac{\text { MEDIA DIARIA DE FUNCIONARIOS AUSENTES } \times 100}{\text { NUMERO DE PESSOAL FIXO (I.P.F.) }}
$$

- FALTAS DIÁRIAS

- LICENÇAS-DOENÇA

- LICENÇAS-MATERNIDADE

- ACIDENTE do tRABALHO

I.A.D. =

3.5. INDICADOR DE PESSOAL TOTAL (I.P.T.)

I.P.T. = I.P.F. + I.P.S. + (I.A.D. de I.P.F.) I.P.T. $=$ 
ANEXO II - Distribulção dos hospitais, segundo a finalidade da entldade mantenedora, o número de leltos, o nümero de funcionärios do hospital, número de pessoal estagiárto, funcionário//eito hospitalar, no de functonärlos do SND e o.percentual de funcionärios do SND en relação ao total de funclanários do hospital. Säo Paulo, março de 1983.

\begin{tabular}{|c|c|c|c|c|c|c|c|}
\hline $\begin{array}{l}\text { NQ } \\
\text { LEII }\end{array}$ & & FINALIDADR & $\begin{array}{l}\text { NUMERO DE } \\
\text { FUNC./HOSP }\end{array}$ & $\begin{array}{c}\text { NOMERO DE } \\
\text { FUNC. /LE TTO }\end{array}$ & $\begin{array}{l}\text { NQ PESSOAL } \\
\text { ESTAGLARIO }\end{array}$ & $\begin{array}{l}\text { KQ FUNC. } \\
\text { DO SND }\end{array}$ & $\begin{array}{c}7 \text { FUNC. } \\
\text { SND }\end{array}$ \\
\hline 200 & I & G & 1115 & 5,6 & 5 & 70 & 6,2 \\
\hline 213 & I & G & 937 & 4,4 & 111 & 66 & 6,9 \\
\hline 245 & I & L & 247 & 1,0 & - & 33 & 13,4 \\
\hline 176 & I & 2 & 216 & 1,2 & - & 15 & 6.9 \\
\hline 170 & I & $\mathbf{L}$ & 235 & 1,4 & 1 & 12 & 5,0 \\
\hline 180 & $I$ & $L$ & 357 & 2,0 & - & 21 & 5,9 \\
\hline 235 & I & $L$ & 710 & 3,0 & 20 & 47 & 6,6 \\
\hline 155 & $I$ & $\mathbf{L}$ & 250 & 1,6 & - & 13 & 5,2 \\
\hline 200 & I & L & 400 & 2,0 & 25 & 38 & 9,5 \\
\hline 200 & I & L & 307 & 1,5 & - & 32 & 10,4 \\
\hline 187 & I & $L$ & 234 & 1,2 & - & 21 & 9,0 \\
\hline 168 & I & $L$ & 238 & 1,4 & - & 23 & 9,7 \\
\hline 195 & I & $\mathrm{L}$ & 322 & 1,6 & 5 & 30 & 9,0 \\
\hline 181 & I & 2 & 300 & 1,6 & - & 27 & 9.0 \\
\hline 182 & I & NL & 140 & 0,8 . & - & 21 & 15,0 \\
\hline 151 & I & NL & 455 & 3,0 & - & 44 & 9,7 \\
\hline 168 & I & NL & 453 & 2,7 & 1 & 65 & 14,3 \\
\hline 240 & I & NL : & 293 & 1.2 & 5 & 37 & 12,6 \\
\hline 186 & I & NL & 230 & 1,2 & - & 31 & 13,5 \\
\hline 214 & I & NL & 385 & 1,8 & 14 & 30 & 7,8 \\
\hline 165 & I & NL & 275 & 1,7 & 75 & 14 & 5,1 \\
\hline 151 & I & NL & 300 & 2,0 & - & 16 & 5,3 \\
\hline 256 & II & G & 1300 & 5,0 & 8 & 51 & 3,8 \\
\hline 250 & II & L & 700 & 2,8 & 5 & 50 & 7,0 \\
\hline 276 & II & L & 460 & 1.7 & - & 23 & 5,0 \\
\hline 330 & II & L & 660 & 2,0 & - & 51 & 7,6 \\
\hline 250 & II & L & 360 & 1,4 & 5 & 27 & 7.5 \\
\hline 276 & II & L & 437 & 1,6 & - & 28 & 6,2 \\
\hline 347 & II & L & 450 & 1.3 & - & 16 & 3.5 \\
\hline 250 & II & NL & 597 & 2,4 & - & 89 & 14,9 \\
\hline 290 & II & NL & 488 & $1 ; 7$ & 2 & 46 & 9,4 \\
\hline 250 & II & NL & 595 & 2,4 & 50 & 52 & 9,6 \\
\hline 287 & II & NL & 537 & 1,9 & - & 54 & 10,0 \\
\hline 300 & II & NL & 400 & 1,3 & 5 & 38 & 9,5 \\
\hline 291 & II & NL & 381 & 1,3 & 2 & 26 & 6,8 \\
\hline 390 & III & G & 2000 & 5,2 & 22 & 90 & 4,4 \\
\hline 430 & III & $G$ & 1987 & 4.6 & 50 & 79 & 3,9 \\
\hline 363 & III & G & 802 & 2,2 & 143 & 101 & 12,6 \\
\hline 350 & III & $\mathrm{L}$ & 684 & 1,9 & - & 42 & 6,1 \\
\hline 410 & III & NL & 526 & 1,3 & 9 & 32 & 6,1 \\
\hline 421 & III & NL & 706 & 1,7 & 7 & 31 & 4.4 \\
\hline 484 & III & $\mathrm{NL}$ & 827 & 1,7 & - & 55 & 6.6 \\
\hline 1055 & IV & $G$ & 3500 & 3,3 & 200 & 201 & 5,6 \\
\hline 1142 & IV & G & 4775 & 3,9 & 375 & 180 & 3,8 \\
\hline 550 & IV & $L$ & 395 & 0,7 & - & 29 & 7,3 \\
\hline 1260 & IV & NL & 2000 & 1,6 & 60 & 142 & 7,1 \\
\hline 550 & IV & NL & 1500 & 2,7 & 130 & 75 & 5,0 \\
\hline 934 & IV & $\mathrm{NL}$ & 2352 & 2,5 & 19 & 141 & 5,9 \\
\hline 732 & IV & NL & 1386 & 1,9 & - & 83 & 6,0 \\
\hline
\end{tabular}


ANEXo III - Distribulģão dos hoppltal segundo a finalldade da entidado mantenedora, o numiero de marco de 1983 .

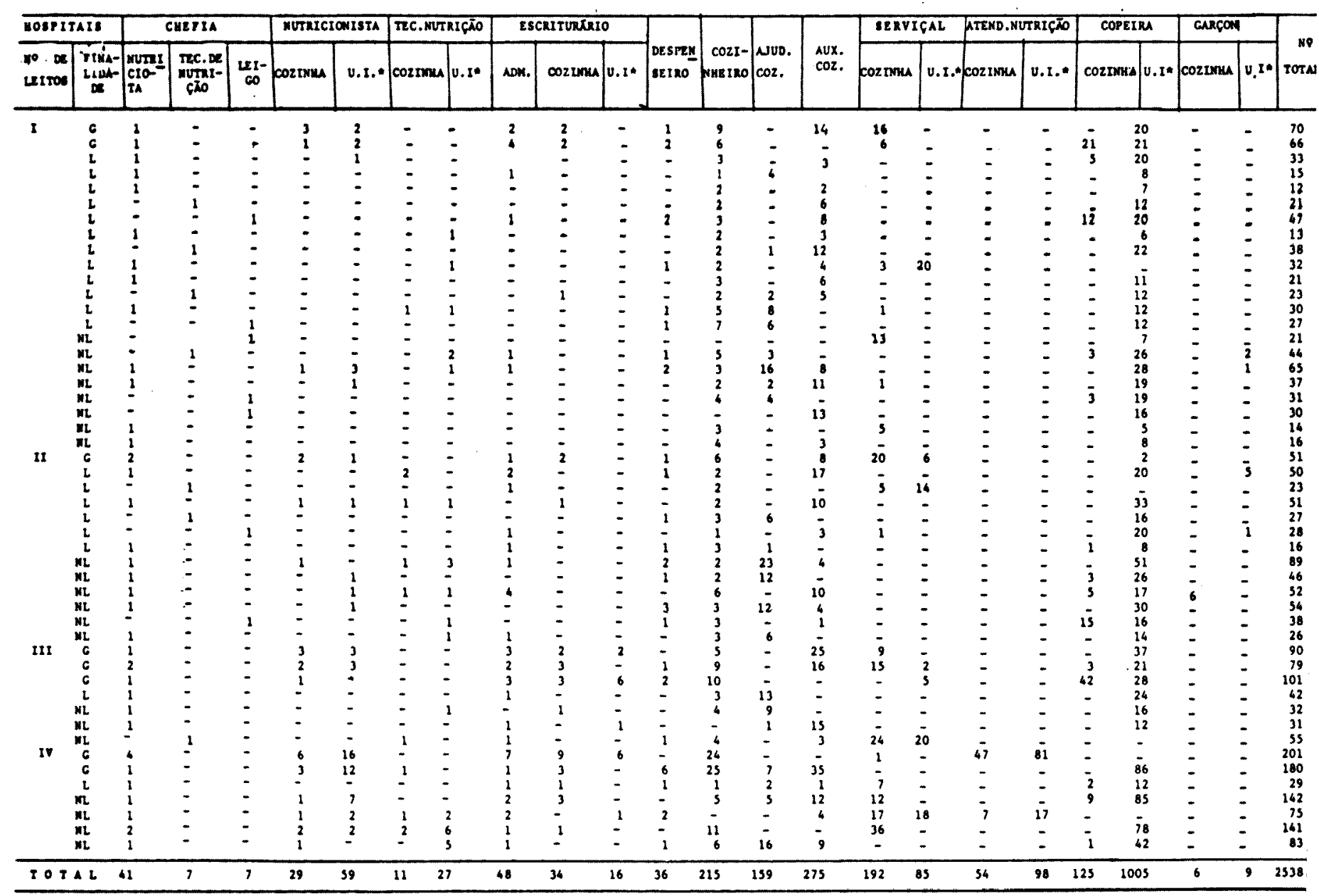

- v.x. - valdede de zatomecón

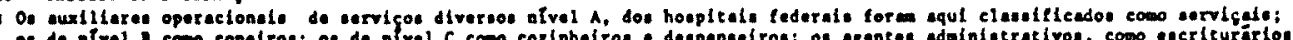

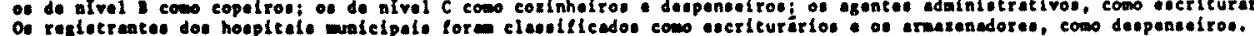


ANEXo IV - Distribulção dos hospltals segundo a finalidade da entidade mantenedora, o número de leltos, a produção díária e a dura ção do trabalho. São Paulo, março de 1983

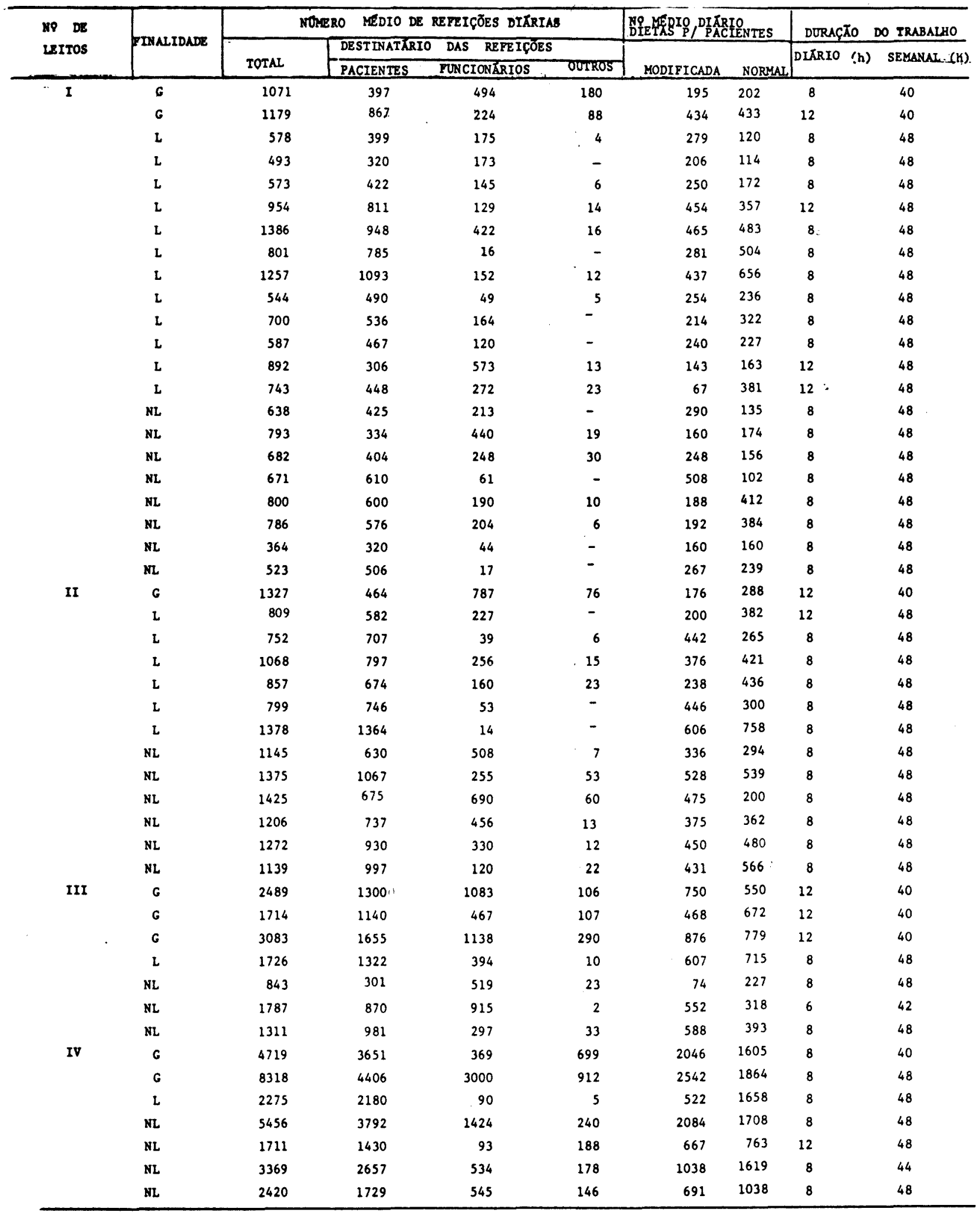

